OPEN ACCESS

Edited by:

Jianmin Cui,

Washington University in St. Louis,

United States

Reviewed by:

Université de Montréal, Canada

Alessio Masi,

University of Florence, Italy

*Correspondence:

Deepanjali Dwivedi

deepanjali_dwivedi@hms.harvard.edu;

ddwivedi@broadinstitute.org

Received: 25 January 2021

Accepted: 13 April 2021

Published: 03 June 2021

Citation:

Dwivedi D and Bhalla US (2021) Physiology and Therapeutic Potential of SK, $H$, and M Medium

AfterHyperPolarization Ion Channels.

Front. Mol. Neurosci. 14:658435.

doi: 10.3389/fnmol.2021.658435

\section{Physiology and Therapeutic Potential of SK, $H$, and M Medium AfterHyperPolarization Ion Channels}

\author{
Deepanjali Dwivedi ${ }^{1,2,3 *}$ and Upinder S. Bhalla ${ }^{1}$ \\ ${ }^{1}$ National Centre for Biological Sciences, Tata Institute of Fundamental Research, GKVK Campus, Bengaluru, India, \\ ${ }^{2}$ Department of Neurobiology, Harvard Medical School, Boston, MA, United States, ${ }^{3}$ Stanley Center at the Broad, \\ Cambridge, MA, United States
}

$\mathrm{SK}, \mathrm{HCN}$, and $\mathrm{M}$ channels are medium afterhyperpolarization (mAHP)-mediating ion channels. The three channels co-express in various brain regions, and their collective action strongly influences cellular excitability. However, significant diversity exists in the expression of channel isoforms in distinct brain regions and various subcellular compartments, which contributes to an equally diverse set of specific neuronal functions. The current review emphasizes the collective behavior of the three classes of mAHP channels and discusses how these channels function together although they play specialized roles. We discuss the biophysical properties of these channels, signaling pathways that influence the activity of the three mAHP channels, various chemical modulators that alter channel activity and their therapeutic potential in treating various neurological anomalies. Additionally, we discuss the role of mAHP channels in the pathophysiology of various neurological diseases and how their modulation can alleviate some of the symptoms.

Keywords: ion channels, neuropsychaitric disorders, therapeutic targets, advances and challenges, SK, HCN and M channels

\section{INTRODUCTION}

The correct regulation of neuronal excitability is crucial for healthy brain functioning. The cooperative activity of depolarizing and hyperpolarizing ion channels shape a neuron's firing activity. Potassium channels are the primary ion channels which mediate outward potassium currents to repolarize/hyperpolarize the membrane potential, thereby limiting neuronal excitability (Ranjan et al., 2019). Afterhyperopolarization mediated by diverse types of potassium channels repolarizes the membrane, limits spike width and amplitude, and controls firing activity, thus preventing neurotoxicity due to excessive firing (Zhang and McBain, 1995). Based on their activation kinetics, different potassium channels mediate afterhyperpolarization at distinct time scales and are categorized as fast afterhyperpolarization (activated in 1-5 s), medium afterhyperpolarization (mAHP, activated between 10-300 ms), and slow afterhyperpolarization (sAHP, activated between 0.5-multiple seconds) (Storm, 1990; Zhang and McBain, 1995). Multiple studies have indicated that hyperpolarization activated cyclic nucleotide $(\mathrm{HCN})$ channels, voltage gated $\mathrm{K}^{+}$channel $7\left(\mathrm{~K}_{\mathrm{v}} 7\right)$ and small conductance calcium activated potassium (SK) channels contribute to mAHP in neurons $(\mathrm{Gu}$ et al., 2005; Mateos-Aparicio et al., 2014). In the present review, we provide a detailed description of these mAHP-mediating ion channels. These channels control cellular excitability, 
and the anomalies associated with them can cause seizures, hyperactivity, and multiple neurological disorders. Thus, the pharmacological manipulation of these channels has therapeutic potential. The current review provides an insight into the biophysical properties of the channels, the kinetics of their various isoforms, their regional expression levels in the brain, and advancements in their therapeutic application for treating multiple neurological disorders.

\section{MAHP CHANNELS AND THEIR ISOFORMS}

Medium afterhyperpolarization channels exhibit a diverse distribution throughout the nervous system. Herein, we discuss the individual properties of the three main categories of $\mathrm{mAHP}$ channels in detail.

Based on phylogenetic analysis, the SK channel family comprises SK1 (KCa2.1), SK2 (KCa2.2), and SK3 (KCa2.2) as well as a fourth channel, SK4 (KCa3.1, IK1), which performs a function that is comparable but unrelated to the functions of the other SK channels (Wei et al., 2005; Kuiper et al., 2012). SK channels are voltage insensitive and are activated solely by an increase of 0.5-1 $\mu \mathrm{M}$ in intracellular calcium $\left(\mathrm{Ca}^{2+}\right.$ ) levels (Blatz and Magleby, 1986; Köhler et al., 1996; Sah, 1996; Hirschberg et al., 1999). An individual channel has a conductance of $10 \mathrm{pS}$ and achieves its half activation at an intracellular calcium level of approximately $0.6 \mu \mathrm{M}$ (Hirschberg et al., 1999). The time constant of channel activation is $5-15 \mathrm{~ms}$, and the deactivation time is $30 \mathrm{~ms}$ (Xia et al., 1998; Oliver et al., 2000). Many channel isoforms are generated by alternative splicing. Among the three SK channels, SK1 undergoes maximum alternative splicing to yield at least 16 SK1 isoforms (Shmukler et al., 2001). The presence of multiple SK1 variants indicates the diversity of the roles of this channel. A study by Strassmaier et al., 2005 reported SK2-L (the longer isoform weighing $78 \mathrm{kDa}$ ) and SK2$\mathrm{S}$ (the smaller isoform weighing $49 \mathrm{KDa}$ ) as two novel isoforms. Additionally, Murthy et al., 2008 discovered a cytoplasmic variant of SK2, which lacks the transmembrane fractions S3, 4, 5, and 6 and mediates the downstream effects of cytokine activation. Another splice variant of the SK2 channel that carries three extra amino acids at the 3' terminus, couples with $\alpha 9 / 10$ nicotinic acetylcholine receptors ( $\mathrm{nAchRs}$ ) at olivocochlear synapses in the cochlea and controls their activity (Scholl et al., 2014). Lastly, $\mathrm{SK} 3-1 \mathrm{~B}$ is a truncated isoform of SK3 that is known to represent $20-60 \%$ of the total SK3 present in the brain (Tomita et al., 2003; Shakkottai et al., 2004; Villalobos et al., 2004). These findings demonstrate the isoform-dependent heterogeneity of the SK channels. Different channel isoforms also exhibit distinct localization in various neuronal compartments or brain regions, thereby imparting specialized neuronal functions to different brain regions (Table $\mathbf{1}$ ).

Hyperpolarization-activated cation $\left(\mathrm{I}_{\mathrm{h}}\right)$ currents are mediated by HCN channels. These channels comprise four $\alpha$ subunits, encoded by four related genes, $\mathrm{HCN} 1,2$, 3, and 4 (Biel et al., 2009). All four isoforms of HCN channels have distinct activation kinetics. The HCN1 isoform exhibits the fastest activation, its
$\mathrm{V}_{1 / 2}$ for activation lies between -90 and $-70 \mathrm{mV}$, and tau for activation lies between 30 and $300 \mathrm{~ms}$. The HCN2 isoform exhibits activation between $150 \mathrm{~ms}$ and $1 \mathrm{~s}$ while the HCN3 isoform exhibits activation between 250 and $400 \mathrm{~ms}$. Both HCN2 and $\mathrm{HCN} 4$ are activated between -70 and $-100 \mathrm{mV}$. HCN4 is the slowest to activate; its activation time is hundreds of milliseconds, and activation occurs at an extremely hyperpolarized potential of $-140 \mathrm{mV}$ (Biel et al., 2009). However, for human HCN channels, HCN2 and 3 have similar activation kinetics with HCN1 being fastest and HCN4 the slowest (Stieber et al., 2005). The four $\mathrm{HCN}$ isoforms exhibit a structural homology of approximately $60 \%$. The major heterogeneity among the different isoforms originates from differences in the $\mathrm{N}$ and $\mathrm{C}$ termini of the channels (Santoro et al., 1998; Kaupp and Seifert, 2001). Different HCN isoforms assemble to form homotetramers or heterotetramers, thus conferring a range of neuronal functions that vary with the constituent subunits. In vivo, HCN1 and HCN2, but not HCN2 and HCN3, can form functional heteromers (Much et al., 2003). HCN channel activity is strongly regulated by changes in the levels of cyclic nucleotide monophosphates (cAMP/cGMP). HCN2 and HCN4 are strongly affected by cAMP levels, with moderate effect on HCN1 and none on HCN3 (Stieber et al., 2005). HCN isoforms can also assemble with different auxiliary subunits, such as KCNE2/minK-related peptide 1 (MiRP1), at the $\mathrm{C}$ terminus to form functional channels (Yu et al., 2001; Decher et al., 2003). In addition to KCNE, tetratricopeptide repeatcontaining Rab8b-interacting protein (TRIP8b) is another regulatory subunit on $\mathrm{HCN}$ channels that binds to the $\mathrm{CNBD}$ and the $\mathrm{N}$ bundle loop on the $\mathrm{C}$ terminus. TRIP8b assists in surface targeting of the channel and regulation of activation kinetics (Porro et al., 2020). Phosphorylation of $\operatorname{Ser}^{237}$ on TRIP8B helps in its binding to the HCN channels (Foote et al., 2019). Furthermore, HCN channels undergo several post-translational modifications, which contribute to their functional heterogeneity and expression dynamics. For example, HCN channels (HCN1, HCN2, and HCN4 but not HCN3) undergo S-palmitoylation, which enhances their ability to form heteromeric channels with other isoforms and accessory proteins (Itoh et al., 2016). Under inflammation and chronic pain, HCN2 channels in dorsal root ganglion (DRG) neurons can undergo SUMOlytion, which increases their surface expression (Forster et al., 2020). N-linked glycosylation of HCN channels is also known to assist in the trafficking of channel proteins to the membrane (Much et al., 2003) (Table 1).

Voltage gated $\mathrm{K}^{+}$channel 7 channels mediate voltageactivated potassium currents called $\mathrm{M}$ currents. These channels are encoded by the $\mathrm{K}_{\mathrm{v}} 7.1-\mathrm{K}_{\mathrm{v}} 7.5$ family of genes and exhibit ionic conductance in the range $1-8 \mathrm{pS}$, which varies among channel isoforms (Barrese et al., 2018). The channels exhibit slow activation (in the range 100-300 ms) and deactivation (in the range 100-450 ms) kinetics and remain open for prolonged periods (Chen and Johnston, 2004; Delmas and Brown, 2005; Hansen et al., 2008; Barrese et al., 2018). Like SK and HCN channels, different $\mathrm{K}_{\mathrm{v}} 7$ isoforms (except $\mathrm{K}_{\mathrm{v}} 7.1$ ) can also form homo or heteromers resulting in ion channels with different kinetics and regional expression, which mediate different regulatory functions (Jentsch, 2000). In the central and 
TABLE 1 | Summary of the regional expression of different mAHP channels in distinct brain regions and the specific subcellular and region-specific distribution of various channel isoforms.

\begin{tabular}{ll}
\hline mAHP channel & Regions \\
\hline SK & Hippocampus (CA1, CA2, CA3 \\
& pyramidal cells, DG neurons, \\
Internueorns) \\
Cortex (piriform cortex, entorhinal \\
cortex, para-, pre- subiculur cortex \\
Cerebellum (Deep nuclei, purkinje \\
cells, golgi cells, granule cells) \\
Amygdala (Basolateral, Basomedial \\
and Lateral amygdaloid nucleus) \\
Nucleus basilis neurons, \\
Paraventricular neurons \\
Striatal cholinergic interneurons and \\
Basal nuclei \\
Olfactory system, Neocortex, \\
septum, Brain stem \\
Striatum, Medial habenular nucleus, \\
Locus coeruleus and dorsal raphe \\
and Thalamus \\
Thalamus (Principal relay nuclei, \\
Geniculate nuclei, Subthalamic \\
nuclei)
\end{tabular}

Cortex (Neocortex, Piriform Cortex, Anterior Cingulate cortex)

Hippocampus (CA1, CA3, Stratum Oriens, Stratum Radiatum, Granule cells)

Amygdala (Basolateral nucleus, central nucleus, lateral nucleus)

Cerebellum (Molecular, Purkinje, Granule cell layer and deep cerebellar nuclei)

DRG, primary nociceptive neurons

Hypothalamus

(Preoptic nuclei, Ventromedial nucle and mammillary nuclei)

Brain Stem

(Dorsal horn and Ventral horn)

Habenula (Lateral and Medial habenula)

$\mathrm{K}_{\mathrm{v}} 7 \quad$ Hippocampal

(CA1, CA2, CA3 pyramidal cells, DG neurons, Internueorns)

Thalamus [Medial Geniculate

nucleus, Ventral posterior thalamic

complex, dorsal lateral geniculate

(dLG)]

olfactory bulb (Granular, Mitral and

Periglomerular cell layer)

Habenula

basal ganglia (Caudate/Putamen, accumbens nucleus, Globus

Pallidus)

amygdala,

midbrain, hypothalamus, substantia nigra (Pars reticulate, Pars compacta), cerebellum (Granule, molecular, purkinje cell layer and deep nuclei)

superior cervical ganglion cells, motor neurons, dorsal horn and spinal neurons

Visceral sensory neurons, DRG, nodose ganglia,

\section{References}

Zhang and McBain, 1995; Stocker and . Pedarzani, 2000; Sailer et al., 2002; Allen et al., 2011

Schwindt et al., 1988; Criado-Marrero et al., 2014

Stocker and Pedarzani, 2000; Walter et al., 2006

Power and Sah, 2008

Williams et al., 1997; Chen and Toney, 2009

Goldberg and Wilson, 2005; Bishop

et al., 2010

Habermann and Fischer, 1979; Stocker and Pedarzani, 2000

Tacconi et al., 2001; Sailer et al., 2002

\section{Subcellular distribution}

- SK1 and SK2 are the predominant channel isoforms present in the hippocampus and cortex, while SK3 is predominant in the striatum, medial habenular nucleus, locus coeruleus, dorsal raphe, and thalamus. Further, the two isoforms of SK2, SK2-S, and SK2-L also have a differential expression within a neuron. SK2-L is present in the postsynaptic density (PSD) while SK2-S localizes in extrasynaptic sites, when not in a multimeric complex with SK2-L (Allen et al., 2011).

- Within the spinal cord, SK2 is present in all the $\alpha$-motoneurons, while SK3 is preferentially present in small diameter $\alpha$-motoneurons (Deardorff et al., 2013).

- Within the hippocampus, SK channels are present throughout a neuron, i.e., in soma, dendrites, and spines (Cai et al., 2004; Dwivedi et al., 2019). At spines, they are present in a complex with NMDARs, mGLuRs, and Calcium channels (Köhler et al., 1996; Bloodgood and Sabatini, 2007; Fakler and Adelman, 2008).

- SK3 channels have presynaptic localization in the hippocampus, present in mossy fibers terminals but not in pyramidal layer (Obermair et al., 2003)

Moosmang et al., 1999; Santoro et al., 2000; Notomi and Shigemoto, 2004; Abbas et al., 2006; Ying et al., 2011; Ding et al., 2016

Moosmang et al., 1999; Santoro et al. 2000; Lörincz et al., 2002; Notomi and Shigemoto, 2004; Gao et al., 2016

Moosmang et al., 1999; Santoro et al., 2000; Lörincz et al., 2002; Notomi and Shigemoto, 2004

Moosmang et al., 1999; Santoro et al., 2000; Notomi and Shigemoto, 2004; Park et al., 2011

Moosmang et al., 1999; Santoro et al., 2000; Notomi and Shigemoto, 2004

Moosmang et al., 1999; Emery et al., 2011; Hou et al., 2015

Moosmang et al., 1999; Santoro et al.,

2000; Notomi and Shigemoto, 2004

Moosmang et al., 1999; Santoro et al., 2000; Notomi and Shigemoto, 2004

Moosmang et al., 1999; Santoro et al., 2000; Notomi and Shigemoto, 2004

Cooper et al., 2000; Saganich et al.,

2001; Roche et al., 2002

Saganich et al., 2001

- Within the brain, HCN1 is enriched in the neocortex, CA1 hippocampus, superior colliculus, fornix, superior colliculus, hypoglossal nucleus, cochlear nuclei, olfactory bulb, layer II and V in cortex and cerebellum. - Unlike HCN1, HCN2 has ubiquitous expression throughout the brain. High levels are observed in the cortex, hippocampus, globus pallidus, brain stem, retina, olfactory bulb, cerebellum, and thalamus.

- Both HCN3 and HCN4 are relatively lesser in the brain.

- HCN3 is present at moderately higher levels in the olfactory bulb, in the piriform cortex, preoptic area, hypothalamic regions, and cochlear nuclei. - HCN4 is enriched especially in olfactory bulb, thalamus, fasciculus retroflexus, substantia nigra and habenula with low levels of expression in hippocampus and dentate granule cells (Moosmang et al., 1999; Santoro et al., 2000; Moosmang et al., 2001; Notomi and Shigemoto, 2004).

- Peripheral nervous system expresses all the HCN isoforms, but HCN1 levels are higher than other isoforms (Novella Romanelli et al., 2016). - In hippocampal and neocortex neurons, HCN channels had a proximal to distal dendritic gradient with limited somatic localization. They have a higher expression in the dendritic shafts than spines (Lörincz et al., 2002). - In the medial perforant pathway, HCN1 channels are localized only on axons (Bender and Baram, 2008).

- In medial superior olive neurons, HCN channels are present in axon initial segment (AIS) and control spike threshold (Ko et al., 2016).

- Within thalamus, HCN2 and HCN4 channels have opposite gradient such that HCN2 channels are more abundantly present in ventrobasal (VB) neurons while HCN4 channels are predominant in reticular thalamic neurons (RTN) neurons (Abbas et al., 2006).

- $\mathrm{K}_{\mathrm{v}} 7.2-\mathrm{K}_{\mathrm{v}} 7.5$ are the primary isoforms which constitute the M currents in the brain.

- M channels are primarily present in axon initial segment, nodes of Ranvier, and on unmyelinated axons (Devaux et al., 2004; Vervaeke et al., 2006).

- In CA1 hippocampal neurons, M channels are present in the perisomatic region regulating somatic excitability but not in distal dendrites (Hu et al., 2007).

Saganich et al., 2001

- In the hippocampus, hilar polymorphic cells, and subiculum pyramidal cells, both $\mathrm{K}_{\mathrm{v}}$ 7.2.and 7.3 were expressed. However, on mossy fiber bundles and neuropil of dentate hilus, CA3, CA1, and subiculum only $K_{v} 7.2$ channels were found (Cooper et al., 2000; Roche et al., 2002) - $\mathrm{K}_{\mathrm{v}} 7.5$ channels localize in synapses of auditory nuclei (Caminos et al., 2007).

Saganich et al., 2001

Tober et al., 1996; Saganich et al., 2001 - In the sciatic nerve, the nodes of Ranvier of large fibers expressed only
Saganich et al., $2001 \quad \mathrm{~K}_{\mathrm{v}} 7.2$. On the contrary, both $\mathrm{K}_{\mathrm{v}} 7.2$ and $\mathrm{K}_{\mathrm{v}} 7.3$ channel isoforms showed expression at nodes of small and intermediate-sized fibers (Schwarz et al., 2006).

- Mesencephalic dopaminergic neurons exclusively express $K_{v} 7.4$ channel isoform (Hansen et al., 2008).

Saganich et al., 2001; Passmore et al.,

2003; Rivera-Arconada and

Lopez-Garcia, 2005

Passmore et al., 2003; Wladyka and

Kunze, 2006; Linley et al., 2008 
peripheral nervous system, $\mathrm{K}_{\mathrm{V}} 7.2-7.5$ isoforms are the primary mediators of $\mathrm{M}$ current, and $\mathrm{K}_{\mathrm{v}} 7.2 / 7.3$ heteromers constitute the predominant $\mathrm{M}$ current-mediating channels in neurons (Wang et al., 1998; Jentsch, 2000). Among all the $\mathrm{K}_{\mathrm{v}} 7$ isoforms, $\mathrm{K}_{\mathrm{v}} 7.2$ has the most splice variants with significantly different $C$ termini but identical $\mathrm{N}$ termini (Nakamura et al., 1998). Two $\mathrm{K}_{\mathrm{v}} 7.2$ splice variants, namely Q2L and Q2S, have also been found. Q2S forms non-functional $\mathrm{M}$ channels in underdeveloped fetal brains, while Q2L forms functional $\mathrm{M}$ channels in developed neurons (Smith et al., 2001). Furthermore, homologous $K_{v} 7.2$ channel splice variants have been reported in the human brain. The variants named $\mathrm{K} 2 \Delta \mathrm{L}, \mathrm{K} 2 \mathrm{KL}, \mathrm{K} 2 \Delta \mathrm{K} \Delta \mathrm{L}$, and $\mathrm{K} 2 \Delta \mathrm{LMP}$. Among these $\mathrm{K} 2 \mathrm{KL}$ and $\mathrm{K} 2 \Delta \mathrm{L}$ form functional channels in COS cells (Tinel et al., 1998).

\section{STRUCTURE OF MAHP CHANNELS}

The three mAHP channels have a high structural similarity with major structural differences in their $\mathrm{N}$ and $\mathrm{C}$ termini. All three channels are tetramers where each subunit has six transmembrane fragments. Different subunits assemble to form homo or heteromeric channels to create channels with varying kinetics and functions in distinct brain regions, thus imparting specialized neuronal activity (Ishii et al., 1997; Sailer et al., 2002; Monaghan et al., 2004; Strassmaier et al., 2005). Subunit (S) 4 of $\mathrm{HCN}$ and $\mathrm{K}_{\mathrm{v}} 7$ channels has positively charged lysine and arginine residues, which confers voltage sensitivity to the channels. S5 and S6 of the channels form the channel pore (Kaupp and Seifert, 2001). Both the $\mathrm{N}$ and C termini of the channels are cytoplasmic. The $\mathrm{C}$ termini of the three channels have binding sites for regulatory proteins. The $\mathrm{C}$ termini of $\mathrm{SK}$ and $\mathrm{K}_{\mathrm{v}} 7$ channels have calmodulin (CaM)-binding domain (CaMBD), while the HCN channels have a cyclic nucleotidebinding domain (CNBD) (Kaupp and Seifert, 2001; Barrese et al., 2018; Kshatri et al., 2018; Figure 1). CaM attached to SK and $\mathrm{K}_{\mathrm{V}} 7$ channels makes them sensitive to changes in intracellular calcium levels (Wainger et al., 2001). CNBD in HCN channels can bind to $\mathrm{cAMP} / \mathrm{cGMP}$, making $\mathrm{HCN}$ channels responsive to signaling pathways that modulate these secondary molecules. Binding of $\mathrm{cAMP} / \mathrm{cGMP}$ to CNBD removes a conformational strain, which favors the activation of HCN channels (Wainger et al., 2001). CaMBD has positively charged and hydrophobic residues that facilitate CaM binding (Fanger et al., 1999; Zhang Y. et al., 2014). An intrinsically disordered region between S6 and CaMBD (R396-M412) on the SK channels assists in the binding of $\mathrm{Ca}^{2+}$ to CaM and causes channel activation (Zhang M. et al., 2013). CaM can achieve different conformations upon binding to different SK2 splice variants, thereby imparting varying calcium sensitivity to different channel isoforms (Zhang et al., 2012). The $\mathrm{C}$ termini of $\mathrm{K}_{\mathrm{V}} 7$ channels comprise four $\alpha$-helices, which serve as a binding site for multiple regulatory molecules. The CaMBD of the $\mathrm{K}_{\mathrm{v}} 7$ channels is on helices $\mathrm{A}$ and $\mathrm{B}$ and serves as a binding site for both CaM and phosphatidylinositol 4,5bisphosphate (PIP2) (Haitin and Attali, 2008; Barrese et al., 2018; Figure 1). Unlike most $\mathrm{K}^{+}$channels (other than the inward rectifying potassium channels), HCN channels exhibit reverse

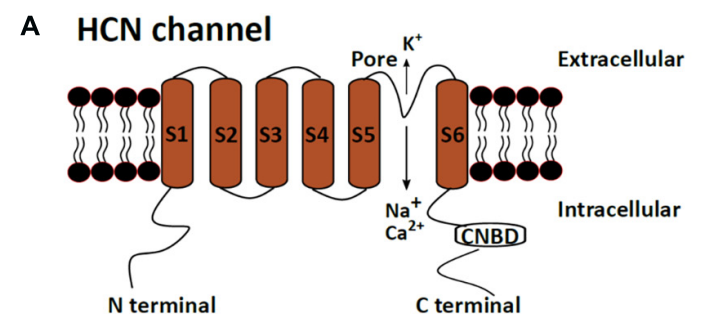

B SK channel

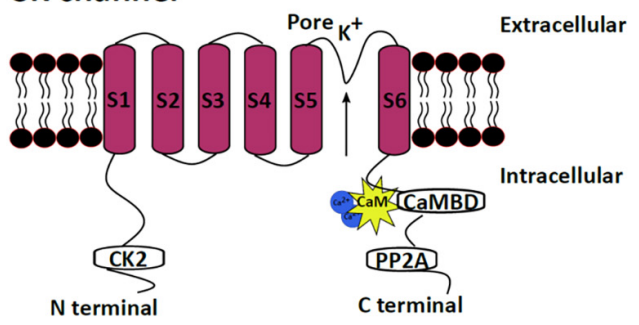

\section{C $\mathrm{K}_{\mathrm{v}} 7 / \mathrm{M}$ channel}

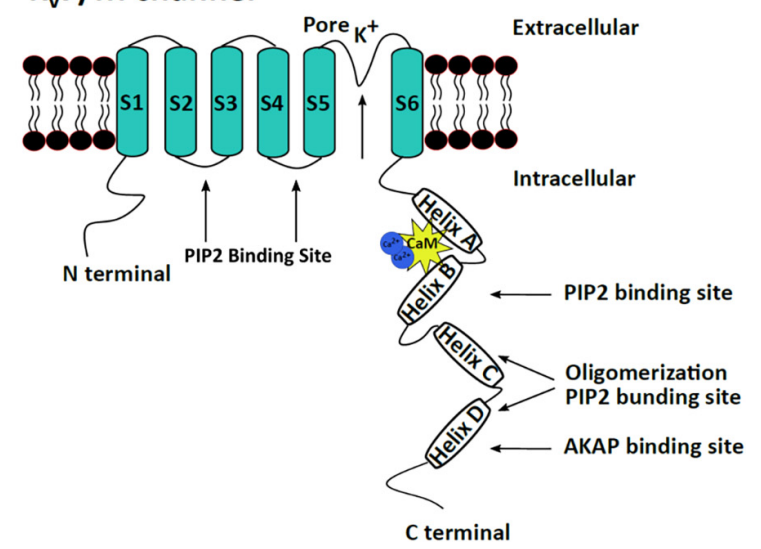

FIGURE 1 | mAHP channel structures. The three mAHP channel subunits have a similar basic structure, which consist of six transmembrane segments, but significant heterogeneity is observed at the $\mathrm{N}$ and $\mathrm{C}$ termini. (A) HCN channels open in response to hyperpolarization and conduct a net inward current through the influx of $\mathrm{Na}^{+}$and $\mathrm{Ca}^{+}$and efflux of $\mathrm{K}^{+}$. The CNBD at the $\mathrm{C}$ terminus serves as the binding site for CAMP or CGMP, which regulates HCN channel activity. (B) SK channels are calcium-dependent potassium-conducting channels regulated by bound protein kinases and phosphatases at the $\mathrm{N}$ and $\mathrm{C}$ termini. (C) Kv7/M channels are voltage-sensitive potassium channels that are regulated by PIP2 and several protein kinases that bind to the $\mathrm{C}$ terminus of the protein.

polarity, making them capable of conducting cationic current in response to hyperpolarization instead of depolarization (Lee and MacKinnon, 2017). Cryo-electron microscopy has assisted in resolving the gating mechanism of $\mathrm{HCN}$ channels. A long S4 linker helix, in association with S4, S5, and S6, assists in stabilizing the closed state of the channel upon cellular depolarization (Lee and MacKinnon, 2017). The $\mathrm{S}_{\mathrm{C}}$-term and $\mathrm{S} 5 \mathrm{~N}$-term mediate the interaction between the voltage-sensitive and pore domains of the channel, which keeps the channel closed during depolarization. However, upon hyperpolarization, 
the long S4 helix undergoes displacement, which opens the HCN channel (Lee and MacKinnon, 2017; Flynn and Zagotta, 2018).

The $\mathrm{C}$ termini of all the $\mathrm{M}$ channel isoforms exhibit a conserved A domain, which along with a proximal part of the $\mathrm{B}$ domain at the $\mathrm{C}$ terminal, assists in subunit assembly (Schwake et al., 2000, 2003; Robbins, 2001; Maljevic et al., 2003). The $\mathrm{N}$ termini of all $\mathrm{M}$ channel isoforms exhibit a high level of homology, while the $\mathrm{C}$ termini vary in lengths (Haitin and Attali, 2008). One CaM molecule per subunit is constitutively bound to the proximal $\mathrm{C}$ terminus of $\mathrm{K}_{\mathrm{V}} 7$ channels and is crucial for proper channel folding (Wiener et al., 2008). The binding of CaM on helix A and B also assists in the heteromeric assembly of $K_{v} 7.2$ and 3 (Liu and Devaux, 2014). In addition to the CaMBD, the $\mathrm{C}$ termini of $\mathrm{K}_{\mathrm{v}} 7$ channels also contain sites for binding other modulatory proteins such as kinases and scaffolding proteins (Delmas and Brown, 2005). Phosphorylation of specific serine residues in the PIP2 binding sites on Kv7 channels alters the PIP2binding efficiencies of the sites and modulates channel activity (Salzer et al., 2017; Figure 1).

Expression and kinetics of mAHP channels are additionally regulated by some auxiliary/accessory proteins. Both $\mathrm{K}_{\mathrm{V}} 7$ and $\mathrm{HCN}$ channels interact with specific auxiliary proteins of the KCNE family, which alter their activation kinetics (Decher et al., 2003; Roura-Ferrer et al., 2009). KCNEs are single-subunit transmembrane proteins that can modulate both $\mathrm{HCN}$ and $\mathrm{K}_{\mathrm{v}} 7$ channels. KCNE 1, 3, and 4 interact with $\mathrm{K}_{\mathrm{v}} 7$ channels; however, only KCNE2 enhances the activity of HCN1, HCN2, and HCN4 (Decher et al., 2003). Deletion of KCNE2 reduces neuronal $\mathrm{HCN} 1$ and HCN2 levels, indicating that it also assists in surface targeting (Ying et al., 2012). Interaction with KCNE1 leads to slower inactivation and increased M current amplitudes (Jentsch, 2000). Furthermore, a single KCNE protein can have differential effects on different $\mathrm{K}_{\mathrm{V}} 7$ isoforms. For example, when KCNE3 interacts with $\mathrm{K}_{\mathrm{V}} 7.2$ channels, it can cause constitutive activation. By contrast, when KCNE3 binds to $\mathrm{K}_{\mathrm{v}} 7.4$ channels, it causes inhibition (Jentsch, 2000). Multiple KCNE proteins can complex with $\mathrm{K}_{\mathrm{v}} 7$ channels and exhibit intricate regulation of the activity of the channels (Lundby et al., 2010; Wrobel et al., 2012).

Therefore, as explained, the three mAHP channels have a similar basic structure. However, because of differences in their $\mathrm{N}$ and $\mathrm{C}$ termini, they can form heteromers with different channel isoforms and can be regulated by multiple regulatory elements. Together, these differences contribute significantly to heterogeneity in the kinetics and functions of the three mAHP channels.

\section{ENDOGENOUS REGULATORS OF THE MAHP CHANNEL ACTIVITY}

\section{Calcium}

Calcium directly or indirectly regulates all three mAHP channels. CaM bound to the $\mathrm{SK}$ and $\mathrm{K}_{\mathrm{V}} 7$ channels sensitizes them to intracellular calcium levels (Fanger et al., 1999; Schumacher et al., 2001; Adelman, 2016). Intracellular calcium levels increase because of calcium influx through voltage-dependent calcium channels, through ionotropic glutamate receptors, such as NMDARs and AMPARs, and calcium-induced calcium release
(CICR) from intracellular calcium reserves (Brennan et al., 2008). In CA1 hippocampal pyramidal neurons, L-type calcium channels in the soma and R-type calcium channels in the dendrites are structurally coupled to SK channels (Bloodgood and Sabatini, 2007). By contrast, P/Q-type calcium channels in Purkinje cells are functionally, but not structurally, coupled to SK channels. Calcium entry through $\mathrm{P} / \mathrm{Q}$-type $\mathrm{Ca}^{2+}$ channels leads to CICR, which activates SK channels (Marrion and Tavalin, 1998; Bloodgood and Sabatini, 2007). Furthermore, in outer hair cells, nAChRs are also coupled to SK channels. $\mathrm{Ca}^{2+}$ influx through nAChRs causes SK channel activation, which hyperpolarizes the outer hair cells (Oliver et al., 2000, 2001). Additionally, in the dendritic spines of hippocampal neurons, metabotropic glutamate receptor (mGluR5) and NMDARs are coupled to SK channels (Lin et al., 2008; Ngo-Anh et al., 2008; García-Negredo et al., 2014). Such functional coupling between ionotropic and metabotropic channels to SK channels has led researchers to propose the presence of microdomains on the cellular membrane. In these microdomains, these channels, along with different membranal and cytoplasmic effector molecules, are in proximity with each other and jointly regulate neuronal functioning (Blackstone and Sheng, 2002; Fakler and Adelman, 2008). Increased intracellular calcium via CaM can increase the SK channel activity with a tau of $\sim 5-10 \mathrm{~ms}$. Such fast $\mathrm{Ca}^{2+}$ regulation is possible as $\mathrm{CaM}$ is constitutively bound to the channel (Adelman, 2016). Using cryo electron microscopy Lee and MacKinnon (2018) have shown that four CaM molecules can bind to one SK channel tetramer (one CaM/subunit). The $\mathrm{C}$ lobe of $\mathrm{CaM}$ is attached to the channel in the absence of $\mathrm{Ca}^{2+}$. However, $\mathrm{Ca}^{2+}$ binding to the $\mathrm{N}$ lobe of CaM produces a conformational change, which results in rearrangement of the S6 of SK channel further opening the channel pore (Lee and MacKinnon, 2018).

Increased intracellular calcium levels can also upregulate adenylyl cyclase activity, which increases intracellular cAMP and augments HCN channel activity (Halls and Cooper, 2011; Neymotin et al., 2016). Contrary to its effect on SK and HCN channels, increased intracellular calcium inhibits $\mathrm{K}_{\mathrm{V}} 7$ channels (Tobelaim et al., 2017). Calcium-free CaM is bound to both helices $A$ and $B$ at the $C$ terminus of the $K_{v} 7$ channels. In this configuration, it assists in PIP2 binding, which is crucial for $\mathrm{K}_{\mathrm{V}} 7$ activation. An increase in intracellular calcium levels causes a structural rearrangement such that the calcium-bound CaM remains bound to helix B only. This rearrangement reduces PIP2 binding affinity, which reduces the opening probability of $\mathrm{K}_{\mathrm{v}} 7.2-\mathrm{K}_{\mathrm{v}} 7.5$ but not of $\mathrm{K}_{\mathrm{v}} 7.1$ channels (Barrese et al., 2018). In the case of $K_{\mathrm{v}} 7.1$ channel, PIP2 and calcium-bound CaM share an overlying binding site. Thus, upon PIP2 depletion, calcium-bound CaM can bind to Kv7.1, mimic the PIP2 binding effect, and assist in channel activation (Tobelaim et al., 2017). Neurotransmitters, such as bradykinin, are known to regulate M channels via the CaM pathway (Gamper and Shapiro, 2003; Gomis-Perez et al., 2017) (Figure 2). Additionally, the $\beta \gamma$ subunits of $\mathrm{G}$ proteins are also known to regulate $\mathrm{K}_{\mathrm{v}} 7.4$ channel activity by increasing its opening probability. They stabilize the coupling between PIP2 and $\mathrm{K}_{\mathrm{V}} 7.4$, thereby mediating their increased activation (Povstyan et al., 2017). Thus, calcium, through CaM directly activates SK channels and inhibits $\mathrm{K}_{\mathrm{v}} 7$ 

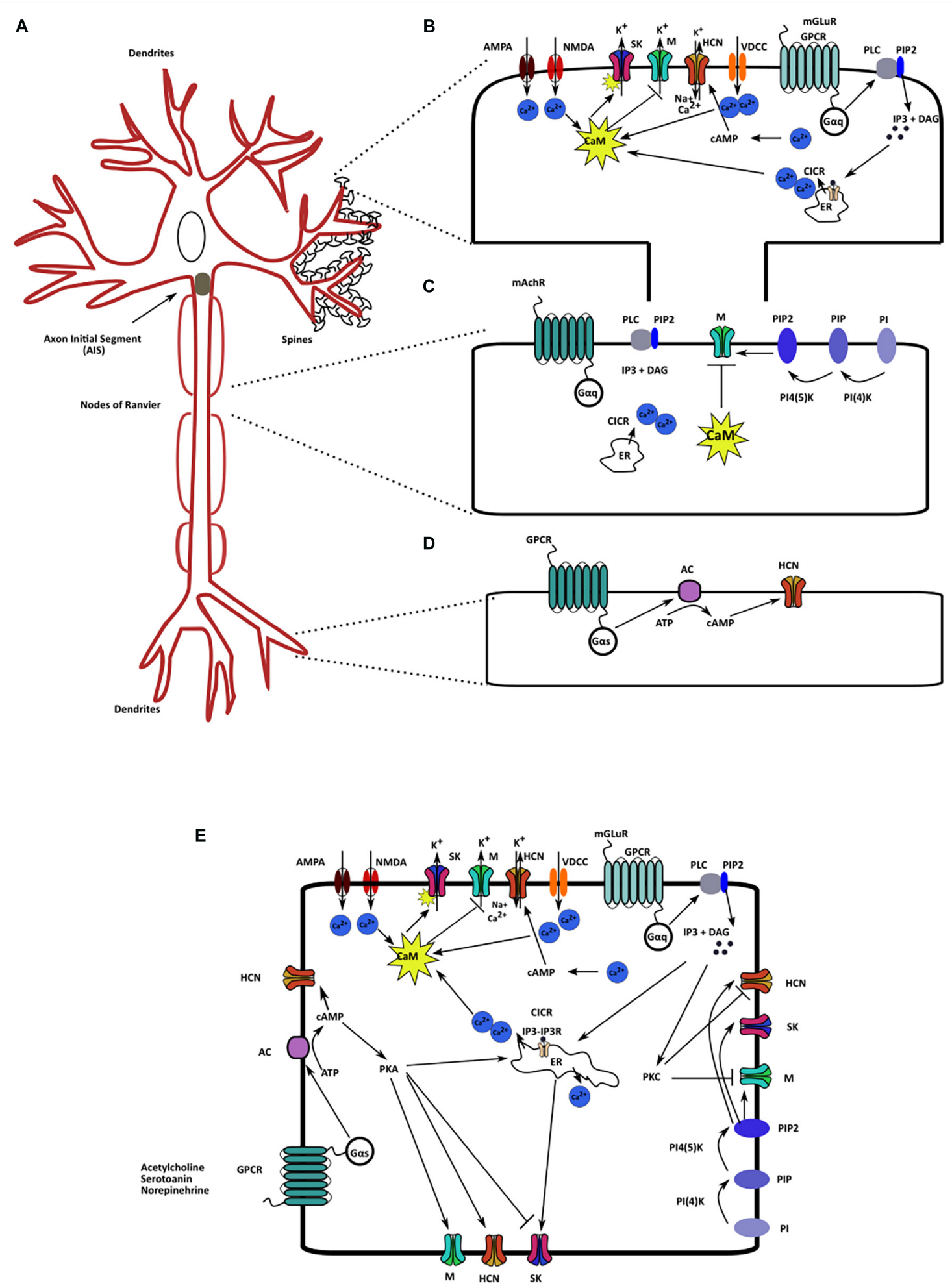

FIGURE 2 | Localization and regulatory pathways of the mAHP channels. (A) A neuron schematic illustrating the localization of the three mAHP channels. SK channels are localized on the spines and modulate synaptic response. $K_{v} 7 / M$ channels present in the axon initial segment and node of Ranvier control cellular resting membrane potential (RMP) and input resistance (IR). HCN channels in hippocampal neurons are present as an increasing gradient from proximal to distal dendrites. (B) SK channels present on the spines are regulated by calcium influx from multiple sources; the primary sources include voltage-dependent calcium channels, ionotropic and metabotropic glutamate receptors, and CICR. (C). PIP2 levels and intracellular calcium via CaM serve as the most critical $\mathrm{K}_{\mathrm{v}} 7 / \mathrm{M}$ channel regulators. (D) Changes in intracellular CAMP levels augment HCN channel activity through CAMP binding on the CNBD on the channel. (E) Various signaling and regulatory proteins co-exist in the intracellular milieu, modulating $\mathrm{mAHP}$ channels and regulating cellular excitability. 
channels. Increased intracellular calcium levels increase $\mathrm{HCN}$ channel function by increasing cAMP levels.

\section{CAMP/cGMP}

Similar to calcium, cyclic nucleotide monophosphates are also critical regulatory molecules for mAHP channels. Binding of cAMP/cGMP to the CNBD on HCN channels is one of the primary mechanisms underlying the regulation of $\mathrm{HCN}$ channel activity. The binding of cAMP to HCN channels is activitydependent; hence, an increase in channel activity increases cAMP affinity to the channel (Wang et al., 2002). The binding of cAMP to the CNBD on HCN channels stabilizes the open channel conformation, which provides prolonged activation of HCN channels and facilitates neuronal excitability and rhythmic activity (Wang et al., 2002). Binding of cAMP to HCN channel can produce a $20 \mathrm{mV}$ shift in their activation curve. However, cAMP binding exhibits variable effects on different $\mathrm{HCN}$ channel isoforms. cAMP binding does not affect HCN3, moderately affects HCN1 (shifts the activation curve by 2-4 $\mathrm{mV}$ ), and strongly activates HCN2 and HCN4 channels (Stieber et al., 2005; Biel et al., 2009). Notably, because of the differential distribution of channel isoforms in various brain regions, changes in cAMP levels exhibit differential effects on the neuronal activity of distinct brain regions. Additionally, other cyclic nucleotides such as CUMP and CCMP (activates HCN2 and HCN4, but not HNC1 and $\mathrm{HCN} 3$ ) can also activate HCN channels (Zong et al., 2012; He et al., 2014).

$\mathrm{G}$ protein-coupled receptor activity causes cAMP production through the catalytic action of adenylyl cyclase. cGMP is produced downstream of the nitric oxide signaling pathway. Nitric oxide binds to and increases the catalytic activity of soluble guanylyl cyclase (Wilson and Garthwaite, 2010). Both cAMP and cGMP have the same binding site on HCN channels although they are produced through different signaling pathways. However, binding affinity of cAMP to HCN channels is $\sim 10-100$ folds greater than that of cGMP (Biel et al., 2009). Neuromodulators such as acetylcholine, noradrenaline, serotonin, and epinephrine increase $\mathrm{HCN}$ channel activity by increasing intracellular cAMP levels (McCormick and Pape, 1990; Wilson and Garthwaite, 2010). However, changes in intracellular cAMP levels also increase $\mathrm{K}_{\mathrm{v}} 7$ channel activity (Schroeder et al., 1998).

Cyclic nucleotide monophosphates levels positively affect $\mathrm{K}_{\mathrm{v}} 7$ channel opening. Increased cAMP levels cause PKA-dependent phosphorylation of $\mathrm{K}_{\mathrm{v}} 7.2$ channels at the $\mathrm{N}$ terminus, which increases the channel conductance (Schroeder et al., 1998). Increasing cAMP levels also increase calcium influx, which in turn affects all the three mAHP channels (Konieczny et al., 2017; Figure 2). Thus, increased intracellular cAMP levels can produce larger mAHPs through their positive effects on the three mAHP channels. The aforementioned effect can function as a feedback mechanism to control neuronal excitability.

\section{PIP2}

Like cAMP and cGMP, an increase in PIP2 levels also activates the three mAHP channels. PIP2 binding stabilizes the channels' open configuration, which leads to increased conductance
(Pian et al., 2006; Brown et al., 2007; Zhang Y. et al., 2014). This interaction between PIP2 and $\mathrm{HCN} / \mathrm{K}_{\mathrm{v}} 7$ channels results from an electrostatic interaction between PIP2 head groups and the channel (Oliver et al., 2004; Zolles et al., 2006). Biological processes, such as the activation of muscarinic receptors that results in $\mathrm{Gq}$ signaling and increased PLC activity, consume PIP2 to produced $\mathrm{IP}_{3}$ and DAG. This causes PIP2 depletion, which results in a reduction in $\mathrm{M}$ and SK currents (Brown et al., 2007; Zhang M. et al., 2014). However, as a feedback mechanism, increased production of $\mathrm{IP}_{3}$ also increases calcium influx by CICR. Neuronal $\mathrm{Ca}^{2+}$ sensor I can sense an increase in calcium influx, which then stimulates the activity of PI4K and replenishes depleted PIP2 levels (Hernandez et al., 2008; Carver and Shapiro, 2018). Increased metabotropic Ach receptor (mAChR) stimulation in the dentate gyrus cells increases PIP2 synthesis as well as $\mathrm{M}$ currents. By contrast, in CA1 cells, the same mechanism causes PIP2 depletion and reduces $M$ currents. Such opposing actions highlight the complexity and pleiotropic effects of the intracellular signaling cascade on M channels (Carver and Shapiro, 2018). Both mAChr and bradykinin cause a reduction in $\mathrm{M}$ and $\mathrm{SK}$ currents by the direct depletion of PIP2 levels. PIP2 binding affinity for $\mathrm{K}_{\mathrm{v}} 7$ is different for different $K_{V} 7$ isoforms. The affinity is highest for $\mathrm{K}_{\mathrm{v}} 7.3$, followed by that of $\mathrm{K}_{\mathrm{v}} 7.2$ and $\mathrm{K}_{\mathrm{v}} 7.4$ (Li et al., 2005). Different heteromers of different $K_{v} 7$ isoforms have affinities that are intermediate to those of their constitutive channels ( $\mathrm{Li}$ et al., 2005). The PIP2 binding site on SK channels is in the vicinity of the CaMBD, and CK2-dependent phosphorylation of the CaMBD also reduces PIP2 binding affinity and SK channel activity (Zhang Y. et al., 2014). However, the PIP2 binding domain on HCN channels is not in proximity with the CNBD; consequently, both PIP2 and cAMP can separately regulate $\mathrm{HCN}$ activity (Zolles et al., 2006). PIP2 can produce a $20 \mathrm{mV}$ positive shift in the activation curve of $\mathrm{HCN}$ channels ( $\mathrm{He}$ et al., 2014; Figure 2). Therefore, PIP2, in addition to being crucial for $\mathrm{K}_{\mathrm{V}} 7$ channel activation, is a positive regulator for the other mAHP channels.

\section{Protein Kinases}

Protein kinases and phosphatases coupled to $\mathrm{SK}$ and $\mathrm{K}_{\mathrm{v}} 7$ can serve as additional channel activity regulators. CK2 bound to the $\mathrm{C}$ termini of SK channels phosphorylates CaM and reduces its calcium sensitivity, which favors reduced SK channel activity. By contrast, $\mathrm{CK} 2$ bound to the $\mathrm{N}$ terminus of $\mathrm{K}_{\mathrm{v}} 7$ phosphorylates $\mathrm{CaM}$ and strengthens its binding to the channel, causing increased channel activity (Bildl et al., 2004). CK2 kinase functioning is checked by coupled phosphatases, namely PP2A for SK and PP1 for $K_{\mathrm{v}} 7$ channels (Maingret et al., 2008; Adelman et al., 2012; Kang et al., 2014). Kinase- and phosphatasedependent regulation of SK channels modulate mGluR longterm potentiation (LTP) in hippocampal CA1 (Sourdet et al., 2003). Identical phosphoregulation of SK channels modulates LTP between parallel fibers and Purkinje cells in the cerebellum (Belmeguenai et al., 2010). Additionally, CK2 is enriched in the post synaptic density (PSD), where it can regulate NMDAR and AMPAR, which are also functionally coupled to SK channels (Castello et al., 2017). Thus, CK2 can directly (as bound to SK 
channel) and indirectly (via NMDAR and AMPAR) modulate SK channels, thereby regulating synaptic receptor functions.

In addition to $\mathrm{CK} 2, \mathrm{PKA}$ is another critical protein kinase that can regulate all the three mAHP channels. cAMP-PKA signaling can regulate the surface expression of SK channels. A high level of PKA activity reduces SK channels surface expression, while reduced PKA activity increases expression levels (Abiraman et al., 2016). A PKA-dependent decrease in SK channels surface expression levels facilitates NMDAR-mediated LTP induction in CA1 hippocampal neurons (Lin et al., 2008; Abiraman et al., 2016). In smooth muscle cells, increased cAMP-PKA activity facilitates $K_{v} 7.5$ and $K_{v} 7.4$ isoform activity (Mani et al., 2016). Similarly, in DRG neurons and hippocampal mossy fibers, PKA augments HCN channel activity (Mellor et al., 2002; Cheng and Zhou, 2013; Figure 2). PKC dependent phosphorylation of $\mathrm{M}$ channels increases their activity. However, under mGluR stimulation, A-kinase anchoring protein (AKAP) binds to PKC and reduces the accessibility of the PKC kinase site, resulting in a decrease in M current (Delmas and Brown, 2005; Kreir et al., 2019). In hippocampal and anterior cingulate cortex neurons, an increase in PLC-PKC activity via the mGluR signaling pathway also reduces $\mathrm{HCN} 1$ channel expression and $\mathrm{HCN}$ currents (Williams et al., 2015; Gao et al., 2016). Additionally, other signaling pathways that affect the above mentioned protein kinases can modulate the MAHP channels and regulate synaptic and cellular functions.

We have described the key regulatory molecules for the mAHP channels. Some of these regulators have a more significant impact on the activity of one type mAHP channel than on the activities of the other types; however, considerable overlap and common signaling pathways can affect all three mAHP channels. The isoform-specific effects of these regulators and the differential distribution of the mAHP channels can provide specialized neuronal functions in distinct brain regions.

\section{FUNCTIONS OF MAHP CHANNELS IN REGULATING INTRINSIC CELLULAR AND NETWORK PROPERTIES}

\section{Intrinsic Cellular Properties}

The diverse functionality of mAHP channels make them critical factors in various neurological diseases. mAHP channels play a crucial role in controlling neuronal excitability. Increased mAHP channel activity reduces the firing threshold for a cell, stabilizes RMP, and limits firing activity, thus controlling intrinsic neuronal excitability. Increased intracellular calcium (SK channels) and voltage change (HCN and M channels) cause channel activation. $\mathrm{M}$ and HCN channels, but not SK channels, are active at the RMP of the cell; hence, they strongly influence the RMP and IR of the cell. HCN channels specifically play a key role in stabilizing cellular RMP (Lupica et al., 2001). However, because of differences in the localization of the channels, $M$ channels affect axonal RMP most significantly, while HCN channels control somatic and dendritic RMPs (Hu and Bean, 2018). Activation of $\mathrm{M}$ and SK channels also leads to spike frequency adaptation, which reduces net spiking output from a neuron ( $\mathrm{Ha}$ and Cheong, 2017). Spike frequency adaptation is a progressive decline in the interspike interval in a spike train produced under sustained depolarization. Thus, the combined effects of the three mAHP channels control various intrinsic cellular properties and neuronal responses to input stimuli.

\section{Spike Generation in Soma and Dendrites}

Specialized localization of M, HCN, and SK channels in different neuronal compartments regulate local neuronal properties. In general, activation of mAHP channels reduces excitability. However, in Layer 5 cortical cells, SK channels have a differential effect on excitability in the soma compared with that on apical dendrites (Bock and Stuart, 2016). SK channel activation in the soma reduces action potential output, while SK channel activation in dendrites increases dendritic spike generation. This differential effect is a result of the functional coupling of SK channels in apical dendrites to R-type calcium channels. Consequently, SK channel activation increases $\mathrm{Ca}^{2+}$ influx through R-type calcium channels, reduces the NMDAR-mediated spike threshold, and increases dendritic excitability (Bock and Stuart, 2016; Bock et al., 2019). M channels specifically regulate axonal properties because $\mathrm{M}$ channels are localized in axon initial segment (AIS), which enables them to regulate axonal excitability, axonal plasticity, and interneuronal signal transmission (Lezmy et al., 2017). In hippocampal neurons, HCN channels exhibit a proximal to distal dendritic gradient. Consequently, they strongly influence proximal to distal dendritic computation and hippocampal-specific learning and memory tasks (Berger et al., 2003). HCN1 channel activity is also crucial for Purkinje cell dendritic integration and assists in motor-dependent memory formation and coordination (Nolan et al., 2003).

\section{Synaptic and Network Activity Patterning}

In addition to controlling intrinsic cellular properties, mAHP channels regulate neuronal synaptic activity, oscillatory activity of various neurons and network rhythms (Llinas and Jahnsen, 1982; Ludwig et al., 2003). Dendritic M and HCN activation produce a shunt inhibition on incoming excitatory post synaptic currents (EPSCs), thus reducing their amplitude and duration. This causes an increased threshold to spike and reduces EPSC integration (Berger et al., 2003). Presynaptic M and HCN channel activation control the paired-pulse ratio in the calyx of Held and sIPSC frequency in the amygdala, respectively (Martire et al., 2004; Huang and Trussell, 2011; Park et al., 2011). In Layer 3 EC neurons, presynaptic HCN channels reduce exocytosis of glutamate; hence, blocking presynaptic $\mathrm{HCN}$ channels produces an increase in miniature excitatory postsynaptic current frequency (Huang et al., 2018). SK channels in nucleus reticularis thalamic neurons and locus coeruleus (LC) control their pacemaker activity, thus driving network oscillations (Matschke et al., 2018). Rhythmic burst firing in nucleus reticularis thalamic neurons dependent on SK channels were reported to generate spindle waves $(7-12 \mathrm{~Hz}$ ) (Bal and Mccormick, 1993). SK channels, with T-type calcium channels in nucleus reticularis thalamic neurons, are responsible for sleeprelated oscillations. SK2 channel knock outs exhibit a reduction 
in low-frequency rhythms in non-rapid-eye-movement sleep and disrupted sleep (Cueni et al., 2008). HCN channels control the circadian rhythm in suprachiasmatic neurons (Akasu et al., 1993; Atkinson et al., 2011), modulate hippocampal theta rhythms by controlling the firing activity of septohippocampal GABAergic neurons and stellate neurons of the entorhinal cortex (Dickson et al., 2000; Fransén et al., 2004; Xu et al., 2004); furthermore, $\mathrm{HCN}$ channels control the pace-making activity of globus pallidus neurons (Chen et al., 2015). Neurotransmitters such as noradrenaline and serotonin can further modulate these oscillatory activities through their effect on HCN channels (McCormick and Pape, 1990; Maingret et al., 2008; Giessel and Sabatini, 2010). Thus, mAHP channels play a significant role in shaping network rhythms, which affects the cognitive state and functioning of animals.

\section{THERAPEUTIC POTENTIALS OF MAHP MODULATORS}

As discussed, mAHP channels are crucial in regulating essential neuronal functioning. Consequently, mutations that directly or indirectly affect these ion channels lead to severe neurological defects. Herein, we provide an in-depth account of various clinical disorders where altered functioning of mAHP channels contributes to multiple symptoms.

\section{Ischemia}

Ischemia is a commonly occurring form of brain damage, where the brain experiences a partial reduction or complete stoppage in blood supply because of cardiac arrest or stroke. Alterations in mAHP channel activity can either aggravate or circumvent ischemic damage. During an ischemic episode, the brain undergoes excitotoxic damage because of elevated extracellular glutamate levels that lead to increased calcium influx through NMDARs (Lo et al., 2003). Additionally, studies have shown that an ischemic attack causes a reduction in SK and an increase in HCN channel activity. This change further increases neuronal activity, thereby aggravating neuronal damage. A specific example of this is CA1 hippocampal neurons, where after an ischemic episode, SK2 channels decouple from NMDARs in the PSD, aggravating increased extracellular glutamate-induced damage to neurons (Allen et al., 2011). These neurons also undergo an increase in HCN1 and HCN2 activity levels after a transient ischemic insult. The increase in $\mathrm{HCN}$ channel activity decays after 4 days of the ischemic incidence, which contributes to the initial excitotoxic damage associated with ischemia. Both SK channel activators and HCN channel antagonists have shown neuroprotective action against ischemic attacks (Table 2). In CA3 cells, as a natural defense mechanism, transient ischemic insult activates SK currents, which provide a neuroprotective effect (Tanabe et al., 1999). In HT22 cells, glutamate-mediated oxidative stress increases mitochondrial SK2 channel activity, which exhibits a neuroprotective effect on these cells (Honrath et al., 2017; Krabbendam et al., 2018). Increasing SK channel activity by using 1-EBIO (SK channel agonist) increases the effect of $\mathrm{Mg}^{2}+$ blocking on NMDARs and prevents glutamate-mediated excitotoxic damage (Allen et al., 2011). The use of the HCN blocker ZD7288 and the M channel activator retigabine soon after ischemic damage (within 0-6 h) prevents excessive activation of postsynaptic NMDARs, prevents LTP deficits, and provides neuroprotection against oxygen or glucose deprivation in organotypic hippocampal cultures and in vivo ischemic models (Boscia et al., 2006; He et al., 2014; Bierbower et al., 2015; Diao et al., 2019; Chen et al., 2020; Table 2). Astrocytes also respond to ischemia to prevent neurotoxicity. $\mathrm{HCN} 1$ and HCN2 levels increase in astrocytes after 4 days and up to 2 weeks, contributing to long-term compensatory or neuroprotective effects (Honsa et al., 2014; Park et al., 2019). Thus, SK and M activators and HCN channel inhibitors are promising therapeutic targets for neuroprotection against ischemic insult (Table 3).

\section{Epilepsy}

Epilepsy is a common neurological disorder caused by bursts of increased neuronal activity in different brain regions, which is characterized by jerking body movements. Because mAHP channels play a crucial role in controlling neuronal excitability, mutations in each of these channels can cause or aggravate epilepsy. Numerous studies have reported that a decrease in the activity of SK and $\mathrm{M}$ channels and an increase in the activity of $\mathrm{HCN}$ channels reduce neuronal mAHPs, which result in seizure phenotypes. Thus, mAHP channel modulators are potential therapeutic targets for epilepsy treatment.

In CA3 hippocampal cells, SK channels control epileptic bursts and spontaneous interictal discharge activity (Alger and Nicoll, 1980; Chamberlin and Dingledine, 1989; Fernández De Sevilla et al., 2006; Bakker et al., 2007). $\mathrm{Ca}^{2+}$ entry facilitated by L-type $\mathrm{Ca}^{2+}$ channels lead to the activation of these SK channels, which control burst duration, frequency, and intensity (Huang et al., 2018). In pilocarpine-treated chronic epilepsy rat models, a reduction in SK channel levels and currents has been observed (Schulz et al., 2012). Epileptic activity may cause different SK channel isoforms to undergo transient downregulation, further propagating acute seizures. In medial temporal lobe epilepsy (TLE) models, SK1 and SK2 channels and SK3 channel are downregulated acutely and chronically, respectively (Oliveira et al., 2010). Loss-of-function mutations in $K_{v} 7.2$ and 7.3 cause benign familial neonatal seizures, and G271V mutations in the pore region of $\mathrm{K}_{\mathrm{v}} 7.2$ cause familial epilepsy (Biervert et al., 1998; Wang et al., 2015). Increasing PIP2 levels by increasing PIP5K can rescue reduced $K_{v} 7.2$ function, thus suggesting that decreased "sensitivity" to PIP2 is responsible for impaired $\mathrm{K}_{\mathrm{V}} 7.2$ currents (Soldovieri et al., 2016). In specific benign familial neonatal seizures mutations, loss of preferential targeting of $\mathrm{K}_{\mathrm{v}} 7.2 / \mathrm{K}_{\mathrm{v}} 7.3$ channels on AIS (due to mutation in the ankyrin $\mathrm{G}$ binding motif at the $\mathrm{C}$ terminal) and axons can cause losses in their function and epilepsy (Chung et al., 2006). Blocking of $\mathrm{M}$ channels increases ADP levels, which produces burst firing in hippocampal neurons, which start or propagate seizure waves and cause neurodegeneration (Vervaeke et al., 2006; Greene et al., 2018).

In contrast to SK and $\mathrm{M}$ channels, where reduced activity leads to epilepsy, an increase as well as a decrease in the 
TABLE 2 | Summary of different mAHP channels' inhibitors and activators.

\begin{tabular}{|c|c|c|c|}
\hline $\begin{array}{l}\text { mAHP } \\
\text { channel }\end{array}$ & Modulator & Effect & References \\
\hline SK & $\begin{array}{l}\text { Inhibitors } \\
\text { - bee venom apamin (extracted } \\
\text { from Apis mellifera) } \\
\text { - scorpion venom toxin scyllatoxin } \\
\text { (extracted from scorpion Leiurus } \\
\text { quinquestriatus hebraeus) } \\
\text { - d-tubocurarine (extracted from }\end{array}$ & $\begin{array}{l}\text { - Both apamin and scyllatoxin block the pore region between S5 and S6, thereby inhibiting } \\
\text { current flow through SK channels. Low levels of apamin can block SK2 channels }\left(\mathrm{IC}_{50} 62\right. \\
\text { pM), while apamin levels as high as } 100 \mathrm{~nm} \text { cannot block SK1 channels } \\
\text { - They bind through their basic amino acid, arginine, on the negatively charged residues in } \\
\text { the pore region of SK channels. } \\
\text { - d-tubocurarine can block SK2 channels at a considerably lower level }\left(\mathrm{IC}_{50} 5.4 \mu \mathrm{M}\right) \text { than } \\
\text { SK1 }\left(\mathrm{IC}_{50} 354.3 \mu \mathrm{M}\right) \text { channels. SK3 has intermediate sensitivity to apamin and }\end{array}$ & $\begin{array}{l}\text { Park, 1994; Ishii et al., } \\
\text { 1997; Fanger et al., } \\
\text { 2001; Köhler et al., } \\
\text { 1996; Nolting et al., } \\
\text { 2007; Sørensen et al., } \\
2008\end{array}$ \\
\hline
\end{tabular}

- d-tubocurarine (extracted from plant Chondrodendron tomentosum)

- Chemical inhibitors like calcium chelators (EGTA, EDTA, and BAPTA) and cadmium

- Artificial blocker, NS8593

Activators

- Chlorzoxazone

-1 -EBIO

- NS 309

- SKS-11 and SKS-14

- CyPPA

- Riluzole.

d-tubocurarine.

- Structural heterogeneity and minor differences in the amino acids in the pore region of different SK isoforms leads to variation in sensitivity to apamin and d-tubocurarine binding - NS8593 is a highly potent negative modulator of SK channels. It acts by increasing the response threshold of SK channels to calcium. The drug can also cross the blood-brain barrier, which increases its clinical use to target SK channels in the brain.

- 1-EBIO ( EC $_{50}$ of $630 \mu \mathrm{M}$ for SK1, $500 \mu \mathrm{M}$ to $1 \mathrm{mM}$ for SK2, and $170 \mu \mathrm{M}$ to $1 \mathrm{mM}$ for SK3) increases calcium sensitivity, which increases SK channel activity.

- 1-EBIO activates SK channels by binding both to the CaMBD and to CaM on the channel's C terminus.

- NS309 (EC50 10-20 nM for KCa3.1 and approximately 600 nM for KCa2 channels) shares the same binding site as 1-EBIO, riluzole and CyPPA.

- SKS-11 and SKS-14 are highly potent SK activators. These chemicals share the same binding site as 1-EBIO and NS309 and bind through strong electrostatic bonds with the channel and lock them in an open state.

- CyPPA has a high specificity toward SK2 and SK3 channels but not SK1 channels. Isoform-specific SK channel modulators facilitate targeting specific regions depending on the isoform expression.

- Cesium and ZD7288 ( $\left(\mathrm{C}_{50}\right.$ approximately $\left.10 \mu \mathrm{M}\right)$ are specific blockers of HCN channels. The $\mathrm{IC}_{50}$ values for blocking the four channel isoforms are similar owing to a high structural homogeneity between the different isoforms.

Inhibitors
- Cesium and ZD7288.

- $\alpha 2$-adrenoceptor agonists, such as clonidine, dexmedetomidine, and guanabenz

- Ivabradine, Clonidine

- Loperamide

- Capsazepine

\section{Activators \\ - Tanshinone IIA, extracted from \\ Salvia miltiorrhiza \\ - Fisetin \\ - Lamotrigine and Gabapentin}

- Alanine 425 and isoleucine 432 on S6 are crucial for binding of ZD7288 to HCN channels.
- These blockers produce a hyperpolarizing shift in the activation voltage of HCN channels and reduce maximal channel conductance.

- Ivabradine ( $\left(\mathrm{C}_{50}\right.$ approximately $\left.1-2 \mu \mathrm{M}\right)$ and clonidine $\left(\mathrm{IC}_{50}\right.$ approximately $\left.10 \mu \mathrm{M}\right)$ are specific HCN4 and HCN1 blockers, which bind to the intracellular side of the channel.

- Loperamide $\left(\mathrm{IC}_{50}\right.$ approximately 4.9-11 $\left.\mu \mathrm{M}\right)$ acts extracellularly and binds to the S1-S2 region on $\mathrm{HCN} 1$ channels.

- Capsazepine $\left(\mathrm{IC}_{50}\right.$ approximately $\left.8 \mu \mathrm{M}\right)$ is another specific $\mathrm{HCN} 1$ and HCN2 channel blocker that blocks HCN channels in a dose-dependent manner

- Tanshinone has a higher specificity for HCN2 than for the other isoforms.

- Fisetin ( $\mathrm{EC}_{50}$ approximately $2 \mu \mathrm{M}$ ) is a flavonoid activator of HCN2 channels, which shifts the channel $V_{1 / 2}$ toward depolarized potentials. It binds to the CNBD on the channel and shares the same binding pocket as cAMP.

- Lamotrigine and Gabapentin increase HCN current amplitude but do not affect channel activation or deactivation kinetics

- Gabapentin is used to treat epilepsy and specifically affects the HCN4 isoform with small effect on other HCN isoforms.

- XE991 ( $\left.\mathrm{IC}_{50} 0.8 \mu \mathrm{M}\right)$ and linopirdine $\left(\mathrm{IC}_{50} 5 \mu \mathrm{M}\right)$ are non-isoform-specific $\mathrm{K}_{\mathrm{v}} 7$ blockers.

- Chromanol 293B, HMR1556, L-768, 673, JNJ282, and JNJ303 can block only K 7.1 when bound to KCNE1 and KCNE3.

- Retigabine is a $K_{v} 7$ channel activator that produces a hyperpolarization shift in the activation voltage, accelerates the activation kinetics of the channels, and slows the channel deactivation rate,

- Retigabine can activate $\mathrm{K}_{\mathrm{v}} 7.2,7.3,7.4$, and 7.5 but not $\mathrm{K}_{\mathrm{v}} 7.1$.

- Retigabine binds at the pore regions, where an interaction with a tryptophan residue at the cytoplasmic site of the S5 domain is crucial, thereby stabilizing the open state of the $\mathrm{K}_{\mathrm{v}} 7$ channels.

- Gabapentin is also a potent activator of $\mathrm{K}_{\mathrm{v}} 7.2 / 7.3$ heteromeric channels as well as $\mathrm{K}_{\mathrm{v}} 7.3$ and 7.5 homomeric channels. It does not act on homomeric $K_{v} 7.2$ and 7.4 channels

- Zinc pyrithione binding occurs through a leucine residue in S5 and an alanine residue in the linker region between S5 and the pore. It has a high specificity of blocking $K_{v} 7.2$ homomeric channels (Xiong et al., 2008).

- Flupirtine binds to all $\mathrm{K}_{\mathrm{v}} 7$ channels except $\mathrm{K}_{\mathrm{v}} 7.2$

- SCR2682 ( $\left(\mathrm{C}_{50}\right.$ of approximately $\left.9.8 \mathrm{nM}\right)$ is a $\mathrm{K}_{\mathrm{v}} 7$ channel activator, with a higher potency than retigabine. It causes a hyperpolarization shift of approximately $37 \mathrm{mV}$ in the channel activation and can inhibit epileptic attacks in mice in a dose-dependent manner.
Brown et al., 2017; Zhang et al., 2012; Schumacher et al., 2001; Christophersen and Wulff, 2015; Cho et al., 2018; Hougaard et al., 2007; Nam et al., 2017

Cheng et al., 2007; Tanguay et al., 2019; Won et al., 2019; Bucchi et al., 2002; Vasilyev et al., 2007; Gill et al., 2004; Zhao et al., 2019

Shang et al., 2012; Carlson et al., 2013; Surges et al., 2003; Peng et al., 2010; Tae et al., 2017

Barrese et al., 2018

Main et al., 2000; Tatulian et al., 2001; Tatulian and Brown, 2003; Wickenden et al. 2009; Corbin-Leftwich et al., 2016; Xiong et al., 2008; Manville and Abbott, 2018; Barrese et al., 2018; Zhang et al., 2019 
TABLE 3 | The table summarizes various neurological anomalies dependent on the altered activity of the mAHP channels and their chemical modulators, which can alleviate the symptoms along with corresponding references.

\begin{tabular}{|c|c|c|c|c|c|}
\hline $\begin{array}{l}\text { S. } \\
\text { No. }\end{array}$ & $\begin{array}{l}\text { Neurological } \\
\text { Disease }\end{array}$ & Decre & $\begin{array}{l}\text { ased/ } \\
\text { ed mAHP } \\
\text { nnel }\end{array}$ & Modulators used & References \\
\hline 1 & Ischemia & $\begin{array}{l}\mathrm{SK} \\
\mathrm{HCN}\end{array}$ & $\begin{array}{ll}1 \\
\end{array}$ & $\begin{array}{l}\text { 1-EBIO, ZD7288, Retigabine provided neuroprotective } \\
\text { effects }\end{array}$ & $\begin{array}{l}\text { Boscia et al., 2006; He et al., 2014; Bierbower et al., 2015; } \\
\text { Honrath et al., 2017, 2018; Chen et al., } 2020\end{array}$ \\
\hline 2 & Epilepsy & $\begin{array}{c}\text { SK } \\
M \\
\text { HCN }\end{array}$ & $\begin{array}{l}\square \\
\square \\
\square \square \\
\square\end{array}$ & $\begin{array}{l}\text { 1-EBIO and Retigabine reduced seizure intensity and } \\
\text { duration. Gabapentin (HCN agonist) reduced focal epilepsy } \\
\text { and ZD7288 reduced hippocampal epilepsy. }\end{array}$ & $\begin{array}{l}\text { Kitayama et al., 2003; Garduño et al., 2005; Lappin et al., } \\
\text { 2005; Anderson et al., 2006; Bialer et al., 2009; Fattore and } \\
\text { Perucca, 2011; Zhao et al., } 2011\end{array}$ \\
\hline 3 & Pain & $\begin{array}{c}\text { SK } \\
M \\
\text { HCN }\end{array}$ & \begin{tabular}{l|}
1 \\
1 \\
1 \\
\end{tabular} & $\begin{array}{l}\text { 1-EBIO, retigabine, flupirtine and ZD7288 provide analgesic } \\
\text { effect. }\end{array}$ & $\begin{array}{l}\text { Boettger et al., 2002; Bahia et al., 2005; Emery et al., 2011; } \\
\text { Rose et al., 2011; Ding et al., } 2016\end{array}$ \\
\hline 4 & Depression & $\begin{array}{c}\text { SK } \\
M \\
\text { HCN }\end{array}$ & 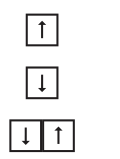 & $\begin{array}{l}\text { Anti-depressant drugs (Prozac) block SK channels. } \\
\text { Retigabine and ZD7288 improved depressive behvaiour }\end{array}$ & $\begin{array}{l}\text { Galeotti et al., 1999; Dreixler et al., 2000a; Terstappen } \\
\text { et al., 2001; Ngo-Anh et al., 2008; Li et al., 2017; Günther } \\
\text { et al., } 2019\end{array}$ \\
\hline 5 & Alcohol addiction & $\begin{array}{c}\text { SK } \\
M \\
\text { HCN }\end{array}$ & $\begin{array}{l}1 \\
1 \\
1 \\
\end{array}$ & $\begin{array}{l}\text { 1-EBIO, retigabine decreased alcohol-seeking behavior and } \\
\text { hyperexcitability correlated with alcohol withdrawal. }\end{array}$ & $\begin{array}{l}\text { Hopf et al., 2010, 2011; Mulholland et al., 2011; Knapp } \\
\text { et al., 2014; McGuier et al., 2016, } 2018\end{array}$ \\
\hline 6 & Schizophrenia & $\begin{array}{c}\text { SK } \\
M \\
\text { HCN }\end{array}$ & \begin{tabular}{l|}
$\uparrow$ \\
1 \\
$\uparrow$ \\
\end{tabular} & $\begin{array}{l}\text { Use of ZD7288 and retigabine can prevent working } \\
\text { memory deficits and reduce dopamine release in } \\
\text { Schizophrenia patients }\end{array}$ & $\begin{array}{l}\text { Hansen et al., 2008; Arnsten, 2011; Gamo et al., 2015; Mi } \\
\text { et al., } 2019\end{array}$ \\
\hline 7 & $\begin{array}{l}\text { Parkinson's } \\
\text { Disease }\end{array}$ & $\begin{array}{c}\text { SK } \\
M \\
\text { HCN }\end{array}$ & $\begin{array}{l}\downarrow \uparrow \\
\downarrow \\
1 \\
1\end{array}$ & $\begin{array}{l}\text { Use of ZD7288 improved motor deficits. Use of } \\
\text { retigabine/flupirtine reduced L-DOPA treatment associated } \\
\text { side-effects. The use of apamin and XE } 991 \text { provided a } \\
\text { neuroprotective effect. }\end{array}$ & $\begin{array}{l}\text { Alvarez-Fischer et al., 2013; Sander et al., 2013; Liu et al., } \\
\text { 2018; Hao et al., } 2019\end{array}$ \\
\hline 8 & Alzheimer's disease & $\begin{array}{l}\text { SK } \\
\text { MCN }\end{array}$ & 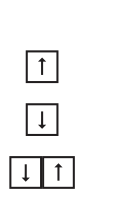 & $\begin{array}{l}\text { The use of HCN blocker decreases secreted A } 342 \text {, sAPP, } \\
\text { and APP-CTF levels. Apamin treatment rescued memory } \\
\text { deficits seen in AD mice }\end{array}$ & $\begin{array}{l}\text { Carlesimo and Oscar-Berman, 1992; Ikonen and Riekkinen, } \\
\text { 1999; Nakagawa et al., 2002; Saito et al., 2012; Frykman } \\
\text { et al., 2017; Proulx et al., } 2020 \\
\text { Carlesimo and Oscar-Berman, 1992; Ikonen and Riekkinen, } \\
\text { 1999; Saito et al., 2012; Frykman et al., 2017; Proulx et al., } \\
2020\end{array}$ \\
\hline
\end{tabular}

activity of $\mathrm{HCN}$ channels are known to cause seizures. Increased HCN activity can reduce the mAHP of the neurons and produce hyperexcitability. Furthermore, reduced HCN levels increase cellular input resistance and dendritic excitability, which also causes hyperexcitability. This causes faster dendritic EPSC integration, which elicits spiking with fewer EPSCs. Increased dendritic excitability also increases EPSCs in the network, which increases network excitability (Biel et al., 2009). Genetic analysis of epilepsy patients revealed that the lossof-function mutations in the HCN1 gene is responsible for various epilepsies, such as febrile seizures, genetic generalized epilepsies, and neonatal epileptic encephalopathy. Mutations in $\mathrm{HCN} 2$ and $\mathrm{HCN} 3$ can also contribute to epilepsy in some cases (Marini et al., 2018; DiFrancesco et al., 2019). In CA1 hippocampal neurons, 1-2 days after a single epileptic event, before the onset of spontaneous seizures, HCN1 channels exhibit an increase in surface expression. However, after 28 days, when spontaneous seizures have begun, the expression levels of HCN channel levels decrease. These bidirectional changes in $\mathrm{HCN}$ levels are responsible for the development of long-term epilepsy symptoms (Shin et al., 2008). Febrile seizures caused by fever are the most common type of seizures in children. A gain-of-function mutation in HCN2 is responsible for these seizures in patients (Dibbens et al., 2010). A hyperthermic event also produces an increase in incoming inhibitory post synaptic potentials (IPSPs), to reduce increased neural excitability during an epileptic activity. However, contrary to expectations, a burst of IPSPs, which is hyperpolarizing in nature, activates HCN channels, thereby causing hyperexcitability and increased seizure attacks (Chen et al., 2001). Contrary to the aforementioned studies, a single seizure episode can reduce HCN1 and HCN2 channel currents after $24 \mathrm{~h}$ for up to 1 week in EC layer III and hippocampal neurons (Shah et al., 2004; Jung et al., 2007; Powell et al., 2008). Additionally, loss of function in 
HCN2 and loss of TRIP8b protein (an auxiliary protein to HCN channels) can lead to the emergence of spontaneous absence seizures (Ludwig et al., 2003; Heuermann et al., 2016). TRIP8b deletion mice have reduced $\mathrm{I}_{\mathrm{h}}$ currents which can cause loss of HCN-mediated inhibition of T-type calcium currents in the thalamocortical relay and cortical neurons. This leads to increased spontaneous oscillatory activity in the thalamocortical neuronal networks and subsequent spontaneous absence seizures in mice (Ludwig et al., 2003; Ramírez et al., 2018; Hammelmann et al., 2019; Zobeiri et al., 2019). In the TLE model of epilepsy, reduced phosphorylation of $\operatorname{Ser}^{237}$ in TRIP8b proteins has also been found to be a contributing factor to epilepsy (Foote et al., 2019). Loss of KCNE2 can also lead to reduced levels and slowed activation kinetics of HCN channels (Ying et al., 2012).

Because a decrease in SK and M channel activity and an increase or a decrease in $\mathrm{HCN}$ channel activity causes epilepsy symptoms, their modulators are useful therapeutic targets. The use of SK and M activators, 1-EBIO, and retigabine reduce epileptic activity. Additionally, they delay seizure initiation; increase the threshold; reduce seizure intensity in the kindling model of epilepsy, audiogenic seizures, and focal epilepsy; and reduce seizure intensity in genetically epilepsy-prone mice. However, they also cause side effects such as reduced locomotor activity, dizziness, fatigue, loss in motor coordination, and impairment in exploratory behavior (Xing and $\mathrm{Hu}, 1999$; Garduño et al., 2005; Lappin et al., 2005; Anderson et al., 2006; Bialer et al., 2009; Fattore and Perucca, 2011; Weisenberg and Wong, 2011). Augmenting $\mathrm{K}_{\mathrm{v}} 7$ activity after an epileptic event also prevents neurodegeneration (Greene et al., 2018). In genetically epilepsy-prone rat models, acoustic seizures were reported to reduce the activity of SK1 and SK3 channels in the inferior colliculus, and the use of 1-EBIO was reported to reduce seizure incidences in these models (Khandai et al., 2020; Table 2). D-23129, a derivative of flupirtine, is also effective against amygdala kindling seizure models (Tober et al., 1996). HCN1 channels limit the spread of seizures from the forebrain to the hindbrain (Huang et al., 2009; Santoro et al., 2010). Because an increase/decrease in the levels or activity of HCN channels can contribute to epilepsy, both blockers and activators of $\mathrm{HCN}$ channels are possible therapeutic agents. Gabapentin, an HCN channel agonist, is reported to be effective against focal epilepsy, while the HCN channel blocker ZD 7288 reduces hippocampal epileptic activity in rabbits (Kitayama et al., 2003; Table 2). In the VB nucleus, loss of HCN2, but not HCN4, alters underlying thalamic oscillations, thereby causing absence seizures (Ludwig et al., 2003; Hammelmann et al., 2019; Zobeiri et al., 2019). By contrast, David et al. (2018) reported a decrease in $\mathrm{I}_{\mathrm{h}}$ levels in the neocortical neurons in absence seizure models and an increase in $\mathrm{I}_{\mathrm{h}}$ currents in the thalamocortical neurons. Microdialysis of ZD7288 in the VB nucleus or knockdown of HCN channels in the VB nucleus abolishes absence seizures (David et al., 2018). Bidirectional changes in HCN levels in different brain regions negates the possibility of treating epilepsy symptoms by using a general $\mathrm{HCN}$ blocker. Additionally, SK channels contribute to alterations in thalamocortical oscillations. In a bicuculline methiodide epilepsy model, the SK channel antagonist apamin was reported to produce epileptic thalamocortical oscillations, which are the underlying causes of absence seizures. Thus, both HCN and SK channels are involved in the etiology of absence seizures and their dual modulation is likely an effective treatment strategy (Ludwig et al., 2003; Kleiman-weiner et al., 2009; Hammelmann et al., 2019).

As explained previously, mAHP channels are critical molecules contributing to epilepsy. The levels of SK and HCN channels increase and decrease in an isoform-specific and a time-dependent manner, which result in epilepsy initiation and progression. Loss-of-function mutations in Kv7 channels can also lead to epilepsy. Additional work to elucidate region-dependent isoform-specific alterations in the levels of the mAHP channels can be effectively used in clinical practice (Table 3).

\section{Pain}

Dorsal root ganglion, peripheral neurons, sensory neurons, and nociceptor neurons express all the three mAHP channels (Akins and McCleskey, 1993; Villière and McLachlan, 1996; Amir and Devor, 1997; Boettger et al., 2002; Passmore et al., 2003; Linley et al., 2008; Hou et al., 2015). These channels regulate the firing activity of the aforementioned neurons, thereby modulating pain responses. Pain or nerve damage reduces mAHP channel activity prompting hyperactivity in these neurons; thus, mAHP channel activators can be used as pain-relieving agents.

Injury to a peripheral neuron or its nearest DRG leads to ectopic spontaneous discharges on account of diminished extracellular potassium or calcium (Xing and $\mathrm{Hu}, 1999$ ). Xing and $\mathrm{Hu}(1999)$ showed that increasing extracellular calcium increases calcium influx, activates SK currents, and reduces firing in DRG neurons. Thus, activating SK channels eases pain perception. Reduction in SK1 and $\mathrm{K}_{\mathrm{v}}$ 7.2, 7.3, and 7.4 currents and increased HCN activity in small and large nuclei DRG neurons after injury contribute to increased neuronal activity and pain sensation (Boettger et al., 2002; Emery et al., 2011; Rose et al., 2011; Yu et al., 2018). Elevated HCN currents in rat thalamus and spinal cord present chronic neuropathic pain. Similarly, HCN2 knockout mice showed a reduction in pain response to thermal or mechanical pain stimuli (Emery et al., 2011). In the spared nerve injury pain model, the medial prefrontal cortex (mPFC) neurons showed reduced cAMP levels and loss in PKA activity leading to a hyperpolarization shift in HCN activity (Matos et al., 2015). Although not examined in this study, loss in PKAdependent regulation will also reduce $M$ channel activity and SK channel surface expression (Lin et al., 2008; Abiraman et al., 2016; Mani et al., 2016). The combined loss of activity of mAHP channels can give rise to increased IR and hyperexcitability in these neurons, thereby increasing pain sensation (Matos et al., 2015). Neuropeptide $S$ is a naturally occurring anxiolytic that inhibits HCN channels on medial amygdala cells. Reducing HCN activity by using neuropeptide $S$ enhances glutamatergic inputs on GABAergic interneurons, which in turn suppresses pyramidal cells and relieve pain (Zhang et al., 2016). Neuropeptide S also possesses weak capacity to bind to SK channels (Liegeois et al., 2005). Mimicking neuropeptide S action and inhibiting HCN 
and SK channels by targeting amygdalar nuclei is a possible pain-relieving mechanism.

Additionally, blocking HCN channels by injection of ZD7288 in the thalamus has shown to attenuate chronic pain and sensitivity to pain in a dose-dependent manner (Ding et al., 2016; Zhang et al., 2016) (Table 2). Propofol (2,6-di-isopropyl phenol) and its derivatives, 2,6- and 2,4-di-tertbutylphenol are potent, selective HCN1 channel blockers and can reduce mechanical and thermal hyperalgesia (Tibbs et al., 2013). Furthermore, chronic pain also contributes to anxiety. Koga et al. (2015) found that an increase in the surface expression of $\mathrm{HCN}$ channels on the anterior cingulate cortex neurons increases both pain and anxiety. The use of ZD7288 reduces pain perception. HCN blockers, such as ZD7288, loperamide, and clonidine, also inhibit spontaneous neuronal discharge and ectopic spontaneous firing activity from DRG neurons in the event of a nerve injury, thus producing analgesic effects (Yagi and Sumino, 1998; Vasilyev et al., 2007; Bernal and Roza, 2018) (Table 2). Ivabradine is an FDA-approved drug that blocks all HCN channel isoforms. The drug can provide prolonged relief from trigeminal neuropathic pain by acting on the peripheral nervous system (Young et al., 2014; Ding et al., 2018). However, a clinical trial conducted by Lee et al. (2019) showed ivabradine reduces the heart rate without significant analgesic effects in human capsaicininduced pain models.

In the spinal nerve ligation pain model, reducing SK channel activity in the central amygdala output nuclei was reported to increase pain sensitivity. SK channel activation by riluzole or 1EBIO can reduce sensory inputs to the spinal cord and produce analgesic effects (Bahia et al., 2005; Thompson et al., 2018). $\mathrm{M}$ channel blockers, such as retigabine and flupirtine, can also relieve pain symptoms, as seen in chronic constriction injury, spinal cord injury, and nerve damage pain models (BlackburnMunro and Jensen, 2003; Devulder, 2010; Rose et al., 2011; Wu et al., 2017; Yu et al., 2018; Table 2). Non-steroidal antiinflammatory drugs, such as meclofenamate, diclofenac, NH6, and NH29 and acetaminophen (paracetamol), relieve migraine and neuropathic pains by activating $M$ channels. These drugs produce a hyperpolarization shift in $\mathrm{M}$ channel activation and reduce their inactivation (Peretz et al., 2005, 2007, 2010; Ray et al., 2019). Artificially synthesized M channel activators, such as pyrazolopyrimidines, benzimidazole, and pyrazolo[1,5-a] pyrimidine- $7(4 \mathrm{H})$-one compounds, have enhanced potency and diminished side effects (Wickenden et al., 2009; Zhang et al., 2011; Zhang F. et al., 2013; Osuma et al., 2019). QO-58 and QOlysine are the pyrazolo[1,5-a] pyrimidine-7 $(4 \mathrm{H})$-one compounds that can alleviate pain symptoms in the chronic constriction injury pain model by activating all $\mathrm{K}_{\mathrm{v}} 7$ isoforms except for $\mathrm{K}_{\mathrm{v}} 7.3$ (Zhang M. et al., 2013; Teng et al., 2016). Paclitaxel treatment in patients with cancer produces hyperexcitability in nociceptive neurons, which contributes to chronic pain. Early treatment with retigabine can avert chronic pain ( $\mathrm{Li}$ et al., 2018). Future investigations are focusing on finding $\mathrm{K}_{\mathrm{v}} 7$ channel activators, targeting the peripheral nervous system and averting the side effects caused by their action on the central nervous system (Hayashi et al., 2014). Reduced activity of SK, M and increased activity of $\mathrm{HCN}$ channels causes hyperexcitability in the sensory or nociceptive neurons, which increases pain sensation. Specific targeting and increasing the activity of the mAHP channels in the pain perception neurons can produce analgesic effects (Table 3).

\section{Depression}

An imbalance in the dopamine (DA) levels in the ventral tegmental area (VTA)-Nucleus accumbens (NAc) circuit in the underlying cause of depression and anxiety behavior (Polter and Kauer, 2014). DA neurons exhibit a wide range of firing patterns from tonic spiking pace-making activity to a bursting response. These diverse firing activities or patterns control dopamine release in the brain (Paladini et al., 2003). Stress and depression can increase or reduce firing in the VTA DA neurons, depending on the severity of the stress. VTA DA neurons exhibit an increase in firing under severe stress conditions and a decrease in firing when subjected to weak stress (Valenti et al., 2012).

Alterations in SK, HCN, and M channel activity cause altered neuronal firing activity, leading to significant stress or depression symptoms. An increase in SK activity, a reduction in $\mathrm{M}$ channel activity, and an increase or decrease in $\mathrm{HCN}$ activity conductance can produce depression symptoms in mice. Hippocampalspecific HCN4 knockdown causes increased anxiety, whereas an increase in perisomatic HCN1 channels in CA1 hippocampal neurons contribute to chronic stress. These findings demonstrate the isoform-specific but opposing effects on a given phenotype within the same brain region (Kim et al., 2017; Kim and Johnston, 2018; Günther et al., 2019). Chronic stress causes an increase in L-type $\mathrm{Ca}^{2+}$ channels and increased intracellular calcium through CICR (Kim et al., 2017; Kim and Johnston, 2018). Increased calcium levels augment both SK and HCN channel activity and reduce $\mathrm{M}$ channel activity. Enhanced SK and HCN channel activity and reduced $M$ channel activity contribute to increased tonic firing activity in VTA DA neurons, which is associated with depressive behavior. SK channel antagonists can transform tonic firing activity to phasic firing activity in DA neurons, which can rescue antidepressive behavior in mice (Van Der Staay et al., 1999; Oster et al., 2015). In the social defeat stress model, VTA neurons exhibit increased excitability due to a reduction in the expression levels of $M$ channel and an increase in $\mathrm{HCN}$ activity. The overexpression of $\mathrm{K}_{\mathrm{v}} 7.2$, retigabine injection in VTA, chronic treatment with fluoxetine (HCN and SK channel antagonist), or local infusion of ZD7288 have been reported to improve social behavior, reduce anxiety, increase sucrose preference, and produce antidepressive behavior in mice (Cao et al., 2010; Friedman et al., 2016; Li et al., 2017) (Table 2).

Multiple antidepressant drugs, including tricyclic antidepressants, such as desipramine, imipramine, and nortriptyline, as well as phenothiazines, such as fluphenazine, promethazine, chlorpromazine and trifluoperazine, and apamin, can block SK2 and SK3 channels, thereby reducing immobility time in the forced swim test, which is a model for depression (Galeotti et al., 1999; Dreixler et al., 2000b; Terstappen et al., 2001) (Table 2). Fluoxetine (prozac) is a common serotonin reuptake inhibitor that is used to treat depression, anxiety, and obsessive-compulsive disorders. It can block all three isoforms of SK channels to varying degrees (Terstappen et al., 2003). 
In addition to the VTA DA circuit, increased activity in the amygdala in response to fear stimuli also contributes to anxiety in animals. The use of the M channel agonist, BMS-204352, and retigabine exhibits an anxiolytic effect on these mice (Rauch et al., 2003; Korsgaard et al., 2005) (Table 2).

Additionally, alterations in HCN channels, but not in SK and $M$ channels, can increase resilience to depression and facilitate coping with stress (Fisher et al., 2018). Contrary to expectations, mice that are resilient to depression were reported to exhibit higher HCN currents than those with depression, but the resilient mice did not exhibit increased firing in VTA neurons. This increased HCN channel activity probably activates some other $\mathrm{K}^{+}$conductance, which restores the firing activity in resilient mice to a level comparable to that of the control mice. Mice with TRIP8b deletion, which causes reduced neuronal expression of HCN channels, and those with HCN1 knockdown exhibit resilience to depressive behavior (Lewis et al., 2011; Kim et al., 2012; Han et al., 2017). Thus, mAHP channels strongly affect the net dopamine level in the brain and control the activity of amygdala neurons, which control emotions in an animal. Hence, mAHP channel modulators potentially exhibit both antidepressive action and can cause an increase in resilience to depression (Table 3).

\section{Alcohol Addiction}

Altered neurotransmission, abnormal molecular pathways, and aberrant ion channel activity can give rise to alcohol addiction and withdrawal relapse. Alcohol addiction involves alcoholseeking behavior, anxiety during alcohol withdrawal, alcoholseeking behavior during withdrawal, and alcohol extinction memory. The aforementioned behavioral decisions are controlled by different brain regions. Altered neuronal excitability due to the mAHP channels affects the functioning of these regions.

Ethanol consumption increases DA neuronal activity in the substantia nigra (SN) and VTA because of the alteration of HCN, M, and SK channel activity (Hopf et al., 2007; Cannady et al., 2017; Rinker et al., 2017). SK channels coupled to NMDA channels, protect against NMDA-dependent excitotoxicity. Chronic ethanol consumption produces NMDASK functional uncoupling causing hyperexcitability in CA1 cells (Mulholland, 2012), reduced HCN currents in VTA neurons, and reduced $\mathrm{K}_{\mathrm{V}} 7.2 / 7.3$ surface expression in nucleus accumbens (NAc) neurons (Hopf et al., 2007; McGuier et al., 2016). VTA DA neurons undergo a transition in firing activity from their regular pace-making activity to burst firing during the withdrawal phase, which is correlated with relapse. A reduction in SK2 levels, which causes NMDAR hyperactivity, was reported to be responsible for this transformation in firing patterns (Hopf et al., 2007; Mulholland, 2012). NAc is correlated with druginduced addiction and reward systems (Janak et al., 1999). After alcohol abstinence, the NAc core neurons become hyperexcitable, which increases alcohol-seeking behavior. This hyperexcitability results from reduced activity of SK3 channels (but not SK2 channels) and reduced $\mathrm{K}_{\mathrm{v}} 7.2 / 7.3$ surface expression levels in NAc neurons (Hopf et al., 2011; McGuier et al., 2016). Systemic retigabine, a microinfusion of retigabine in NAc and VTA DA neurons, retigabine administration in rats, and the use of chlorzoxone, an SK agonist, have been reported to reduce firing in NAc neurons as well as ethanol consumption (Hopf et al., 2011; Knapp et al., 2014; McGuier et al., 2016, 2018). The use of an SK activator (1-EBIO) is also reported to reduce motivation for alcohol (Hopf et al., 2010). Furthermore, 1-EBIO reduced network hyperexcitability and neurotoxicity associated with ethanol withdrawal in mice (Mulholland, 2012; Table 2).

Increased lateral habenula activity due to a decrease in $\mathrm{K}_{\mathrm{v}}$ 7.2/7.3 channel activity causes alcohol withdrawal-driven anxiety. Inhibition of habenula by the $M$ channel agonist retigabine rescued anxiety phenotypes and alcohol preference in tested animals (Kang et al., 2017). The inhibition of serotonergic pathways can also treat alcohol withdrawal-associated anxiety. Inhibiting serotonergic pathway increases $\mathrm{K}_{\mathrm{v}} 7.2 / 7.3$ channel expression, which reduces firing in lateral habenula neurons and helps treat alcohol addiction (Fu et al., 2020). In addition to the use of SK activators, which can restore regular firing activity in VTA, NAc, and hippocampal neurons and assist in alcohol abstinence, SK blocker treatment in the infralimbic prefrontal cortex causes alcohol extinction memory (Cannady et al., 2017). mGluR5 and SK2 are coupled functionally and act collectively to regulate neural excitability (Sourdet et al., 2003). Increasing mGluR activity aids in alcohol and cocaine-seeking extinction learning (Gass and Olive, 2009; Cleva et al., 2011; Cannady et al., 2017). Increased mGluR activity downregulates SK2 channels in the infralimbic prefrontal cortex, contributing to extinction learning. Microinfusion of the SK blocker apamin in the infralimbic prefrontal cortex aids in the process of extinction learning (Cannady et al., 2017). Thus, the use of an SK activator can control neuronal hyperexcitability due to alcohol withdrawal, and SK inhibitors can facilitate extinction learning. The dual effect of SK channel activators and inhibitors highlight the heterogeneity of SK channel operating in diverse brain regions, which further emphasizes the need for directed channel inhibition and activation in various brain regions to alleviate diverse disease symptoms (Table 2). In summary, excessive alcohol consumption leads to addiction, and withdrawal causes anxiety owing to changes in the firing pattern of VTA, SN, NAc, and habenula neurons, which in turn affect the dopamine levels in the brain. The use of SK and $\mathrm{M}$ activators can restore regular firing activity and help overcome addiction (Table 3 ).

\section{Schizophrenia}

Schizophrenia is a degenerative mental disorder characterized by hallucinations, anxiety, and eccentric behavior. Like depression, alterations in brain dopamine levels contribute to the pathophysiology of schizophrenia. Genetic mutations and environmental components can trigger and aggravate schizophrenia symptoms.

Midbrain DA neurons exhibit high levels of expression of SK3 and $\mathrm{K}_{\mathrm{v}}$ 7.2/7.4 homomeric channels, which control their firing patterns and hence dopamine release (Rimini et al., 2000; Stocker and Pedarzani, 2000; Hansen et al., 2008). Alterations in SK and $M$ channel activity can cause an imbalance in dopamine levels in the brain, thereby contributing to schizophrenia symptoms such as hallucinations (Hansen et al., 2008). An increase in CAG repeats in the SK3 gene with a higher polymorphism in the repeat 
length of CAG increases susceptibility to schizophrenia (Bates and Davies, 1997; Chandy et al., 1998; Wittekindt et al., 1998; Cardno et al., 1999). Increased glutamine (because of increased CAG numbers) contributes to a gain-in-function mutation in SK channels by either enhancing the channel's calcium sensitivity or modifying its kinetic properties. In maternal immune activation and juvenile social isolation mouse models of schizophrenia, layer 5 PFC neurons had higher expression levels of SK3 channel (with no change in SK1 and SK2 expression levels), which cause depolarized cellular RMP, higher levels mAHP expression, and schizophrenia-related behavioral deficits (Mi et al., 2019). By contrast, some other studies have either reported a lack of association between SK3 gene CAG repeat polymorphism and schizophrenia or have observed loss-of-function variants in the SK3 gene. A frameshift mutation in exon 1 of the SK3 gene produced a truncated form of the protein that did not exhibit transmembrane segments, was accumulated in the nucleus, and was not express on the cell surface (Bowen et al., 2001; Miller et al., 2001; Laurent et al., 2003; Ritsner et al., 2003; Tomita et al., 2003). Linkage studies have also demonstrated an association between SK3 gene polymorphism and mutations in phosphatidylinositol-4-phosphate 5-kinase II alpha in patients with schizophrenia (Wittekindt et al., 1998; Brzustowicz et al., 2000; Bakker et al., 2007). Phosphatidylinositol-4-phosphate 5kinase II alpha mediates PIP2 synthesis. Loss of function of phosphatidylinositol-4-phosphate 5-kinase II alpha, as observed in patients with schizophrenia, reduces PIP2 levels, which reduces $\mathrm{M}$ channel activity (Bakker et al., 2007; Fedorenko et al., 2008). Disrupted M channel activity in neurons in the $\mathrm{SN}$ and VTA DA alters brain dopamine levels. $\mathrm{K}_{\mathrm{v}} 7.4$ channel enhancers, such as retigabine, can increase $\mathrm{M}$ channel activity in DA neurons and can alleviate schizophrenia symptoms (Hansen et al., 2008; Peng et al., 2017).

Neuronal NMDAR hypofunction is one of the most promising theories explaining the pathophysiology of schizophrenia. In support of the NMDAR hypofunction theory, the use of phencyclidine, an NMDAR blocker, was reported to produce psychotic schizophrenia-like symptoms in experimental animals (Lodge and Anis, 1982; Davies et al., 1988; Javitt, 1991). Increased SK activity can cause NMDAR hypofunction (Bates and Davies, 1997; Chandy et al., 1998; Gargus et al., 1998). Reduced SK2 channel activity in DA neurons produces bursting firing activity, which increases dopamine levels in the brain, contributing to schizophrenia symptoms. Hence, blocking dopamine receptors is an approved remedy for patients with schizophrenia (Olney and Farber, 1995; Farde, 1998; Lam et al., 2013). SK2 activators also reduces dopamine release and might alleviate some symptoms. However, the use of SK2 activators will increase NMDAR hypofunction and aggravate the symptoms. Thus, additional meticulous investigation to assess the role of SK channels in schizophrenia is crucial for understanding its therapeutic potential. However, selective blocking or activating specific SK isoforms in distinct brain regions, while sparing others, is a potential therapeutic strategy.

Altered neuronal activity in the PFC, which regulates the working memory, also contributes to schizophrenia symptoms. Disrupted in schizophrenia 1 (DISC1) protein is a cAMP effector protein; low levels of DISC1 are correlated with schizophrenia
(El-Hassar et al., 2014). In PFC pyramidal neurons, diminished levels of DISC1 cause an increase in mGluR-dependent increase in intracellular calcium influx, which augments SK channel activity (El-Hassar et al., 2014). In PFC neuronal spines, DISC1, along with other cAMP effector proteins, such as PDE4 and D1Rs, are also co-localized with HCN channels. DISC1 regulates cAMP levels; hence, its loss of function, as observed in schizophrenia, causes increased cAMP levels, which in turn increase HCN channel activity and lead to spine loss (Arnsten, 2011; Paspalas et al., 2013). Stress is another factor, which can act as a stimulant or exaggerator of schizophrenia symptoms. Increased stress can elevate cAMP and PKA levels through D1R activation, which further increases $\mathrm{HCN}$, and probably $\mathrm{M}$ channel activity; both cooperatively reduce firing activity and the number of spines in PFC neurons (Arnsten, 2011). A specific HCN blocker, ZD7288, can rescue this reduced firing response in PFC and prevent working memory deficits (Gamo et al., 2015; Table 2). Positron emission tomography imaging studies in patients with schizophrenia have shown increased D1R binding in PFC neurons, and the use of effective antipsychotic drugs has been shown to reduce D1R expression (Abi-Dargham et al., 2002; Hirvonen et al., 2006). Thereby, region-specific gain-offunction mutations of SK channels and reduced PIP2 levels that diminish $\mathrm{M}$ channel function cause abnormal dopamine levels in the brain circuits. Additionally, increased HCN channel activity contributes to hyperactivity in DA neurons. Thus, use of mAHP channel modulators can restore dopamine levels and firing activity of specific neurons, thereby alleviating schizophrenia symptoms (Table 3 ).

\section{Parkinson Disease}

Parkinson disease (PD) is a neurodegenerative disease characterized by loss of DA neurons in the substantia nigra (SN) and basal ganglia because of $\alpha$-synuclein aggregates called Lewy bodies. This loss of function of DA neurons reduces brain dopamine levels and causes ataxia, tremors, and motor disability, the common symptoms of PD. PD is associated with the dysfunction of multiple ion channels (Pedarzani and Stocker, 2008; Wang et al., 2008). SK, HCN, and M channels present in DA neurons and striatal cholinergic interneurons control the firing activity of DA neurons. The single spiking tonic firing mode of these neurons is reported to control baseline dopamine levels, while their transition to burst firing activity increases their postsynaptic dopamine release (Pedarzani and Stocker, 2008; Carbone et al., 2017). SK, HCN, and M channel blockers can alleviate PD symptoms and provide neuroprotective effects, while $M$ activators reduce the side effects associated with levodopa (L-DOPA) treatment.

In a rat model of $\mathrm{PD}, \mathrm{SK} 3$, and $\mathrm{SK} 2$ exhibited opposite trends of change. In the SN, downregulation of SK3 channels is observed with disease progression, while in the subthalamic nucleus (STN), a delayed increase in SK2 levels (21 days after PD induction) was reported. Furthermore, differential effects of blocking these SK channels were reported in the SN and STN. Blocking SK channels by using apamin in the substantia nigra pars compacta (SNc) alleviated PD symptoms, while the symptoms were aggravated when the channels were blocked in the STN (Mourre et al., 2017). Initial PD symptoms were reported to correlate with changes 
in beta frequency oscillations in globus pallidus (GPe) neurons. In healthy brains, the activities of different GPe neurons are unsynchronized. However, upon dopamine depletion in PD GPe neurons are unable to maintain their pacemaking activity leading to increased intraneuronal oscillations within basal ganglia with a sharp peak in the beta frequency range. Alteration in $\mathrm{HCN}$ and SK channels have been reported to be responsible for GPe neuron synchronization and changes in network properties (Chan et al., 2011; Schwab et al., 2013). Microinjection of the HCN blocker ZD7288 in vivo in the GPe increases the firing activity of some neurons and reduces firing in some others. Overall, ZD7288 improves motor deficits observed in 1methyl-4-phenyl-1,2,3,6-tetrahydropyridine) PD mouse models (Hao et al., 2019). In PD rat models, many DA neurons were reported to undergo degeneration, and the surviving DA neurons exhibited a reduction in $\mathrm{HCN}$ channels, which altered their firing pattern (Guatteo et al., 2017). Downregulation of HCN channels by multiple mechanisms contribute to various PD symptoms.

SUMOlytation of $\alpha$-synuclein helps in correct protein folding and produces soluble protein. By contrast, deSUMOlytation of $\alpha$-synuclein causes their aggregation leading to PD. Impaired SUMOlytation can also lead to a reduction in surface levels of HCN channels in PD (Parker et al., 2017). Progression of PD also correlates with mitochondrial dysfunction, which in turn increases oxidative stress on the cell and reduces ATP levels in the cell. This produces low cAMP levels and reduced HCN functions (Schapira and Gegg, 2011; Carbone et al., 2017). Reduction in HCN channel transcription produces a spike-timing impairment in Ach-releasing striatal interneurons (Chl), which reduces the net Ach release. Although both Ach and DA levels are low in PD brains, surviving $\mathrm{Chl}$ neurons increase their Ach release, which leads to an increase in the Ach/DA ratio and contributes to PD symptoms (McKinley et al., 2019). $\mathrm{K}_{\mathrm{v}} 7.2,7.3$, and 7.5 expressed on striatal neurons and Chls can regulate their activity and excitability.

The use of artificial L-DOPA is a long-term treatment strategy for PD (Dunnett and Björklund, 1999). It compensates for the lack of DA and mitigates motor deficit. However, its chronic use leads to impairment of voluntary movement (dyskinesia) and increased severity of involuntary movement (Sander et al., 2012). The administration of $\mathrm{K}_{\mathrm{v}} 7$ channel openers retigabine and flupirtine along with L-DOPA has been reported to reduce the symptoms of dyskinesia without influencing the effect of L-DOPA (Sander et al., 2012; Pérez-Ramírez et al., 2015). A specific activator of $K_{v} 7.2 / 7.3$, ICA27243, exhibits a substantial antidyskinetic effect, without the side effects of sedation and ataxia, which are observed with the use of retigabine. The beneficial effects were because of specific targeting of striatal neurons only, which spared other channel isoforms (Sander et al., 2013).

SK and $M$ channel blockers have shown neuroprotective activity in different PD models (Salthun-Lassalle et al., 2004; Doo et al., 2010; Alvarez-Fischer et al., 2013; Paz et al., 2018; Table 2). Blocking $M$ channels by using XE 991 prevents the loss of DA neurons, increases the activity of surviving striatal DA neurons, restores dopamine levels, and improves motor coordination (Liu et al., 2018). Thus, where M channel activators can facilitate circumventing the side-effects of L-DOPA treatment, $M$ channel blockers serve a neuroprotective role. Both $\mathrm{M}$ and SK blockers cause an increase in intracellular $\mathrm{Ca}^{2+}$ levels, which increases DA neuron excitability. In the 1methyl-4-phenyl-1,2,3,6-tetrahydropyridine-induced PD model, bee venom (apamin) acupuncture in limbs or intraperitoneal administration of apamin prevented the loss of DA neurons in the SN and striatum, thus evidencing its neuroprotective action. Moreover, in an in vitro mesencephalic neuronal culture, the use of apamin prevented neuronal degeneration (Salthun-Lassalle et al., 2004). The use of bee venom to block SK activity has also been reported to cause an increase in basal dopamine levels in the striatum, which reduces motor deficits, prevents catalepsy symptoms, and causes a general increase in motor activity in PD mouse models (Alvarez and Sabatini, 2007; Chen et al., 2014; Maurice et al., 2015). Bee venom exhibits neuroprotective effects because it downregulates Jun N-kinase activity, which is responsible for the degenerative effects observed in 1-methyl4-phenyl-1,2,3,6-tetrahydropyridine-induced PD models (Doo et al., 2010; Alvarez-Fischer et al., 2013). Other studies have also shown that Jun $\mathrm{N}$-kinase activity causes neurodegenerative effects in PD animal models and reducing its activity can be a therapeutic strategy. Patients with PD and animal models exhibit an increase in Jun N-kinase activity (Hunot et al., 2004).

Contrary to the aforementioned results, where SK blockers were reported to provide a neuroprotective effect and increase in basal DA levels, an organotypic PD culture of the SN was reported to exhibit rescue effects in the presence of 1EBIO, an SK channel activator. The SN cells exhibited a change in firing behavior from their regular pace-making to an irregular bursting activity. Furthermore, the cells exhibited an increase in resting membrane potential and neurotoxic death. 1-EBIO reduced burst firing and prevented the 6-OHDA mediated death of these neurons (Wang et al., 2014). Thus, contradictory information is available to answer the question of whether a blocker or an enhancer of SK channels has therapeutic potential. Possibly, SK channels influence both excitability and spiking patterns; consequently, they have a complex effect on the disease pathophysiology. Therefore, a detailed study is necessary to understand the contribution of SK channels to PD and how their modulation might alleviate PD symptoms. A clinical trial that used bee venom, patients with PD did not show improvement. However, the authors believe that the use of higher levels of the toxin at an increased frequency might result in an improvement in the symptoms (Hartmann et al., 2016).

As with other neurological disorders, region-dependent alterations in SK channel expression levels are observed, such that blocking SK channels in the SNc but not in STN alleviates PD symptoms. An M channel opener can circumvent side effects of L-DOPA treatment, and an HCN channel opener can be used to restore dopamine/Ach ratios. A drug cocktail modulating all mAHP channels can potentially be used to treat multiple PD symptoms (Table 3 ).

\section{Alzheimer's Disease}

Aggregation of insoluble $A \beta$ fibrils in the brain is the principal underlying cause of Alzheimer's Disease (AD). Amyloid precursor protein (APP) cleaved by $\beta$ secretase yields a 
carboxy-terminal fragment (APP-CTF $\beta$ ) and an amino-terminal soluble APP fragment (sAPP $\beta$ ). Furthermore, abnormal APPCTF $\beta$ cleavage by $\gamma$ secretase (presenilin) yields A 42 and APP intracellular domain (AICD). A $\beta 42$ undergoes fibril aggregation, causing progressive neurodegeneration, while AICD modulates intracellular calcium signaling assisting in aggregate formation (Leissring et al., 2002; Vassar et al., 2014; Frykman et al., 2017). Inhibition of $\beta$ and $\gamma$ secretase is the most promising contender for $\mathrm{AD}$ treatment. However, $\beta$ and $\gamma$ secretase inhibition can also influence other cellular pathways, producing severe side effects. For example, $\beta$ secretase augments $M$ channel activity. Reducing $\beta$ secretase activity will also inhibit $\mathrm{M}$ currents, which might aggravate seizure phenotypes in patients with AD (Vossel et al., 2013; Vassar et al., 2014; Hessler et al., 2015).

According to the calcium hypothesis proposed by Khachaturian (1989), intracellular calcium dysregulation contributes to the phenotypes associated with AD. Studies have demonstrated that changes in calcium dynamics assist in $A \beta$ fibril formation, and $A \beta$ fibril aggregation further increases calcium influx, which increase neurological deterioration. A study by Yoo et al. (2000) showed that reduced calcium entry is an early event in the Presenilin AD model and facilitates $A \beta$ fibril formation. Furthermore, fibril aggregation increases $G$ protein-coupled receptor-mediated CICR, which increases intracellular calcium levels and contributes to neurotoxicity (Leissring et al., 2002; Stutzmann, 2005). Human studies have shown that an increase in intracellular calcium influx induced by $\mathrm{A} \beta$ fibril aggregation increases the vulnerability of cortical cells to calcium-mediated neurotoxicity (Mattson et al., 1992). Increased intracellular $\mathrm{Ca}^{2+}$ levels can cause increase SK channel activity, leading to memory deficit, which is observed in $\mathrm{AD}$ mouse models and patients with $\mathrm{AD}$ (Carlesimo and Oscar-Berman, 1992). A study provided evidence of an agedependent increment in SK channel activity, which can lead to further aggravation of AD symptoms (Blank et al., 2003). Thus, apamin treatment has been reported to reduce deficits in spatial learning and working memory in $\mathrm{AD}$ mice (Ikonen and Riekkinen, 1999; Proulx et al., 2020). Increased calcium influx also reduces PIP2 binding to $\mathrm{M}$ channels and diminishes their kinetics. Additionally, reduced expression levels of KCNE5 (auxiliary protein to $\mathrm{K}_{\mathrm{v}} 7$ channels, which assist their activity) reduces the activity of $K_{v} 7.3$ and $K_{v} 7.5$ channels in cerebral arteries in the $\mathrm{AD}$ mouse model. Consequently, blood flow in the cerebral areas decreases, promoting fibril aggregation (de Jong and Jepps, 2018).

The effect of HCN channels on $\mathrm{AD}$ pathophysiology is not well understood. Both HCN1 upregulation and HCN2 blocking can be useful in treating $\mathrm{AD}$ pathophysiology. In $\mathrm{AD}$ mouse models and in the brains of patients with $\mathrm{AD}$, HCN1 channel expression is reduced (Saito et al., 2012). In AD mouse models, aging causes HCN1 channels to get sequestered in the endoplasmic reticulum, thereby reducing net $\mathrm{HCN}$ channel expression on the distal dendrites of CA1 neurons and resulting in CA1 hyperexcitability and seizure phenotypes (Musial et al., 2018). X11 and X11L are the proteins that assist in $\mathrm{A} \beta$ trafficking. $\mathrm{HCN}$ channels can form a complex with X11, X11L, and APP. Mutant mice lacking X11 and X11L were reported to exhibit a higher incidence of seizure because of reduced HCN channel conductance. HCN1 knockout mice and mice with HCN1 blocking were reported to exhibit increased A $\beta$ aggregation (Saito et al., 2012). Thus, reduced HCN channel expression contributes to $\mathrm{AD}$ symptoms. Consistent with the aforementioned results, treatment of $A \beta$ aggregation in CA1 hippocampal cells caused increased HCN1 expression and reduced neuronal excitability (Eslamizade et al., 2015). However, contrary results were obtained in another study; blocking HCN2 channels in HEK cells reduced secretion of A $\beta 42$, sAPP, and APPCTF by reducing APP maturation or $\beta$ action (Frykman et al., 2017). The differential effects may be isoform-specific effects or part of underlying signaling changes, the details of which warrant examination.

$\mathrm{AD}$ involves complex changes in intracellular calcium dynamics, which directly or indirectly affect all three mAHP channels. Increased SK currents, reduced $M$ currents and increased or decreased HCN currents in neurons and cerebral arteries control fibril aggregation, seizure incidence and memory deficits. Thus, mAHP channel modulators can potentially alleviate some AD symptoms (Table 3).

\section{CONCLUSION}

The therapeutic potential of mAHP channels is being explored recently for treating various neurological anomalies. Decades of research have provided us with extensive information about the heterogeneity of channel isoforms and their expression in various brain regions. The current review highlights the commonalities and specializations of the three mAHP channels. Although the three channels work together to reduce excessive neuronal firing, share similar subcellular and regional localization, are controlled by similar regulatory pathways, and exhibit similar activation and inactivation kinetics, they have region-specific isoforms that are responsible for specialized neuronal functions. The concept of isoforms is an essential point of consideration for future research because it stresses the point that an indiscriminate modulation of an ion channel might produce undesirable effects. For example, in schizophrenia, $\mathrm{M}$ channel activity decreases in DA neurons and increases in PFC neurons, causing reduced spiking response and spine loss, respectively. The use of an $\mathrm{M}$ channel activator to rescue firing activity in DA neurons aggravates the spine loss phenotype of PFC neurons. Similarly, an $\mathrm{M}$ channel blocker rescues the spine loss phenotype in PFC neurons, but it further reduces DA firing activity. Similarly, in the PD model, SK channels in SNc and STN neurons exhibit opposite trends. In SNc neurons, a reduction in the levels of SK3 is observed, while in STN neurons, a delayed increase in SK2 levels is observed. Thus, the use of a general activator or blocker may have limited clinical potential. In the worst case, the general activator or blocker may aggravate disease symptoms. Consequently, isoform- and region-specific modulation is needed to provide an effective treatment strategy. Multiple other examples cited in this review clearly illustrate isoform- and 
region-specific alteration in the activity of various mAHP channel, which demands the identification, synthesis, and use of isoform- and region-specific modulators. Research in the past few years appears to be focused on the synthesis of several isoform-specific modulators. Additionally, intervention timing might be another crucial factor in treating various neurological diseases. Studies have shown transient as well as long-term changes in mAHP channel levels, emphasizing the need for extensive information on age-dependent and regiondependent alterations to identify the correct intervention that can be used to treat disease symptoms. In addition to isoformspecific modulators, region-specific gene targeting to remedy gain- or loss-of-function mutations in mAHP channels can also be used to treat abnormal neurological functions. With the advancement of region-specific targeting techniques, we might witness a revolution in treatment methodology in the near future.

\section{REFERENCES}

Abbas, S. Y., Ying, S. W., and Goldstein, P. A. (2006). Compartmental distribution of hyperpolarization-activated cyclic-nucleotide-gated channel 2 and hyperpolarization-activated cyclic-nucleotide-gated channel 4 in thalamic reticular and thalamocortical relay neurons. Neuroscience 141, 1811-1825. doi: 10.1016/j.neuroscience.2006.05.034

Abi-Dargham, A., Mawlawi, O., Lombardo, I., Gil, R., Martinez, D., Huang, Y., et al. (2002). Prefrontal dopamine D1 receptors and working memory in schizophrenia. J. Neurosci. 22, 3708-3719.

Abiraman, K., Sah, M., Walikonis, R. S., Lykotrafitis, G., and Tzingounis, A. V. (2016). Tonic PKA activity regulates SK channel nanoclustering and somatodendritic distribution. J. Mol. Biol. 428, 2521-2537. doi: 10.1016/j.jmb. 2016.04.014

Adelman, J. P. (2016). SK channels and calmodulin. Channels 10, 1-6. doi: 10.1080/ 19336950.2015 .1029688

Adelman, J. P., Maylie, J., and Sah, P. (2012). Small-conductance Ca 2+-activated K + channels: form and function. Annu. Rev. Physiol. 74, 245-269. doi: 10.1146/ annurev-physiol-020911-153336

Akasu, T., Shoji, S., and Hasuo, H. (1993). Inward rectifier and low-threshold calcium currents contribute to the spontaneous firing mechanism in neurons of the rat suprachiasmatic nucleus. Pflügers Arch. Eur. J. Physiol. 425, 109-116. doi: 10.1007/BF00374510

Akins, P. T., and McCleskey, E. W. (1993). Characterization of potassium currents in adult rat sensory neurons and modulation by opioids and cyclic AMP. Neuroscience 56, 759-769. doi: 10.1016/0306-4522(93)90372-M

Alger, B. E., and Nicoll, R. A. (1980). Epileptiform burst afterhyperpolarization: calcium-dependent potassium potential in hippocampal CA1 pyramidal cells. Science 210, 1122-1124. doi: 10.1126/science.7444438

Allen, D., Nakayama, S., Kuroiwa, M., Nakano, T., Palmateer, J., Kosaka, Y., et al. (2011). SK2 channels are neuroprotective for ischemia-induced neuronal cell death. J. Cereb. Blood Flow Metab. 31, 2302-2312. doi: 10.1038/jcbfm.2011.90

Alvarez, V. A., and Sabatini, B. L. (2007). Anatomical and physiological plasticity of dendritic spines. Annu. Rev. Neurosci. 30, 79-97. doi: 10.1146/annurev.neuro. 30.051606.094222

Alvarez-Fischer, D., Noelker, C., Vulinoviæ, F., Grünewald, A., Chevarin, C., Klein, C., et al. (2013). Bee venom and its component apamin as neuroprotective agents in a Parkinson disease mouse model. PLoS One 8:e61700. doi: 10.1371/ journal.pone.0061700

Amir, R., and Devor, M. (1997). Spike-evoked suppression and burst patterning in dorsal root ganglion neurons of the rat. J. Physiol. 501, 183-196. doi: 10.1111/j. 1469-7793.1997.183bo.x

Anderson, N. J., Slough, S., and Watson, W. P. (2006). In vivo characterisation of the small-conductance $\mathrm{KCa}$ (SK) channel activator

\section{AUTHOR CONTRIBUTIONS}

DD wrote the manuscript. Both authors structured and refined the manuscript.

\section{FUNDING}

DD and USB received support from NCBS-TIFR and the Department of Atomic Energy, Government of India, under project no. 12-R\&D-TFR-5.04-0800. USB was a JC Bose Fellow.

\section{ACKNOWLEDGMENTS}

We would like to thank Dr. Vinu Varghese for providing useful inputs to the manuscript.

1-ethyl-2-benzimidazolinone (1-EBIO) as a potential anticonvulsant. Eur. J. Pharmacol. 546, 48-53. doi: 10.1016/j.ejphar.2006.07.007

Arnsten, A. F. T. (2011). Prefrontal cortical network connections: key site of vulnerability in stress and schizophrenia. Int. J. Dev. Neurosci. 29, 215-223. doi: 10.1016/j.ijdevneu.2011.02.006

Atkinson, S. E., Maywood, E. S., Chesham, J. E., Wozny, C., Colwell, C. S., Hastings, M. H., et al. (2011). Cyclic AMP signaling control of action potential firing rate and molecular circadian pacemaking in the suprachiasmatic nucleus. J. Biol. Rhythms 26, 210-220. doi: 10.1177/0748730411402810

Bahia, P. K., Suzuki, R., Benton, D. C. H., Jowett, A. J., Chen, M. X., Trezise, D. J., et al. (2005). A functional role for small-conductance calcium-activated potassium channels in sensory pathways including nociceptive processes. J. Neurosci. 25, 3489-3498. doi: 10.1523/JNEUROSCI.0597-05.2005

Bakker, S. C., Hoogendoorn, M. L. C., Hendriks, J., Verzijlbergen, K., Caron, S., Verduijn, W., et al. (2007). The PIP5K2A and RGS4 genes are differentially associated with deficit and non-deficit schizophrenia. Genes Brain Behav. 6, 113-119. doi: 10.1111/j.1601-183X.2006.00234.x

Bal, B. Y. T., and Mccormick, D. A. (1993). Mechanisms of oscillatory activity in guinea-pig nucleus reticularis thalami in vitro: a mammalian pacemaker. J. Physiol. 468, 669-691. doi: 10.1113/jphysiol.1993.sp019794

Barrese, V., Stott, J. B., and Greenwood, I. A. (2018). KCNQ-encoded potassium channels as therapeutic targets. Annu. Rev. Pharmacol. Toxicol. 58, 625-673. doi: 10.1146/annurev-pharmtox

Bates, G. P., and Davies, S. W. (1997). Transgenic mouse models of neurodegenerative disease caused by CAG/polyglutamine expansions. Mol. Med. Today 3, 508-515. doi: 10.1016/S1357-4310(97)01142-8

Belmeguenai, A., Hosy, E., Bengtsson, F., Pedroarena, C. M., Piochon, C., Teuling, E., et al. (2010). Intrinsic plasticity complements long-term potentiation in parallel fiber input gain control in cerebellar Purkinje cells. J. Neurosci. 30, 13630-13643. doi: 10.1523/JNEUROSCI.3226-10.2010

Bender, R. A., and Baram, T. Z. (2008). Hyperpolarization activated cyclicnucleotide gated $(\mathrm{HCN})$ channels in developing neuronal networks. Prog. Neurobiol. 86, 129-140. doi: 10.1016/j.pneurobio.2008.09.007

Berger, T., Senn, W., and Lüscher, H. R. (2003). Hyperpolarization-activated current Ih disconnects somatic and dendritic spike initiation zones in layer V pyramidal neurons. J. Neurophysiol. 90, 2428-2437. doi: 10.1152/jn.00377. 2003

Bernal, L., and Roza, C. (2018). Hyperpolarization-activated channels shape temporal patterns of ectopic spontaneous discharge in C-nociceptors after peripheral nerve injury. Eur. J. Pain 22, 1377-1387. doi: 10.1002/ejp.1226

Bialer, M., Johannessen, S. I., Levy, R. H., Perucca, E., Tomson, T., and White, H. S. (2009). Progress report on new antiepileptic drugs: a summary of the Ninth Eilat Conference (EILAT IX). Epilepsy Res. 83, 1-43. doi: 10.1016/j.eplepsyres. 2008.09.005 
Biel, M., Wahl-Schott, C., Michalakis, S., and Zong, X. (2009). Hyperpolarizationactivated cation channels: from genes to function. Physiol. Rev. 89, 847-885. doi: 10.1152/physrev.00029.2008

Bierbower, S. M., Choveau, F. S., Lechleiter, J. D., and Shapiro, M. S. (2015). Augmentation of M-type (KCNQ) potassium channels as a novel strategy to reduce stroke-induced brain injury. J. Neurosci. 35, 2101-2111. doi: 10.1523/ JNEUROSCI.3805-14.2015

Biervert, C., Schroeder, B. C., Kubisch, C., Berkovic, S. F., Propping, P., Jentsch, T. J., et al. (1998). A potassium channel mutation in neonatal human epilepsy. Science 279, 403-406. doi: 10.1126/science.279.5349.403

Bildl, W., Strassmaier, T., Thurm, H., Andersen, J., Eble, S., Oliver, D., et al. (2004). Protein kinase CK2 is coassembled with small conductance Ca 2+-activated K+ channels and regulates channel gating. Neuron 43, 847-858. doi: 10.1016/ j.neuron.2004.08.033

Bishop, M. W., Chakraborty, S., Matthews, G. A. C., Dougalis, A., Wood, N. W., Festenstein, R., et al. (2010). Hyperexcitable substantia nigra dopamine neurons in PINK1- and HtrA2/omi-deficient mice. J. Neurophysiol. 104, 3009-3020. doi: $10.1152 /$ jn.00466.2010

Blackburn-Munro, G., and Jensen, B. S. (2003). The anticonvulsant retigabine attenuates nociceptive behaviours in rat models of persistent and neuropathic pain. Eur. J. Pharmacol. 460, 109-116. doi: 10.1016/S0014-2999(02)02924-2

Blackstone, C., and Sheng, M. (2002). Postsynaptic calcium signaling microdomains in neurons. Front. Biosci. 7, d872-d885. doi: 10.2741/blacksto

Blank, T., Nijholt, I., Kye, M. J., Radulovic, J., and Spiess, J. (2003). Smallconductance, $\mathrm{Ca} 2+$-activated $\mathrm{K}+$ channel SK3 generates age-related memory and LTP deficits. Nat. Neurosci. 6, 911-912. doi: 10.1038/nn1101

Blatz, A. L., and Magleby, K. L. (1986). Single apamin-blocked Ca-activated K+ channels of small conductance in cultured rat skeletal muscle. Nature 323, 718-720. doi: 10.1038/323718a0

Bloodgood, B. L., and Sabatini, B. L. (2007). Nonlinear regulation of unitary synaptic signals by CaV2.3 voltage-sensitive calcium channels located in dendritic spines. Neuron 53, 249-260. doi: 10.1016/j.neuron.2006.12.017

Bock, T., and Stuart, G. J. (2016). The impact of BK channels on cellular excitability depends on their subcellular location. Front. Cell. Neurosci. 10:206. doi: 10. 3389/fncel.2016.00206

Bock, T., Honnuraiah, S., and Stuart, G. J. (2019). Paradoxical excitatory impact of SK channels on dendritic excitability. J. Neurosci. 39, 7826-7839. doi: 10.1523/ JNEUROSCI.0105-19.2019

Boettger, M. K., Till, S., Chen, M. X., Anand, U., Otto, W. R., Plumpton, C., et al. (2002). Calcium-activated potassium channel SK1- and IK1-like immunoreactivity in injured human sensory neurones and its regulation by neurotrophic factors. Brain 125, 252-263. doi: 10.1093/brain/awf026

Boscia, F., Annunziato, L., and Taglialatela, M. (2006). Retigabine and flupirtine exert neuroprotective actions in organotypic hippocampal cultures. Neuropharmacology 51, 283-294. doi: 10.1016/j.neuropharm.2006.03.024

Bowen, T., Williams, N., Norton, N., Spurlock, G., Wittekindt, O. H., MorrisRosendahl, D. J., et al. (2001). Mutation screening of the KCNN3 gene reveals a rare frameshift mutation [3]. Mol. Psychiatry 6, 259-260. doi: 10.1038/sj.mp. 4000128

Brennan, A. R., Dolinsky, B., Vu, M. A. T., Stanley, M., Yeckel, M. F., and Arnsten, A. F. T. (2008). Blockade of IP3-mediated SK channel signaling in the rat medial prefrontal cortex improves spatial working memory. Learn. Mem. 15, 93-96. doi: $10.1101 / 1 \mathrm{~m} .767408$

Brown, B. M., Shim, H., Zhang, M., Yarov-Yarovoy, V., and Wulff, H. (2017). Structural determinants for the selectivity of the positive KCa3.1 gating modulator 5-methylnaphtho[2,1-d] oxazol-2-amine (SKA-121). Mol. Pharmacol. 92, 469-480. doi: 10.1124/mol.117.109421

Brown, D. A., Hughes, S. A., Marsh, S. J., and Tinker, A. (2007). Regulation of $\mathrm{M}(\mathrm{Kv} 7.2 / 7.3)$ channels in neurons by PIP2 and products of PIP2 hydrolysis: Significance for receptor-mediated inhibition. J. Physiol. 582, 917-925. doi: 10.1113/jphysiol.2007.132498

Brzustowicz, L. M., Hodgkinson, K. A., Chow, E. W. C., Honer, W. G., and Bassett, A. S. (2000). Location of a major susceptibility locus for familial schizophrenia on chromosome 1q21-q22. Science 288, 678-682. doi: 10.1126/science.288. 5466.678

Bucchi, A., Baruscotti, M., and Difrancesco, D. (2002). Current-dependent block of rabbit sino-atrial node I f channels by ivabradine. J. Gen. Physiol. 120, 1-13. doi: 10.1085/jgp.20028593
Cai, X., Liang, C. W., Muralidharan, S., Kao, J. P., Tang, C. M., and Thompson, S. M. (2004). Unique roles of SK and Kv4.2 potassium channels in dendritic integration. Neuron 44, 351-364. doi: 10.1016/j.neuron.2004. 09.026

Caminos, E., Garcia-Pino, E., Martinez-Galan, J. R., and Juiz, J. M. (2007). The potassium channel KCNQ5/Kv7.5 is localized in synaptic endings of auditory brainstem nuclei of the rat. J. Comp. Neurol. 505, 363-378. doi: 10.1002/cne. 21497

Cannady, R., McGonigal, J. T., Newsom, R. J., Woodward, J. J., Mulholland, P. J., and Gass, J. T. (2017). Prefrontal cortex KCa2 channels regulate mglu5dependent plasticity and extinction of alcohol-seeking behavior. J. Neurosci. 37, 4359-4369. doi: 10.1523/JNEUROSCI.2873-16.2017

Cao, J. L., Covington, H. E., Friedman, A. K., Wilkinson, M. B., Walsh, J. J., Cooper, D. C., et al. (2010). Mesolimbic dopamine neurons in the brain reward circuit mediate susceptibility to social defeat and antidepressant action. J. Neurosci. 30, 16453-16458. doi: 10.1523/JNEUROSCI.3177-10.2010

Carbone, C., Costa, A., Provensi, G., Mannaioni, G., and Masi, A. (2017). The hyperpolarization-activated current determines synaptic excitability, calcium activity and specific viability of Substantia Nigra dopaminergic neurons. Front. Cell. Neurosci. 11:187. doi: 10.3389/fncel.2017.00187

Cardno, A. G., Bowen, T., Guy, C. A., Jones, L. A., Mccarthy, G., Williams, N. M., et al. (1999). CAG repeat length in the hKCa3 gene and symptom dimensions in schizophrenia. Biol. Psychiatry 45, 1592-1596. doi: 10.1016/s0006-3223(99) 00033-5

Carlesimo, G. A., and Oscar-Berman, M. (1992). Memory deficits in Alzheimer's patients: a comprehensive review. Neuropsychol. Rev. 3, 119-169. doi: 10.1007/ BF01108841

Carlson, A. E., Rosenbaum, J. C., Brelidze, T. I., Klevit, R. E., and Zagotta, W. N. (2013). Flavonoid regulation of HCN2 channels. J. Biol. Chem. 288, 33136-33145. doi: 10.1074/jbc.M113.501759

Carver, C. M., and Shapiro, M. S. (2018). Gq-coupled muscarinic receptor enhancement of KCNQ2 / 3 channels and activation of TRPC channels in multimodal control of excitability in dentate gyrus granule cells Gq-coupled muscarinic receptor enhancement of KCNQ2 / 3 channels and activation of TRPC. J. Neurosci. 39, 1566-1587. doi: 10.1523/JNEUROSCI.1781-18.2018

Castello, J., Ragnauth, A., Friedman, E., and Rebholz, H. (2017). CK2-an emerging target for neurological and psychiatric disorders. Pharmaceuticals 10:7. doi: $10.3390 /$ ph10010007

Chamberlin, N. L., and Dingledine, R. (1989). Control of epileptiform burst rate by CA3 hippocampal cell afterhyperpolarizations in vitro. Brain Res. 492, 337-346. doi: 10.1016/0006-8993(89)90917-7

Chan, C. S., Glajch, K. E., Gertler, T. S., Guzman, J. N., Mercer, J. N., Lewis, A. S., et al. (2011). HCN channelopathy in external globus pallidus neurons in models of Parkinson's disease. Nat. Neurosci. 14, 85-94. doi: 10.1038/nn.2692

Chandy, K. G., Fantino, E., Wittekindt, O., Kalman, K., Tong, L.-L., Ho, T.-H., et al. (1998). Isolation of a novel potassium channel gene hSKCa3 containing a polymorphic CAG repeat: a candidate for schizophrenia and bipolar disorder? Mol. Psychiatry 3, 32-37. doi: 10.1038/sj.mp.4000353

Chen, C., Liu, L., Shu, Y. Q., Jing, P., Lu, Y., Zhang, X. X., et al. (2020). Blockade of HCN2 channels provides neuroprotection against ischemic injury via accelerating autophagic degradation in hippocampal neurons. Neurosci. Bull. 36, 875-894. doi: 10.1007/s12264-020-00513-7

Chen, K., Aradi, I., Thon, N., Eghbal-Ahmadi, M., Baram, T. Z., and Soltesz, I. (2001). Persistently modified h-channels after complex febrile seizures convert the seizure-induced enhancement of inhibition to hyperexcitability. Nat. Med. 7, 331-337. doi: 10.1038/85480

Chen, L., Deltheil, T., Turle-Lorenzo, N., Liberge, M., Rosier, C., Watabe, I., et al. (2014). SK channel blockade reverses cognitive and motor deficits induced by nigrostriatal dopamine lesions in rats. Int. J. Neuropsychopharmacol. 17, 1295-1306. doi: 10.1017/S1461145714000236

Chen, L., Xu, R., Sun, F. J., Xue, Y., Hao, X. M., Liu, H. X., et al. (2015). Hyperpolarization-activated cyclic nucleotide-gated $(\mathrm{HCN})$ channels regulate firing of globus pallidus neurons in vivo. Mol. Cell. Neurosci. 68, 46-55. doi: 10.1016/j.mcn.2015.04.001

Chen, Q. H., and Toney, G. M. (2009). Excitability of paraventricular nucleus neurones that project to the rostral ventrolateral medulla is regulated by small-conductance Ca2+-activated K+ channels. J. Physiol. 587, 4235-4247. doi: 10.1113/jphysiol.2009.175364 
Chen, X., and Johnston, D. (2004). Properties of single voltage-dependent K+ channels in dendrites of CA1 pyramidal neurones of rat hippocampus. J. Physiol. 559, 187-203. doi: 10.1113/jphysiol.2004.068114

Cheng, L., Kinard, K., Rajamani, R., and Sanguinetti, M. C. (2007). Molecular mapping of the binding site for a blocker of pacemaker channels. J. Pharm. Exp. Ther. 322, 931-939. doi: 10.1124/jpet.107.121467.four

Cheng, Q., and Zhou, Y. (2013). Novel role of KT5720 on regulating hyperpolarization-activated cyclic nucleotide-gated channel activity and dorsal root ganglion neuron excitability. DNA Cell Biol. 32, 320-328. doi: 10.1089/dna. 2013.2021

Cho, L. T. Y., Alexandrou, A. J., Torella, R., Knafels, J., Hobbs, J., Taylor, T., et al. (2018). An intracellular allosteric modulator binding pocket in SK2 ion channels is shared by multiple chemotypes. Structure 26, 533-544.e3. doi: 10. 1016/j.str.2018.02.017

Christophersen, P., and Wulff, H. (2015). Pharmacological gating modulation of small- and intermediate-conductance $\mathrm{Ca} 2+$-activated $\mathrm{K}+$ channel (KCa2.x and KCa3.1). Channels 9, 336-343. doi: 10.1080/19336950.2015.1071748

Chung, H. J., Jan, Y. N., and Jan, L. Y. (2006). Polarized axonal surface expression of neuronal KCNQ channels is mediated by multiple signals in the KCNQ2 and KCNQ3 C-terminal domains. Proc. Natl. Acad. Sci. U.S.A. 103, 8870-8875. doi: 10.1073/pnas.0603376103

Cleva, R. M., Hicks, M. P., Gass, J. T., Wischerath, K. C., Plasters, E. T., Widholm, J. J., et al. (2011). MGluR5 positive allosteric modulation enhances extinction learning following cocaine self-administration. Behav. Neurosci. 125, 10-19. doi: $10.1037 / \mathrm{a} 0022339$

Cooper, E. C., Aldape, K. D., Abosch, A., Barbaro, N. M., Berger, M. S., Peacock, W. S., et al. (2000). Colocalization and coassembly of two human brain M-type potassium channel subunits that are mutated in epilepsy. Proc. Natl. Acad. Sci. U.S.A. 97, 4914-4919. doi: 10.1073/pnas.090092797

Corbin-Leftwich, A., Mossadeq, S. M., Ha, J., Ruchala, I., Le, A. H. N., and VillalbaGalea, C. A. (2016). Retigabine holds KV7 channels open and stabilizes the resting potential. J. Gen. Physiol. 147, 229-241. doi: 10.1085/jgp.201511517

Criado-Marrero, M., Santini, E., and Porter, J. T. (2014). Modulating fear extinction memory by manipulating SK potassium channels in the infralimbic cortex. Front. Behav. Neurosci. 8:96. doi: 10.3389/fnbeh.2014.00096

Cueni, L., Canepari, M., Luján, R., Emmenegger, Y., Watanabe, M., Bond, C. T., et al. (2008). T-type Ca2+ channels, SK2 channels and SERCAs gate sleeprelated oscillations in thalamic dendrites. Nat. Neurosci. 11, 683-692. doi: 10. 1038/nn.2124

David, F., Çarçak, N., Furdan, S., Onat, F., Gould, T., Mészáros, Á, et al. (2018). Suppression of hyperpolarization-activated cyclic nucleotide-gated channel function in thalamocortical neurons prevents genetically determined and pharmacologically induced absence seizures. J. Neurosci. 38, 6615-6627. doi: 10.1523/JNEUROSCI.0896-17.2018

Davies, S. N., Martin, D., Millar, J. D., Aram, J. A., Church, J., and Lodge, D. (1988). Differences in results from in vivo and in vitro studies on the use-dependency of $\mathrm{N}$-methylaspartate antagonism by MK-801 and other phencyclidine receptor ligands. Eur. J. Pharmacol. 145, 141-151. doi: 10.1016/0014-2999(88)90 225-7

de Jong, I. E. M., and Jepps, T. A. (2018). Impaired Kv7 channel function in cerebral arteries of a tauopathy mouse model (rTg4510). Physiol. Rep. 6, 1-10. doi: 10.14814/phy2.13920

Deardorff, A. S., Romer, S. H., Deng, Z., Bullinger, K. L., Nardelli, P., Cope, T. C., et al. (2013). Expression of postsynaptic Ca2+-activated K+ (SK) channels at C-bouton synapses in mammalian lumbar -motoneurons. J Physiol. 591, 875-897. doi: 10.1113/jphysiol.2012.240879

Decher, N., Bundis, F., Vajna, R., and Steinmeyer, K. (2003). KCNE2 modulates current amplitudes and activation kinetics of HCN4: Influence of KCNE family members on HCN4 currents. Pflugers Arch. Eur. J. Physiol. 446, 633-640. doi: $10.1007 / \mathrm{s} 00424-003-1127-7$

Delmas, P., and Brown, D. A. (2005). Pathways modulating neural KCNQ / M Kv7 potassium channels. Nat. Rev. Neurosci. 6, 850-862. doi: 10.1038/nrn1785

Devaux, J. J., Kleopa, K. A., Cooper, E. C., and Scherer, S. S. (2004). KCNQ2 is a nodal $\mathrm{K}^{+}$channel. J. Neurosci. 24, 1236-1244. doi: 10.1523/JNEUROSCI.451203.2004

Devulder, J. (2010). Flupirtine in pain management pharmacological properties and clinical use. CNS Drugs 24, 867-881. doi: 10.2165/11536230-00000000000000
Diao, Y., Yan, W., Sun, W., Luo, Y., Li, J., and Yin, Y. (2019). The dual role of $\mathrm{KCNQ} / \mathrm{M}$ channels upon OGD or OGD/R insults in cultured cortical neurons of mice: timing is crucial in targeting M-channels against ischemic injuries. J. Cell. Physiol. 234, 12714-12726. doi: 10.1002/jcp.27889

Dibbens, L. M., Reid, C. A., Hodgson, B., Thomas, E. A., Phillips, A. M., Gazina, E., et al. (2010). Augmented currents of an HCN2 variant in patients with febrile seizure syndromes. Ann. Neurol. 67, 542-546. doi: 10.1002/ana.2 1909

Dickson, C. T., Magistretti, J., Shalinsky, M. H., Fransé, E. N., Hasselmo, M. E., Alonso, A., et al. (2000). Properties and role of $\mathrm{I} h$ in the pacing of subthreshold oscillations in entorhinal cortex layer II neurons. J. Neurophysiol. 83, 25622579. doi: 10.1152/jn.2000.83.5.2562

DiFrancesco, J. C., Castellotti, B., Milanesi, R., Ragona, F., Freri, E., Canafoglia, L., et al. (2019). HCN ion channels and accessory proteins in epilepsy: genetic analysis of a large cohort of patients and review of the literature. Epilepsy Res. 153, 49-58. doi: 10.1016/j.eplepsyres.2019.04.004

Ding, W., You, Z., Shen, S., Chen, L., Zhu, S., and Mao, J. (2016). Inhibition of HCN channel activity in the thalamus attenuates chronic pain in rats. Neurosci. Lett. 631, 97-103. doi: 10.1016/j.neulet.2016.08.021

Ding, W., You, Z., Shen, S., Yang, J., Lim, G., Doheny, J. T., et al. (2018). Increased HCN channel activity in the gasserian ganglion contributes to trigeminal neuropathic pain. J. Pain 19, 626-634. doi: 10.1016/j.jpain.2018.01.003

Doo, A. R., Kim, S. T., Kim, S. N., Moon, W., Yin, C. S., Chae, Y., et al. (2010). Neuroprotective effects of bee venom pharmaceutical acupuncture in acute 1-methyl-4-phenyl-1,2,3,6-tetrahydropyridineinduced mouse model of Parkinson's disease. Neurol. Res. 32(Suppl. 1), 4-7. doi: 10.1179/016164109X

Dreixler, J. C., Bian, J.-T., Cao, Y.-J., Roberts, M. T., Roizen, J. D., and Houamed, K. M. (2000a). Block of rat brain recombinant SK channels by tricyclic antidepressants and related compounds. Eur. J. Pharmacol. 401, 1-7. doi: 10. 1016/s0014-2999(00)00401-5

Dreixler, J. C., Jenkins, A., Cao, Y.-J., Roizen, J. D., and Houamed, K. M. (2000b). Patch-clamp analysis of anesthetic interactions with recombinant SK2 subtype neuronal calcium-activated potassium channels. Anesth. Analg. 90, 727-732. doi: 10.1097/00000539-200003000-00040

Dunnett, S. B., and Björklund, A. (1999). Prospects for new restorative and neuroprotective treatments in Parkinson's disease. Nature 399(6738 Suppl.), A32-A39. doi: 10.1038/399a032

Dwivedi, D., Chattarji, S., and Bhalla, U. S. (2019). Impaired reliability and precision of spiking in adults but not juveniles in a mouse model of Fragile $\mathrm{X}$ syndrome. eNeuro 6:ENEURO.0217-19.2019. doi: 10.1523/ENEURO.0217-19. 2019

El-Hassar, L., Simen, A. A., Duque, A., Patel, K. D., Kaczmarek, L. K., Arnsten, A. F. T., et al. (2014). Disrupted in schizophrenia 1 modulates medial prefrontal cortex pyramidal neuron activity through cAMP regulation of transient receptor potential c and small-conductance $\mathrm{k}+$ channels. Biol. Psychiatry 76 , 476-485. doi: 10.1016/j.biopsych.2013.12.019

Emery, E. C., Young, G. T., Berrocoso, E. M., Chen, L., and McNaughton, P. A. (2011). HCN2 ion channels play a central role in inflammatory and neuropathic pain. Science 333, 1462-1466. doi: 10.1126/science.1206243

Eslamizade, M. J., Saffarzadeh, F., Mousavi, S. M. M., Meftahi, G. H., Hosseinmardi, N., Mehdizadeh, M., et al. (2015). Alterations in cal pyramidal neuronal intrinsic excitability mediated by $\mathrm{iH}$ channel currents in a rat model of amyloid beta pathology. Neuroscience 305, 279-292. doi: 10.1016/j.neuroscience.2015. 07.087

Fakler, B., and Adelman, J. P. (2008). Control of KCa channels by calcium nano/microdomains. Neuron 59, 873-881. doi: 10.1016/j.neuron.2008.09.001

Fanger, C. M., Ghanshani, S., Logsdon, N. J., Rauer, H., Kalman, K., Zhou, J., et al. (1999). Calmodulin mediates calcium-dependent activation of the intermediate conductance K(Ca) channel, IKCa1. J. Biol. Chem. 274, 5746-5754. doi: 10. 1074/jbc.274.9.5746

Fanger, C. M., Rauer, H., Neben, A. L., Miller, M. J., Rauer, H., Wulff, H., et al. (2001). Calcium-activated potassium channels sustain calcium signaling in $\mathrm{T}$ lymphocytes. Selective blockers and manipulated channel expression levels. J. Biol. Chem. 276, 12249-12256. doi: 10.1074/jbc.M011342200

Farde, L. (1998). Brain imaging of schizophrenia - the dopamine hypothesis. Schizophr. Res. 28, 157-162. doi: 10.1016/s0920-9964(97)00121-7

Fattore, C., and Perucca, E. (2011). Novel medications for epilepsy. Drugs 71, 2151-2178. doi: 10.2165/11594640-000000000-00000 
Fedorenko, O., Strutz-Seebohm, N., Henrion, U., Ureche, O. N., Lang, F., Seebohm, G., et al. (2008). A schizophrenia-linked mutation in PIP5K2A fails to activate neuronal M channels. Psychopharmacology 199, 47-54. doi: 10.1007/s00213008-1095-x

Fernández De Sevilla, D., Garduño, J., Galván, E., and Buño, W. (2006). Calciumactivated after hyperpolarizations regulate synchronization and timing of epileptiform bursts in hippocampal CA3 pyramidal neurons. J. Neurophysiol. 96, 3028-3041. doi: 10.1152/jn.00434.2006

Fisher, D. W., Han, Y., Lyman, K. A., Heuermann, R. J., Bean, L. A., Ybarra, N., et al. (2018). HCN channels in the hippocampus regulate active coping behavior. J. Neurochem. 146, 753-766. doi: 10.1111/jnc.14539

Flynn, G. E., and Zagotta, W. N. (2018). Insights into the molecular mechanism for hyperpolarization-dependent activation of HCN channels. Proc. Natl. Acad. Sci. U.S.A. 115, E8086-E8095. doi: 10.1073/pnas.1805596115

Foote, K. M., Lyman, K. A., Han, Y., Michailidis, I. E., Heuermann, R. J., Mandikian, D., et al. (2019). Phosphorylation of the HCN channel auxiliary subunit TRIP8b is altered in an animal model of temporal lobe epilepsy and modulates channel function. J. Biol. Chem. 294, 15743-15758. doi: 10.1074/jbc. RA119.010027

Forster, L. A., Jansen, L. A. R., Rubaharan, M., Murphy, A. Z., and Baro, D. J. (2020). Alterations in SUMOylation of the hyperpolarization-activated cyclic nucleotide-gated ion channel 2 during persistent inflammation. Eur. J. Pain 24, 1517-1536. doi: 10.1002/ejp.1606

Fransén, E., Alonso, A. A., Dickson, C. T., Magistretti, J., and Hasselmo, M. E. (2004). Ionic mechanisms in the generation of subthreshold oscillations and action potential clustering in entorhinal layer II stellate neurons. Hippocampus 14, 368-384. doi: 10.1002/hipo.10198

Friedman, A. K., Juarez, B., Ku, S. M., Zhang, H., Calizo, R. C., Walsh, J. J., et al. (2016). KCNQ channel openers reverse depressive symptoms via an active resilience mechanism. Nat. Commun. 7:11671. doi: 10.1038/ncomms11671

Frykman, S., Inoue, M., Ikeda, A., Teranishi, Y., Kihara, T., Lundgren, J. L., et al. (2017). Maturation and processing of the amyloid precursor protein is regulated by the potassium/sodium hyperpolarization-activated cyclic nucleotide-gated ion channel 2 (HCN2). Biochem. Biophys. Res. Commun. 483, 352-358. doi: 10.1016/j.bbrc.2016.12.140

Fu, R., Mei, Q., Shiwalkar, N., Zuo, W., Zhang, H., Gregor, D., et al. (2020). Anxiety during alcohol withdrawal involves 5-HT2C receptors and M-channels in the lateral habenula. Neuropharmacology 163:107863. doi: 10.1016/j.neuropharm. 2019.107863

Galeotti, N., Ghelardini, C., Caldari, B., and Bartolini, A. (1999). Effect of potassium channel modulators in mouse forced swimming test. $\mathrm{Br} . \mathrm{J}$. Pharmacol. 126, 1653-1659. doi: 10.1038/sj.bjp.0702467

Gamo, N. J., Lur, G., Higley, M. J., Wang, M., Paspalas, C. D., Vijayraghavan, S., et al. (2015). Stress impairs prefrontal cortical function via D1 dopamine receptor interactions with hyperpolarization-activated cyclic nucleotidegated channels. Biol. Psychiatry 78, 860-870. doi: 10.1016/j.biopsych.2015. 01.009

Gamper, N., and Shapiro, M. S. (2003). Calmodulin mediates Ca2+-dependent modulation of M- type K+ channels. J. Gen. Physiol. 122, 17-31. doi: 10.1085/ jgp. 200208783

Gao, S. H., Wen, H. Z., Shen, L. L., Zhao, Y. D., and Ruan, H. Z. (2016). Activation of mGluR1 contributes to neuronal hyperexcitability in the rat anterior cingulate cortex via inhibition of $\mathrm{HCN}$ channels. Neuropharmacology 105, 361-377. doi: 10.1016/j.neuropharm.2016.01.036

García-Negredo, G., Soto, D., Llorente, J., Morató, X., Galenkamp, K. M. O., Gómez-Soler, M., et al. (2014). Coassembly and coupling of SK2 channels and mGlu5 receptors. J. Neurosci. 34, 14793-14802. doi: 10.1523/JNEUROSCI. 2038-14.2014

Garduño, J., Galván, E., Fernández De Sevilla, D., and Buño, W. (2005). 1Ethyl-2-benzimidazolinone (EBIO) suppresses epileptiform activity in in vitro hippocampus. Neuropharmacology 49, 376-388. doi: 10.1016/j.neuropharm. 2005.03.021

Gargus, J. J., Fantino, E., and Gutman, G. A. (1998). A piece in the puzzle: an ion channel candidate gene for schizophrenia. Mol. Med. Today 4, 518-524. doi: 10.1016/S1357-4310(98)01358-6

Gass, J. T., and Olive, M. F. (2009). Positive allosteric modulation of mGluR5 receptors facilitates extinction of a cocaine contextual memory. Biol. Psychiatry 65, 717-720. doi: 10.1016/j.biopsych.2008.11.001
Giessel, A. J., and Sabatini, B. L. (2010). M1 muscarinic receptors boost synaptic potentials and calcium influx in dendritic spines by inhibiting postsynaptic SK channels. Neuron 68, 936-947. doi: 10.1016/j.neuron.2010.09.004

Gill, C. H., Randall, A., Bates, S. A., Hill, K., Owen, D., Larkman, P. M., et al. (2004). Characterization of the human HCN1 channel and its inhibition by capsazepine. Br. J. Pharmacol. 143, 411-421. doi: 10.1038/sj.bjp.070 5945

Goldberg, J. A., and Wilson, C. J. (2005). Control of spontaneous firing patterns by the selective coupling of calcium currents to calcium-activated potassium currents in striatal cholinergic interneurons. J. Neurosci. 25, 10230-10238. doi: 10.1523/JNEUROSCI.2734-05.2005

Gomis-Perez, C., Soldovieri, M. V., Malo, C., Ambrosino, P., Taglialatela, M., Areso, P., et al. (2017). Differential regulation of pi(4,5)p2 sensitivity of kv7.2 and kv7.3 channels by calmodulin. Front. Mol. Neurosci. 10:117. doi: 10.3389/ fnmol.2017.00117

Greene, D. L., Kosenko, A., and Hoshi, N. (2018). Attenuating M-current suppression in vivo by a mutant Kcnq2 gene knock-in reduces seizure burden and prevents status epilepticus-induced neuronal death and epileptogenesis. Epilepsia 59, 1908-1918. doi: 10.1111/epi.14541

Gu, N., Vervaeke, K., Hu, H., and Storm, J. F. (2005). Kv7/KCNQ/M and $\mathrm{HCN} / \mathrm{h}$, but not KCa2/SK channels, contribute to the somatic medium afterhyperpolarization and excitability control in CA1 hippocampal pyramidal cells. J. Physiol. 566(Pt 3), 689-715. doi: 10.1113/jphysiol.2005.086835m

Guatteo, E., Rizzo, F. R., Federici, M., Cordella, A., Ledonne, A., Latini, L., et al. (2017). Functional alterations of the dopaminergic and glutamatergic systems in spontaneous $\alpha$-synuclein overexpressing rats. Exp. Neurol. 287, 21-33. doi: 10.1016/j.expneurol.2016.10.009

Günther, A., Luczak, V., Gruteser, N., Abel, T., and Baumann, A. (2019). HCN4 knockdown in dorsal hippocampus promotes anxiety-like behavior in mice. Genes Brain Behav. 18:e12550. doi: 10.1111/gbb.12550

Ha, G. E., and Cheong, E. (2017). Spike frequency adaptation in neurons of the central nervous system. Exp. Neurobiol. 26, 179-185. doi: 10.5607/en.2017.26. 4.179

Habermann, E., and Fischer, K. (1979). Bee venom neurotoxin (Apamin): Iodine Labeling and characterization of binding sites. Eur. J. Biochem. 94, 355-364. doi: 10.1111/j.1432-1033.1979.tb12901.x

Haitin, Y., and Attali, B. (2008). The C-terminus of Kv7 channels: a multifunctional module. J. Physiol. 586, 1803-1810. doi: 10.1113/jphysiol.2007.14 9187

Halls, M. L., and Cooper, D. M. F. (2011). Regulation by Ca2+-signaling pathways of adenylyl cyclases. Cold Spring Harb. Perspect. Biol. 3, 1-22. doi: 10.1101/ cshperspect.a004143

Hammelmann, V., Stieglitz, M. S., Hülle, H., Le Meur, K., Kass, J., Brümmer, M., et al. (2019). Abolishing cAMP sensitivity in HCN2 pacemaker channels induces generalized seizures. JCI Insight 4:e126418. doi: 10.1172/jci.insight. 126418

Han, Y., Heuermann, R. J., Lyman, K. A., Fisher, D., Ismail, Q. A., and Chetkovich, D. M. (2017). HCN-channel dendritic targeting requires bipartite interaction with TRIP8b and regulates antidepressant-like behavioral effects. Mol. Psychiatry 22, 458-465. doi: 10.1038/mp.2016.99

Hansen, H. H., Waroux, O., Seutin, V., Jentsch, T. J., Aznar, S., and Mikkelsen, J. D. (2008). Kv7 channels: interaction with dopaminergic and serotonergic neurotransmission in the CNS. J. Physiol. 586, 1823-1832. doi: 10.1113/jphysiol. 2007.149450

Hao, X. M., Xu, R., Chen, A. Q., Sun, F. J., Wang, Y., Liu, H. X., et al. (2019). Endogenous HCN channels modulate the firing activity of globus pallidus neurons in Parkinsonian animals. Front. Aging Neurosci. 10:190. doi: 10.3389/ fnagi.2019.00190

Hartmann, A., Müllner, J., Meier, N., Hesekamp, H., Van Meerbeeck, P., Habert, M. O., et al. (2016). Bee venom for the treatment of Parkinson disease a randomized controlled clinical trial. PLoS One 11:e0158235. doi: 10.1371/ journal.pone. 0158235

Hayashi, H., Iwata, M., Tsuchimori, N., and Matsumoto, T. (2014). Activation of peripheral KCNQ channels attenuates inflammatory pain. Mol. Pain 10, 1-9. doi: 10.1186/1744-8069-10-15

He, C., Chen, F., Li, B., and Hu, Z. (2014). Neurophysiology of HCN channels: from cellular functions to multiple regulations. Prog. Neurobiol. 112, 1-23. doi: 10.1016/j.pneurobio.2013.10.001 
Hernandez, C. C., Zaika, O., Tolstykh, G. P., and Shapiro, M. S. (2008). Regulation of neural KCNQ channels: signalling pathways, structural motifs and functional implications. J. Physiol. 586, 1811-1821. doi: 10.1113/jphysiol.2007.14 8304

Hessler, S., Zheng, F., Hartmann, S., Rittger, A., Lehnert, S., Völkel, M., et al. (2015). $\beta$-secretase BACE1 regulates hippocampal and reconstituted M-currents in a $\beta$-subunit-like fashion. J. Neurosci. 35, 3298-3311. doi: 10.1523/JNEUROSCI. 3127-14.2015

Heuermann, R. J., Jaramillo, T. C., Ying, S. W., Suter, B. A., Lyman, K. A., Han, Y., et al. (2016). Reduction of thalamic and cortical Ih by deletion of TRIP8b produces a mouse model of human absence epilepsy. Neurobiol. Dis. 85, 81-92. doi: 10.1016/j.nbd.2015s.10.005

Hirschberg, B., Maylie, J., Adelman, J. P., and Marrion, N. V. (1999). Gating properties of single SK channels in hippocampal CA1 pyramidal neurons. Biophys. J. 77, 1905-1913. doi: 10.1016/S0006-3495(99)77032-3

Hirvonen, J., van Erp, T. G., Jukka Huttunen, M., Aalto, S., Någren, K., Huttunen, M., et al. (2006). Brain dopamine D 1 receptors in twins discordant for schizophrenia. Am. J. Psychiatry 163, 1747-1753. doi: 10.1176/ajp.2006.163.10. 1747

Honrath, B., Krabbendam, I. E., Ijsebaart, C., Pegoretti, V., Bendridi, N., Rieusset, J., et al. (2018). SK channel activation is neuroprotective in conditions of enhanced ER-mitochondrial coupling article. Cell Death Dis. 9, 1-11. doi: 10. 1038/s41419-018-0590-1

Honrath, B., Matschke, L., Meyer, T., Magerhans, L., Perocchi, F., Ganjam, G. K., et al. (2017). SK2 channels regulate mitochondrial respiration and mitochondrial Ca2+ uptake. Cell Death Differ. 24, 761-773. doi: 10.1038/cdd. 2017.2

Honsa, P., Pivonkova, H., Harantova, L., Butenko, O., Kriska, J., Dzamba, D., et al. (2014). Increased expression of hyperpolarization-activated cyclic nucleotidegated $(\mathrm{HCN})$ channels in reactive astrocytes following ischemia. Glia 62, 2004-2021. doi: 10.1002/glia.22721

Hopf, F. W., Bowers, M. S., Chang, S. J., Chen, B. T., Martin, M., Seif, T., et al. (2010). Reduced nucleus accumbens SK channel activity enhances alcohol seeking during abstinence. Neuron 65, 682-694. doi: 10.1016/j.neuron.2010. 02.015

Hopf, F. W., Martin, M., Chen, B. T., Bowers, M. S., Mohamedi, M. M., and Bonci, A. (2007). Withdrawal from intermittent ethanol exposure increases probability of burst firing in VTA neurons in vitro. J. Neurophysiol. 98, 2297-2310. doi: 10.1152/jn.00824.2007

Hopf, F. W., Simms, J. A., Chang, S. J., Seif, T., Bartlett, S. E., and Bonci, A. (2011). Chlorzoxazone, an SK-type potassium channel activator used in humans, reduces excessive alcohol intake in rats. Biol. Psychiatry 69, 618-624. doi: 10.1016/j.biopsych.2010.11.011

Hou, B., Chen, H., Qu, X., Lin, X., Luo, F., and Li, C. (2015). Characteristics of hyperpolarization-activated cyclic nucleotide-gated channels in dorsal root ganglion neurons at different ages and sizes. NeuroReport 26, 981-987. doi: 10.1097/WNR.0000000000000455

Hougaard, C., Eriksen, B. L., Jørgensen, S., Johansen, T. H., Dyhring, T., Madsen, L. S., et al. (2007). Selective positive modulation of the SK3 and SK2 subtypes of small conductance Ca 2+-activated $\mathrm{K}+$ channels. Br. J. Pharmacol. 151, 655-665. doi: 10.1038/sj.bjp.0707281

Hu, H., Vervaeke, K., and Storm, J. F. (2007). M-channels (Kv7/KCNQ channels) that regulate synaptic integration, excitability, and spike pattern of CA1 pyramidal cells are located in the perisomatic region. J. Neurosci. 27, 1853-1867. doi: 10.1523/JNEUROSCI.4463-06.2007

$\mathrm{Hu}, \mathrm{W}$., and Bean, B. P. (2018). Differential control of axonal and somatic resting potential by voltage-dependent conductances in cortical layer 5 pyramidal neurons. Neuron 97, 1315-1326.e3. doi: 10.1016/j.neuron.2018.02.016

Huang, H., and Trussell, L. O. (2011). KCNQ5 channels control resting properties and release probability of a synapse. Nat. Neurosci. 14, 840-847. doi: 10.1038/ nn. 2830

Huang, Y., Liu, X., Wang, G., and Wang, Y. (2018). SK channels participate in the formation of after burst hyperpolarization and partly inhibit the burst strength of epileptic ictal discharges. Mol. Med. Rep. 17, 1762-1774. doi: 10.3892/mmr. 2017.8068

Huang, Z., Walker, M. C., and Shah, M. M. (2009). Loss of dendritic HCN1 subunits enhances cortical excitability and epileptogenesis. J. Neurosci. 29, 10979-10988. doi: 10.1523/JNEUROSCI.1531-09.2009
Hunot, S., Vila, M., Teismann, P., Davis, R. J., Hirsch, E. C., Przedborski, S., et al. (2004). JNK-mediated induction of cyclooxygenase 2 is required for neurodegeneration in a mouse model of Parkinson's disease. Proc. Natl. Acad. Sci. U.S.A. 101, 665-670. doi: 10.1073/pnas.0307453101

Ikonen, S., and Riekkinen, P. (1999). Effects of apamin on memory processing of hippocampal-lesioned mice. Eur. J. Pharmacol. 382, 151-156. doi: 10.1016/ S0014-2999(99)00616-0

Ishii, T. M., Maylie, J., and Adelman, J. P. (1997). Determinants of apamin and dtubocurarine block in SK potassium channels. J. Biol. Chem. 272, 23195-23200. doi: 10.1074/jbc.272.37.23195

Itoh, M., Ishihara, K., Nakashima, N., and Takano, M. (2016). The hyperpolarization-activated cyclic nucleotide-gated (HCN) channels contain multiple S-palmitoylation sites. J. Physiol. Sci. 66, 241-248. doi: 10.1007/s12576-015-0420-5

Janak, P. H., Chang, J. Y., and Woodward, D. J. (1999). Neuronal spike activity in the nucleus accumbens of behaving rats during ethanol self-administration. Brain Res. 817, 172-184. doi: 10.1016/S0006-8993(98)01245-1

Javitt, C. (1991). Recent advances in the phencyclidine model of schizophrenia. Am. J. Psychiatry 148, 1301-1308. doi: 10.1176/ajp.148.10.1301

Jentsch, T. J. (2000). Neuronal KCNQ potassium channels: physislogy and role in disease. Nat. Rev. Neurosci. 1, 21-30. doi: 10.1038/35036198

Jung, S., Jones, T. D., Lugo, J. N., Sheerin, A. H., Miller, J. W., D’Ambrosio, R., et al. (2007). Progressive dendritic HCN channelopathy during epileptogenesis in the rat pilocarpine model of epilepsy. J. Neurosci. 27, 13012-13021. doi: 10.1523/JNEUROSCI.3605-07.2007

Kang, S., Li, J., Zuo, W., Fu, R., Gregor, D., Krnjevic, K., et al. (2017). Ethanol withdrawal drives anxiety-related behaviors by reducing $\mathrm{m}$-type potassium channel activity in the lateral habenula. Neuropsychopharmacology 42, 18131824. doi: 10.1038/npp.2017.68

Kang, S., Xu, M., Cooper, E. C., and Hoshi, N. (2014). Channel-anchored protein kinase CK2 and protein phosphatase 1 reciprocally regulate KCNQ2-containing M-channels via phosphorylation of calmodulin. J. Biol. Chem. 289, 1153611544. doi: 10.1074/jbc.M113.528497

Kaupp, U. B., and Seifert, R. (2001). Molecular diversity of pacemaker ion channels. Annu. Rev. Physiol. 63, 235-257. doi: 10.1146/annurev.physiol.63.1.235

Khachaturian, Z. S. (1989). Calcium, membranes, aging and Alzheimer's disease: Introduction and overview. Ann. N. Y. Acad. Sci. 568, 1-4. doi: 10.1111/j.17496632.1989.tb12485.x

Khandai, P., Forcelli, P. A., and N'Gouemo, P. (2020). Activation of small conductance calcium-activated potassium channels suppresses seizure susceptibility in the genetically epilepsy-prone rats. Neuropharmacology 163:107865. doi: 10.1016/j.neuropharm.2019.107865

Kim, C. S., and Johnston, D. (2018). A possible link between HCN channels and depression. Chronic Stress 2, 1-6. doi: 10.1177/2470547018787781

Kim, C. S., Brager, D. H., and Johnston, D. (2017). Perisomatic changes in h-channels regulate depressive behaviors following chronic unpredictable stress. Mol. Psychiatry 23, 892-903. doi: 10.1038/mp.2017.28

Kim, C. S., Chang, P. Y., and Johnston, D. (2012). Enhancement of dorsal hippocampal activity by knockdown of hon 1 channels leads to anxiolytic- and antidepressant-like behaviors. Neuron 75, 503-516. doi: 10.1016/j.neuron.2012. 05.027

Kitayama, M., Miyata, H., Yano, M., Saito, N., Matsuda, Y., Yamauchi, T., et al. (2003). Ih blockers have a potential of antiepileptic effects. Epilepsia 44, 20-24. doi: 10.1046/j.1528-1157.2003.22702.x

Kleiman-weiner, M., Beenhakker, M. P., Segal, W. A., and Huguenard, J. R. (2009). Synergistic roles of GABAA receptors and SK channels in regulating thalamocortical oscillations. J. Neurophysiol. 102, 203-213. doi: 10.1152/jn. 91158.2008

Knapp, C. M., O’Malley, M., Datta, S., and Ciraulo, D. A. (2014). The Kv7 potassium channel activator retigabine decreases alcohol consumption in rats. Am. J. Drug Alcohol Abuse 40, 244-250. doi: 10.3109/00952990.2014.892951

Ko, K. W., Rasband, M. N., Meseguer, V., Kramer, R. H., and Golding, N. L. (2016). Serotonin modulates spike probability in the axon initial segment through HCN channels. Nat. Neurosci. 19, 826-834. doi: 10.1038/nn.4293

Koga, K., Descalzi, G., Chen, T., Ko, H. G., Lu, J., Li, S., et al. (2015). Coexistence of two forms of LTP in ACC provides a synaptic mechanism for the interactions between anxiety and chronic pain. Neuron $85,377-389$. doi: 10.1016/j.neuron. 2014.12.021 
Köhler, A. M., Hirschberg, B., Bond, C. T., Kinzie, J. M., Marrion, N. V., Maylie, J., et al. (1996). Small-Conductance, Calcium-Activated Potassium Channels from Mammalian Brain. Science 273, 1709-1714. doi: 10.1126/science.273.5282.1709

Konieczny, V., Tovey, S. C., Mataragka, S., Prole, D. L., and Taylor, C. W. (2017). Cyclic AMP recruits a discrete intracellular $\mathrm{Ca}^{2+}$ store by unmasking hypersensitive $\mathrm{IP}_{3}$ receptors. Cell Rep. 18, 711-722. doi: 10.1016/j.celrep.2016. 12.058

Korsgaard, M. P. G., Hartz, B. P., Brown, W. D., Ahring, P. K., Strøbæk, D., and Mirza, N. R. (2005). Anxiolytic effects of maxipost (BMS-204352) and retigabine via activation of neuronal Kv7 channels. J. Pharmacol. Exp. Ther. 314, 282-292. doi: 10.1124/jpet.105.083923

Krabbendam, I. E., Honrath, B., Culmsee, C., and Dolga, A. M. (2018). Mitochondrial Ca2+-activated $\mathrm{K}+$ channels and their role in cell life and death pathways. Cell Calcium 69, 101-111. doi: 10.1016/j.ceca.2017.07.005

Kreir, M., De Bondt, A., Van den Wyngaert, I., Teuns, G., Lu, H. R., and Gallacher, D. J. (2019). Role of Kv7.2/Kv7.3 and M1 muscarinic receptors in the regulation of neuronal excitability in hiPSC-derived neurons. Eur. J. Pharmacol. 858:172474. doi: 10.1016/j.ejphar.2019.172474

Kshatri, A. S., Gonzalez-Hernandez, A., and Giraldez, T. (2018). Physiological roles and therapeutic potential of $\mathrm{Ca}^{2+}$ activated potassium channels in the nervous system. Front. Mol. Neurosci. 11:258. doi: 10.3389/fnmol.2018.00258

Kuiper, E. F. E., Nelemans, A., Luiten, P., Nijholt, I., Dolga, A., and Eisel, A. D. (2012). Kca2 and Kca3 channels in learning and memory processes, and neurodegeneration. Front. Pharmacol. 3:107. doi: 10.3389/fphar.2012.00107

Lam, J., Coleman, N., Garing, A. L. A., and Wulff, H. (2013). The therapeutic potential of small-conductance $\mathrm{KCa} 2$ channels in neurodegenerative and psychiatric diseases. Expert Opin. Ther. Targets 17, 1203-1220. doi: 10.1517/ 14728222.2013 .823161

Lappin, S. C., Dale, T. J., Brown, J. T., Trezise, D. J., and Davies, C. H. (2005). Activation of SK channels inhibits epileptiform bursting in hippocampal CA3 neurons. Brain Res. 1065, 37-46. doi: 10.1016/j.brainres.2005.10.024

Laurent, C., Niehaus, D., Bauché, S., Levinson, D. F., Soubigou, S., Pimstone, S., et al. (2003). CAG repeat polymorphisms in KCNN3 (HSKCa3) and PPP2R2B show no association or linkage to schizophrenia. Am. J. Med. Genet. B Neuropsychiatr. Genet. 116B, 45-50. doi: 10.1002/ajmg.b.10797

Lee, C. H., and MacKinnon, R. (2017). Structures of the human HCN1 hyperpolarization-activated channel. Cell 168, 111-120.e11. doi: 10.1016/j.cell. 2016.12.023

Lee, C. H., and MacKinnon, R. (2018). Activation mechanism of a human SKcalmodulin channel complex elucidated by cryo-EM structures. Science 360, 508-513. doi: 10.1126/science.aas 9466

Lee, M. C., Bond, S., Wheeler, D., Scholtes, I., Armstrong, G., McNaughton, P., et al. (2019). randomised, double-blind, placebo-controlled crossover trial of the influence of the HCN channel blocker ivabradine in a healthy volunteer pain model: an enriched population trial. Pain 160, 2554-2565. doi: 10.1097/j. pain.0000000000001638

Leissring, M. A., Murphy, M. P., Mead, T. R., Akbari, Y., Sugarman, M. C., Jannatipour, M., et al. (2002). A physiologic signaling role for the $\gamma$-secretasederived intracellular fragment of APP. Proc. Natl. Acad. Sci. U.S.A. 99, 46974702. doi: 10.1073/pnas.072033799

Lewis, A. S., Vaidya, S. P., Blaiss, C. A., Liu, Z., Stoub, T. R., Brager, D. H., et al. (2011). Deletion of the hyperpolarization-activated cyclic nucleotidegated channel auxiliary subunit TRIP8b impairs hippocampal Ih localization and function and promotes antidepressant behavior in mice. J. Neurosci. 31, 7424-7440. doi: 10.1523/JNEUROSCI.0936-11.2011

Lezmy, J., Lipinsky, M., Khrapunsky, Y., Patrich, E., Shalom, L., Peretz, A., et al. (2017). M-current inhibition rapidly induces a unique CK2-dependent plasticity of the axon initial segment. Proc. Natl. Acad. Sci. U.S.A. 114, E10234E10243. doi: 10.1073/pnas.1708700114

Li, L., Sun, H., Ding, J., Niu, C., Su, M., Zhang, L., et al. (2017). Selective targeting of M-type potassium Kv7.4 channels demonstrates their key role in the regulation of dopaminergic neuronal excitability and depression-like behaviour. $\mathrm{Br}$. J. Pharmacol. 174, 4277-4294. doi: 10.1111/bph.14026

Li, Y., Gamper, N., Hilgemann, D. W., and Shapiro, M. S. (2005). Regulation of Kv7 (KCNQ) K+ channel open probability by phosphatidylinositol 4,5bisphosphate. J. Neurosci. 25, 9825-9835. doi: 10.1523/JNEUROSCI.2597-05. 2005
Li, Y., Xu, J., Xu, Y., Zhao, X. Y., Liu, Y., Wang, J., et al. (2018). Regulatory effect of general anesthetics on activity of potassium channels. Neurosci. Bull. 34, 887-900. doi: 10.1007/s12264-018-0239-1

Liegeois, J., Mercier, F., Graulich, A., Graulich-Lorge, F., Scuvee-Moreau, J., and Seutin, V. (2005). Modulation of small conductance calcium-activated potassium (SK) channels: a new challenge in medicinal chemistry. Curr. Med. Chem. 10, 625-647. doi: 10.2174/0929867033457908

Lin, M. T., Luján, R., Watanabe, M., Adelman, J. P., and Maylie, J. (2008). SK2 channel plasticity contributes to LTP at Schaffer collateral-CA1 synapses. Nat. Neurosci. 11, 170-177. doi: 10.1038/nn2041

Linley, J. E., Rose, K., Patil, M., Robertson, B., Akopian, A. N., and Gamper, N. (2008). Inhibition of $M$ current in sensory neurons by exogenous proteases: a signaling pathway mediating inflammatory nociception. J. Neurosci. 28, 1124011249. doi: 10.1523/JNEUROSCI.2297-08.2008

Liu, H., Jia, L., Chen, X., Shi, L., and Xie, J. (2018). The Kv7/KCNQ channel blocker XE991 protects nigral dopaminergic neurons in the 6-hydroxydopamine rat model of Parkinson's disease. Brain Res. Bull. 137, 132-139. doi: 10.1016/j. brainresbull.2017.11.011

Liu, W., and Devaux, J. J. (2014). Calmodulin orchestrates the heteromeric assembly and the trafficking of KCNQ2/3 (Kv7.2/3) channels in neurons. Mol. Cell. Neurosci. 58, 40-52. doi: 10.1016/j.mcn.2013.12.005

Llinas, R., and Jahnsen, H. (1982). Electrophysiology of mammalian thalamic neurones in vitro. Nature 297, 406-408. doi: 10.1038/297406a0

Lo, E. H., Dalkara, T., and Moskowitz, M. A. (2003). Neurological diseases: mechanisms, challenges and opportunities in stroke. Nat. Rev. Neurosci. 4, 399-414. doi: 10.1038/nrn1106

Lodge, D., and Anis, N. A. (1982). Effects of phencyclidine on excitatory amino acid activation of spinal interneurones in the cat. Eur. J. Pharmacol. 77, 203-204. doi: 10.1016/0014-2999(82)90022-x

Lörincz, A., Notomi, T., Tamás, G., Shigemoto, R., and Nusser, Z. (2002). Polarized and compartment-dependent distribution of HCN1 in pyramidal cell dendrites. Nat. Neurosci. 5, 1185-1193. doi: 10.1038/nn962

Ludwig, A., Budde, T., Stieber, J., Moosmang, S., Wahl, C., Holthoff, K., et al. (2003). Absence epilepsy and sinus dysrhythmia in mice lacking the pacemaker channel HCN2. EMBO J. 22, 216-224. doi: 10.1093/emboj/cdg032

Lundby, A., Tseng, G. N., and Schmitt, N. (2010). Structural basis for KV7.1KCNEx interactions in the IKs channel complex. Heart Rhythm 7, 708-713. doi: 10.1016/j.hrthm.2009.12.017

Lupica, C. R., Bell, J. A., Hoffman, A. F., and Watson, P. L. (2001). Contribution of the hyperpolarization-activated current (Ih) to membrane potential and GABA release in hippocampal interneurons. J. Neurophysiol. 86, 261-268. doi: 10.1152/jn.2001.86.1.261

Main, M. J., Cryan, J. E., Dupere, J. R. B., Cox, B., Clare, J. J., and Burbidge, S. A. (2000). Modulation of KCNQ2/3 potassium channels by the novel anticonvulsant retigabine. Mol. Pharmacol. 58, 253-262. doi: 10.1124/mol.58. 2.253

Maingret, F., Coste, B., Hao, J., Giamarchi, A., Allen, D., Crest, M., et al. (2008). Neurotransmitter modulation of small-conductance Ca2+- activated $\mathrm{K}+$ channels by regulation of Ca2+ gating. Neuron 59, 439-449. doi: 10.1016/ j.neuron.2008.05.026

Maljevic, S., Lerche, C., Seebohm, G., Alekov, A. K., Busch, A. E., and Lerche, H. (2003). C-terminal interaction of KCNQ2 and KCNQ3 K+ channels. J. Physiol. 548, 353-360. doi: 10.1113/jphysiol.2003.040980

Mani, B. K., Robakowski, C., Brueggemann, L. I., Cribbs, L. L., Tripathi, A., Majetschak, M., et al. (2016). Kv7.5 Potassium channel subunits are the primary targets for PKA-dependent enhancement of vascular smooth muscle Kv7 currents. Mol. Pharmacol. 89, 323-334. doi: 10.1124/mol.115.101758

Manville, R. W., and Abbott, G. W. (2018). Ancient and modern anticonvulsants act synergistically in a KCNQ potassium channel binding pocket. Nat. Commun. 9:3845. doi: 10.1038/s41467-018-06339-2

Marini, C., Porro, A., Rastetter, A., Dalle, C., Rivolta, I., Bauer, D., et al. (2018) HCN1 mutation spectrum: From neonatal epileptic encephalopathy to benign generalized epilepsy and beyond. Brain 141, 3160-3178. doi: 10.1093/brain/ awy263

Marrion, N. V., and Tavalin, S. J. (1998). Selective activation of Ca2+-activated K+ channels by co-localized Ca2+ channels in hippocampal neurons. Nature 395, 900-905. doi: 10.1038/27674 
Martire, M., Castaldo, P., D’Amico, M., Preziosi, P., Annunziato, L., and Taglialatela, M. (2004). M channels containing KCNQ2 subunits modulate norepinephrine, aspartate, and GABA release from hippocampal nerve terminals. J. Neurosci. 24, 592-597. doi: 10.1523/JNEUROSCI.3143-03.2004

Mateos-Aparicio, P., Murphy, R., and Storm, J. F. (2014). Complementary functions of SK and Kv7/M potassium channels in excitability control and synaptic integration in rat hippocampal dentate granule cells. J. Physiol. 592, 669-693. doi: 10.1113/jphysiol.2013.267872

Matos, S. C., Zhang, Z., and Séguéla, P. (2015). Peripheral neuropathy induces $\mathrm{HCN}$ channel dysfunction in pyramidal neurons of the medial prefrontal cortex. J. Neurosci. 35, 13244-13256. doi: 10.1523/jneurosci.0799-15.2015

Matschke, L. A., Rinné, S., Snutch, T. P., Oertel, W. H., Dolga, A. M., and Decher, N. (2018). Calcium-activated SK potassium channels are key modulators of the pacemaker frequency in locus coeruleus neurons. Mol. Cell. Neurosci. 88, 330-341. doi: 10.1016/j.mcn.2018.03.002

Mattson, M. P., Cheng, B., Davis, D., Bryant, K., Lieberburg, I., and Rydel, R. E. (1992). $\beta$-Amyloid peptides destabilize calcium homeostasis and render human cortical neurons vulnerable to excitotoxicity. J. Neurosci. 12, 376-389. doi: 10.1523/jneurosci.12-02-00376.1992

Maurice, N., Deltheil, T., Melon, C., Degos, B., Mourre, C., Amalric, M., et al. (2015). Bee venom alleviates motor deficits and modulates the transfer of cortical information through the basal ganglia in rat models of Parkinson's disease. PLoS One 10:e0142838. doi: 10.1371/journal.pone.0142838

McCormick, D. A., and Pape, H. C. (1990). Noradrenergic and serotonergic modulation of a hyperpolarization-activated cation current in thalamic relay neurones. J. Physiol. 431, 319-342. doi: 10.1113/jphysiol.1990.sp018332

McGuier, N. S., Griffin, W. C., Gass, J. T., Padula, A. E., Chesler, E. J., and Mulholland, P. J. (2016). Kv7 channels in the nucleus accumbens are altered by chronic drinking and are targets for reducing alcohol consumption. Addict. Biol. 21, 1097-1112. doi: 10.1111/adb.12279

McGuier, N. S., Rinker, J. A., Cannady, R., Fulmer, D. B., Jones, S. R., Hoffman, M., et al. (2018). Identification and validation of midbrain Kcnq4 regulation of heavy alcohol consumption in rodents. Neuropharmacology 138, 10-19. doi: 10.1016/j.neuropharm.2018.05.020

McKinley, J. W., Shi, Z., Kawikova, I., Hur, M., Bamford, I. J., Sudarsana Devi, S. P., et al. (2019). Dopamine deficiency reduces striatal cholinergic interneuron function in models of Parkinson's disease. Neuron 103, 1056-1072.e6. doi: 10. 1016/j.neuron.2019.06.013

Mellor, J., Nicoll, R. A., and Schmitz, D. (2002). Mediation of hippocampal mossy fiber long-term potentiation by presynaptic Ih channels. Science 295, 143-147. doi: 10.1126/science. 1064285

Mi, Z., Yang, J., He, Q., Zhang, X., Xiao, Y., and Shu, Y. (2019). Alterations of electrophysiological properties and ion channel expression in prefrontal cortex of a mouse model of schizophrenia. Front. Cell. Neurosci. 13:554. doi: 10.3389/ fncel.2019.00554

Miller, M. J., Rauer, H., Tomita, H., Rauer, H., Gargus, J. J., Gutman, G. A., et al. (2001). Nuclear localization and dominant-negative suppression by a mutant SKCa3 N-terminal channel fragment identified in a patient with schizophrenia. J. Biol. Chem. 276, 27753-27756. doi: 10.1074/jbc.C100221200

Monaghan, A. S., Benton, D. C. H., Bahia, P. K., Hosseini, R., Shah, Y. A., Haylett, D. G., et al. (2004). The SK3 subunit of small conductance $\mathrm{Ca} 2+$-activated $\mathrm{K}+$ channels interacts with both SK1 and SK2 subunits in a heterologous expression system. J. Biol. Chem. 279, 1003-1009. doi: 10.1074/jbc.M30807 0200

Moosmang, S., Biel, M., Hofmann, F., and Ludwig, A. (1999). Differential distribution of four hyperpolarization-activated cation channels in mouse brain. Biol. Chem. 380, 975-980. doi: 10.1515/BC.1999.121

Moosmang, S., Stieber, J., Zong, X., Biel, M., Hofmann, F., and Ludwig, A. (2001). Cellular expression and functional characterization of four hyperpolarizationactivated pacemaker channels in cardiac and neuronal tissues. Eur. J. Biochem. 268, 1646-1652. doi: 10.1046/j.1432-1327.2001.02036.x

Mourre, C., Manrique, C., Camon, J., Aidi-Knani, S., Deltheil, T., Turle-Lorenzo, N., et al. (2017). Changes in SK channel expression in the basal ganglia after partial nigrostriatal dopamine lesions in rats: functional consequences. Neuropharmacology 113, 519-532. doi: 10.1016/j.neuropharm.2016. 11.003

Much, B., Wahl-Schott, C., Zong, X., Schneider, A., Baumann, L., Moosmang, S., et al. (2003). Role of subunit heteromerization and N-linked glycosylation in the formation of functional hyperpolarization-activated cyclic nucleotide-gated channels. J. Biol. Chem. 278, 43781-43786. doi: 10.1074/jbc.M306958200

Mulholland, P. J. (2012). KCa2 channels: novel therapeutic targets for treating alcohol withdrawal and escalation of alcohol consumption. Alcohol 46, 309315. doi: 10.1016/j.alcohol.2011.11.002

Mulholland, P. J., Becker, H. C., Woodward, J. J., and Chandler, L. J. (2011). Small conductance calcium-activated potassium type 2 channels regulate alcoholassociated plasticity of glutamatergic synapses. Biol. Psychiatry 69, 625-632. doi: 10.1016/j.biopsych.2010.09.025

Murthy, S. R. K., Teodorescu, G., Nijholt, I. M., Dolga, A. M., Grissmer, S., Spiess, J., et al. (2008). Identification and characterization of a novel, shorter isoform of the small conductance Ca2+-activated K+ channel SK2. J. Neurochem. 106, 2312-2321. doi: 10.1111/j.1471-4159.2008.05557.x

Musial, T. F., Molina-Campos, E., Bean, L. A., Ybarra, N., Borenstein, R., Russo, M. L., et al. (2018). Store depletion-induced h-channel plasticity rescues a channelopathy linked to Alzheimer's disease. Neurobiol. Learn. Mem. 154, 141-157. doi: 10.1016/j.nlm.2018.06.004

Nakagawa, S., Kim, J., Lee, R., Malberg, J. E., Chen, J., Steffen, C., et al. (2002). Regulation of neurogenesis in adult mouse hippocampus by cAMP and the cAMP response element-binding protein. J. Neurosci. 22, 3673-3682. doi: 10. 1523/JNEUROSCI.22-09-03673.2002

Nakamura, M., Watanabe, H., Kubo, Y., Yokoyama, M., Matsumoto, T., Sasai, H., et al. (1998). KQT2, a new putative potassium channel family produced by alternative splicing. Isolation, genomic structure, and alternative splicing of the putative potassium channels. Recept. Channels 5, 255-271.

Nam, Y. W., Orfali, R., Liu, T., Yu, K., Cui, M., Wulff, H., et al. (2017). Structural insights into the potency of SK channel positive modulators. Sci. Rep. 7:17178. doi: 10.1038/s41598-017-16607-8

Neymotin, S. A., McDougal, R. A., Bulanova, A. S., Zeki, M., Lakatos, P., Terman, D., et al. (2016). Calcium regulation of HCN channels supports persistent activity in a multiscale model of neocortex. Neuroscience 316, 344-366. doi: 10.1016/j.neuroscience.2015.12.043

Ngo-Anh, T. J., Bloodgood, B. L., Lin, M. M. T., Sabatini, B. L., Maylie, J., Adelman, J. P., et al. (2008). KCa channels as therapeutic targets in episodic ataxia type-2. Brain Res. 11, 170-177.

Nolan, M. F., Malleret, G., Lee, K. H., Gibbs, E., Dudman, J. T., Santoro, B., et al. (2003). The hyperpolarization-activated HCN1 channel is important for motor learning and neuronal integration by cerebellar Purkinje cells. Cell 115, 551-564. doi: 10.1016/S0092-8674(03)00884-5

Nolting, A., Ferraro, T., D'Hoedt, D., and Stocker, M. (2007). An amino acid outside the pore region influences apamin sensitivity in small conductance Ca2+-activated K+ channels. J. Biol. Chem. 282, 3478-3486. doi: 10.1074/jbc. M607213200

Notomi, T., and Shigemoto, R. (2004). Immunohistochemical localization of Ih channel subunits, HCN1-4, in the rat brain. J. Comp. Neurol. 471, 241-276. doi: 10.1002/cne.11039

Novella Romanelli, M., Sartiani, L., Masi, A., Mannaioni, G., Manetti, D., Mugelli, A., et al. (2016). HCN channels modulators: the need for selectivity. Curr. Top. Med. Chem. 16, 1764-1791. doi: 10.2174/1568026616999160315130832

Obermair, G. J., Kaufmann, W. A., Knaus, H. G., and Flucher, B. E. (2003). The small conductance Ca2+-activated $\mathrm{K}+$ channel SK3 is localized in nerve terminals of excitatory synapses of cultured mouse hippocampal neurons. Eur. J. Neurosci. 17, 721-731. doi: 10.1046/j.1460-9568.2003.02488.x

Oliveira, M. S., Skinner, F., Arshadmansab, M. F., Garcia, I., Mello, C. F., Knaus, H. G., et al. (2010). Altered expression and function of small-conductance (SK) Ca $2+$-activated $\mathrm{K}+$ channels in pilocarpine-treated epileptic rats. Brain Res. 1348, 187-199. doi: 10.1016/j.brainres.2010.05.095

Oliver, D., Klöcker, N., Schuck, J., Baukrowitz, T., Ruppersberg, J. P., and Fakler, B. (2000). Gating of Ca2+-activated K+ channels controls fast inhibitory synaptic transmission at auditory outer hair cells. Neuron 26, 595-601. doi: 10.1016/ S0896-6273(00)81197-6

Oliver, D., Lien, C. C., Soom, M., Baukrowitz, T., Jonas, P., and Fakler, B. (2004). Functional conversion between A-type and delayed rectifier K+ channels by membrane lipids. Science 304, 265-270. doi: 10.1126/science.1094113

Oliver, D., Ludwig, J., Reisinger, E., Zoellner, W., Ruppersberg, J. P., and Fakler, B. (2001). Memantine inhibits efferent cholinergic transmission in the cochlea by blocking nicotinic acetylcholine receptors of outer hair cells. Mol. Pharmacol. 60, 183-189. doi: 10.1124/mol.60.1.183 
Olney, J. W., and Farber, N. B. (1995). Glutamate receptor dysfunction and schizophrenia. Arch. Gen. Psychiatry 52, 998-1007. doi: 10.1001/archpsyc.1995. 03950240016004

Oster, A., Faure, P., and Gutkin, B. S. (2015). Mechanisms for multiple activity modes of VTA dopamine neurons. Front. Comput. Neurosci. 9:95. doi: 10.3389/ fncom.2015.00095

Osuma, A. T., Xu, X., Wang, Z., Van Camp, J. A., and Freiberg, G. M. (2019). Design and evaluation of pyrazolopyrimidines as KCNQ channel modulators. Bioorg. Med. Chem. Lett. 29:126603. doi: 10.1016/j.bmcl.2019.08.007

Paladini, C. A., Robinson, S., Morikawa, H., Williams, J. T., and Palmiter, R. D. (2003). Dopamine controls the firing pattern of dopamine neurons via a network feedback mechanism. Proc. Natl. Acad. Sci. U.S.A. 100, 2866-2871. doi: 10.1073/pnas.0138018100

Park, J. H., Kim, D. W., Lee, T. K., Park, C. W., Park, Y. E., Ahn, J. H., et al. (2019). Improved $\mathrm{HCN}$ channels in pyramidal neurons and their new expression levels in pericytes and astrocytes in the gerbil hippocampal CA1 subfield following transient ischemia. Int. J. Mol. Med. 44, 1801-1810. doi: 10.3892/ijmm.2019. 4353

Park, K., Yi, J. H., Kim, H., Choi, K., Kang, S. J., and Shin, K. S. (2011). HCN channel activity-dependent modulation of inhibitory synaptic transmission in the rat basolateral amygdala. Biochem. Biophys. Res. Commun. 404, 952-957. doi: 10.1016/j.bbrc.2010.12.087

Park, Y. B. (1994). Ion selectivity and gating of small conductance $\mathrm{Ca}(2+)$-activated $\mathrm{K}+$ channels in cultured rat adrenal chromaffin cells. J. Physiol. 481, 555-570. doi: 10.1113/jphysiol.1994.sp020463

Parker, A. R., Welch, M. A., Forster, L. A., Tasneem, S. M., Dubhashi, J. A., and Baro, D. J. (2017). SUMOylation of the hyperpolarization-activated cyclic nucleotidegated channel 2 increases surface expression and the maximal conductance of the hyperpolarization-activated current. Front. Mol. Neurosci. 9:168. doi: 10.3389/fnmol.2016.00168

Paspalas, C. D., Wang, M., and Arnsten, A. F. T. (2013). Constellation of $\mathrm{HCN}$ channels and cAMP regulating proteins in dendritic spines of the primate prefrontal cortex: potential substrate for working memory deficits in schizophrenia. Cereb. Cortex 23, 1643-1654. doi: 10.1093/cercor/bhs152

Passmore, G. M., Selyanko, A. A., Mistry, M., Al-Qatari, M., Marsh, S. J., Matthews, E. A., et al. (2003). KCNQ/M currents in sensory neurons: significance for pain therapy. J. Neurosci. 23, 7227-7236. doi: 10.1523/jneurosci.23-18-07227.2003

Paz, R. M., Tubert, C., Stahl, A., Díaz, A. L., Etchenique, R., Murer, M. G., et al. (2018). Inhibition of striatal cholinergic interneuron activity by the Kv7 opener retigabine and the nonsteroidal anti-inflammatory drug diclofenac. Neuropharmacology 137, 309-321. doi: 10.1016/j.neuropharm.2018.05.010

Pedarzani, P., and Stocker, M. (2008). Molecular and cellular basis of small- and intermediate-conductance, calcium-activated potassium channel function in the brain. Cell. Mol. Life Sci. 65, 3196-3217. doi: 10.1007/s00018-008-8216-x

Peng, B. W., Justice, J. A., Zhang, K., He, X. H., and Sanchez, R. M. (2010). Increased basal synaptic inhibition of hippocampal area CA1 pyramidal neurons by an antiepileptic drug that enhances i H. Neuropsychopharmacology 35, 464-472. doi: 10.1038/npp.2009.150

Peng, H., Bian, X. L., Ma, F. C., and Wang, K. W. (2017). Pharmacological modulation of the voltage-gated neuronal Kv7/KCNQ/M-channel alters the intrinsic excitability and synaptic responses of pyramidal neurons in rat prefrontal cortex slices. Acta Pharmacol. Sin. 38, 1248-1256. doi: 10.1038/aps. 2017.72

Peretz, A., Degani, N., Nachman, R., Uziyel, Y., Gibor, G., Shabat, D., et al. (2005). Meclofenamic acid and diclofenac, novel templates of KCNQ2/Q3 potassium channel openers, depress cortical neuron activity and exhibit anticonvulsant properties. Mol. Pharmacol. 67, 1053-1066. doi: 10.1124/mol.104.007112

Peretz, A., Pell, L., Gofman, Y., Haitin, Y., Shamgar, L., Patrich, E., et al. (2010). Targeting the voltage sensor of Kv7.2 voltage-gated $\mathrm{K}+$ channels with a new gating-modifier. Proc. Natl. Acad. Sci. U.S.A. 107, 15637-15642. doi: 10.1073/ pnas.0911294107

Peretz, A., Sheinin, A., Yue, C., Degani-Katzav, N., Gibor, G., Nachman, R., et al. (2007). Pre- and postsynaptic activation of M-channels by a novel opener dampens neuronal firing and transmitter release. J. Neurophysiol. 97, 283-295. doi: 10.1152/jn.00634.2006

Pérez-Ramírez, M. B., Laville, A., Tapia, D., Duhne, M., Lara-González, E., Bargas, J., et al. (2015). KV7 channels regulate firing during synaptic integration in
GABAergic striatal neurons. Neural Plast. 2015:472676. doi: 10.1155/2015/ 472676

Pian, P., Bucchi, A., Robinson, R. B., and Siegelbaum, S. A. (2006). Regulation of gating and rundown of $\mathrm{HCN}$ hyperpolarization-activated channels by exogenous and endogenous PIP2. J. Gen. Physiol. 128, 593-604. doi: 10.1085/ jgp. 200609648

Polter, A. M., and Kauer, J. A. (2014). Stress and VTA synapses: implications for addiction and depression. Eur. J. Neurosci. 39, 1179-1188. doi: 10.1111/ejn. 12490

Porro, A., Binda, A., Pisoni, M., Donadoni, C., Rivolta, I., and Saponaro, A. (2020). Rational design of a mutation to investigate the role of the brain protein TRIP8b in limiting the cAMP response of HCN channels in neurons. J. Gen. Physiol. 152:e202012596. doi: 10.1085/jgp.202012596

Povstyan, O. V., Barrese, V., Stott, J. B., and Greenwood, I. A. (2017). Synergistic interplay of $\mathrm{G} \beta \gamma$ and phosphatidylinositol 4,5-bisphosphate dictates Kv7.4 channel activity. Pflugers Arch. Eur. J. Physiol. 469, 213-223. doi: 10.1007/ s00424-016-1916-4

Powell, K. L., Ng, C., O’Brien, T., Xu, S. H., Williams, D. A., Foote, S., et al. (2008). Decreases in HCN mRNA expression in the hippocampus after kindling and status epilepticus in adult rats. Epilepsia 49, 1686-1695. doi: 10.1111/j.15281167.2008.01593.x

Power, J. M., and Sah, P. (2008). Competition between calcium-activated K+ channels determines cholinergic action on firing properties of basolateral amygdala projection neurons. J. Neurosci. 28, 3209-3220. doi: 10.1523/ JNEUROSCI.4310-07.2008

Proulx, É, Power, S. K., Oliver, D. K., Sargin, D., McLaurin, J., and Lambe, E. K. (2020). Apamin improves prefrontal nicotinic impairment in mouse model of Alzheimer's disease. Cereb. Cortex 30, 563-574. doi: 10.1093/cercor/bhz107

Ramírez, D., Zúñiga, R., Concha, G., and Zúñiga, L. (2018). HCN channels: new therapeutic targets for pain treatment. Molecules 23:2094. doi: 10.3390/ molecules23092094

Ranjan, R., Logette, E., Marani, M., Herzog, M., Tâche, V., Scantamburlo, E., et al. (2019). A kinetic map of the homomeric voltage-gated potassium channel (Kv) family. Front. Cell. Neurosci. 13:358. doi: 10.3389/fncel.2019.00358

Rauch, S. L., Shin, L. M., and Wright, C. I. (2003). Neuroimaging studies of amygdala function in anxiety disorders. Ann. N. Y. Acad. Sci. 985, 389-410. doi: 10.1111/j.1749-6632.2003.tb07096

Ray, S., Salzer, I., Kronschläger, M. T., and Boehm, S. (2019). The paracetamol metabolite $\mathrm{N}$-acetylp-benzoquinone imine reduces excitability in first- and second-order neurons of the pain pathway through actions on KV7 channels. Pain 160, 954-964. doi: 10.1097/j.pain.0000000000001474

Rimini, R., Rimland, J. M., and Terstappen, G. C. (2000). Quantitative expression analysis of the small conductance calcium-activated potassium channels, SK1, SK2 and SK3, in human brain. Mol. Brain Res. 85, 218-220. doi: 10.1016/S0169328X(00)00255-2

Rinker, J. A., Fulmer, D. B., Trantham-Davidson, H., Smith, M. L., Williams, R. W., Lopez, M. F., et al. (2017). Differential potassium channel gene regulation in BXD mice reveals novel targets for pharmacogenetic therapies to reduce heavy alcohol drinking. Alcohol 58, 33-45. doi: 10.1016/j.alcohol.2016.05.007

Ritsner, M., Amir, S., Koronyo-Hamaoui, M., Gak, E., Ziv, H., Halperin, T., et al. (2003). Association study of CAG repeats in the KCNN3 gene in Israeli patients with major psychosis. Psychiatr. Genet. 13, 143-150. doi: 10.1097/00041444200309000-00002

Rivera-Arconada, I., and Lopez-Garcia, J. A. (2005). Effects of M-current modulators on the excitability of immature rat spinal sensory and motor neurones. Eur. J. Neurosci. 22, 3091-3098. doi: 10.1111/j.1460-9568.2005. 04507.x

Robbins, J. (2001). KCNQ potassium channels: physiology, pathophysiology, and pharmacology. Pharmacol. Ther. 90, 1-19. doi: 10.1016/S0163-7258(01)00 116-4

Roche, J. P., Westenbroek, R., Sorom, A. J., Hille, B., Mackie, K., and Shapiro, M. S. (2002). Antibodies and a cysteine-modifying reagent show correspondence of M current in neurons to KCNQ2 and KCNQ3 K + channels. Br. J. Pharmacol. 137, 1173-1186. doi: 10.1038/sj.bjp.0704989

Rose, K., Ooi, L., Dalle, C., Robertson, B., Wood, I. C., and Gamper, N. (2011). Transcriptional repression of the $\mathrm{M}$ channel subunit Kv7.2 in chronic nerve injury. Pain 152, 742-754. doi: 10.1016/j.pain.2010.12.028 
Roura-Ferrer, M., Etxebarria, A., Solé, L., Oliveras, A., Comes, N., Villarroel, A., et al. (2009). Functional implications of KCNE subunit expression for the Kv7.5 (KCNQ5) channel. Cell. Physiol. Biochem. 24, 325-334. doi: 10.1159/000257425

Saganich, M. J., Machado, E., and Rudy, B. (2001). Differential expression of genes encoding subthreshold-operating voltage-gated $\mathrm{K}+$ channels in brain. J. Neurosci. 21, 4609-4624. doi: 10.1523/JNEUROSCI.21-13-04609.2001

Sah, P. (1996). Ca*'-activated K+ currents in neurones: types, physiological roles and modulation. Trends Neurosci. 19, 150-154. doi: 10.1016/s0166-2236(96) 80026-9

Sailer, C. A., Hu, H., Kaufmann, W. A., Trieb, M., Schwarzer, C., Storm, J. F., et al. (2002). Regional differences in distribution and functional expression of small-conductance Ca2+-activated $\mathrm{K}+$ channels in rat brain. J. Neurosci. 22, 9698-9707. doi: 10.1523/JNEUROSCI.22-22-09698.2002

Saito, Y., Inoue, T., Zhu, G., Kimura, N., Okada, M., Nishimura, M., et al. (2012). Hyperpolarization-activated cyclic nucleotide gated channels: a potential molecular link between epileptic seizures and $\mathrm{A} \beta$ generation in Alzheimer's disease. Mol. Neurodegener. 7:50. doi: 10.1186/1750-1326-7-50

Salthun-Lassalle, B., Hirsch, E. C., Wolfart, J., Ruberg, M., and Michel, P. P. (2004). Rescue of mesencephalic dopaminergic neurons in culture by lowlevel stimulation of voltage-gated sodium channels. J. Neurosci. 24, 5922-5930. doi: 10.1523/JNEUROSCI.5668-03.2004

Salzer, I., Erdem, F. A., Chen, W. Q., Heo, S., Koenig, X., Schicker, K. W., et al. (2017). Phosphorylation regulates the sensitivity of voltage-gated Kv7.2 channels towards phosphatidylinositol-4,5-bisphosphate. J. Physiol. 595, 759776. doi: 10.1113/JP273274

Sander, S. E., Lambrecht, C., and Richter, A. (2013). The KV7.2/3 preferring channel opener ICA 27243 attenuates L-DOPA-induced dyskinesia in hemiparkinsonian rats. Neurosci. Lett. 545, 59-63. doi: 10.1016/j.neulet.2013. 04.017

Sander, S. E., Lemm, C., Lange, N., Hamann, M., and Richter, A. (2012). Retigabine, a K V7 (KCNQ) potassium channel opener, attenuates 1-DOPA-induced dyskinesias in 6-OHDA-lesioned rats. Neuropharmacology 62, 1052-1061. doi: 10.1016/j.neuropharm.2011.10.016

Santoro, B., Chen, S., Lüthi, A., Pavlidis, P., Shumyatsky, G. P., Tibbs, G. R., et al. (2000). Molecular and functional heterogeneity of hyperpolarizationactivated pacemaker channels in the mouse CNS. J. Neurosci. 20, 5264-5275. doi: 10.1523/jneurosci.20-14-05264.2000

Santoro, B., Lee, J. Y., Englot, D. J., Gildersleeve, S., Piskorowski, R. A., Siegelbaum, S. A., et al. (2010). Increased seizure severity and seizure-related death in mice lacking HCN1 channels. Epilepsia 51, 1624-1627. doi: 10.1111/j.1528-1167. 2010.02554.x

Santoro, B., Liu, D. T., Yao, H., Bartsch, D., Kandel, E. R., Siegelbaum, S. A., et al. (1998). Identification of a gene encoding a hyperpolarization-activated pacemaker channel of brain. Cell 93, 717-729. doi: 10.1016/S0092-8674(00) 81434-8

Schapira, A. H. V., and Gegg, M. (2011). Mitochondrial contribution to Parkinson's disease pathogenesis. Parkinson's Dis. 2011:159160. doi: 10.4061/2011/15 9160

Scholl, E. S., Pirone, A., Cox, D. H., Duncan, R. K., and Jacob, M. H. (2014). Alternative splice isoforms of small conductance calcium-activated SK2 channels differ in molecular interactions and surface levels. Channels 8, 62-75. doi: $10.4161 /$ chan. 27470

Schroeder, B. C., Kubisch, C., Stein, V., and Jentsch, T. J. (1998). Moderate loss of function of cyclic-AMP-modulated KCNQ2/KCNQ3 K+ channels causes epilepsy. Nature 396, 687-690. doi: 10.1038/25367

Schulz, R., Kirschstein, T., Brehme, H., Porath, K., Mikkat, U., and Köhling, R. (2012). Network excitability in a model of chronic temporal lobe epilepsy critically depends on SK channel-mediated AHP currents. Neurobiol. Dis. 45, 337-347. doi: 10.1016/j.nbd.2011.08.019

Schumacher, M. A., Rivard, A. F., Bächinger, H. P., and Adelman, J. P. (2001). Structure of the gating domain of a Ca2+-activated $\mathrm{K}+$ channel complexed with Ca2+/calmodulin. Nature 410, 1120-1124. doi: 10.1038/35074145

Schwab, B. C., Heida, T., Zhao, Y., Marani, E., van Gils, S. A., and van Wezel, R. J. A. (2013). Synchrony in Parkinson's disease: importance of intrinsic properties of the external globus pallidus. Front. Syst. Neurosci. 7:60. doi: 10.3389/fnsys.2013. 00060

Schwake, M., Jentsch, T. J., and Friedrich, T. (2003). A carboxy-terminal domain determines the subunit specificity of KCNQ K+ channel assembly. EMBO Rep. 4, 76-81. doi: 10.1038/sj.embor.embor715
Schwake, M., Pusch, M., Kharkovets, T., and Jentsch, T. J. (2000). Surface expression and single channel properties of KCNQ2/KCNQ3, M-type K+ channels involved in epilepsy. J. Biol. Chem. 275, 13343-13348. doi: 10.1074/ jbc. 275.18 .13343

Schwarz, J. R., Glassmeier, G., Cooper, E. C., Kao, T. C., Nodera, H., Tabuena, D., et al. (2006). KCNQ channels mediate IKs, a slow K+ current regulating excitability in the rat node of Ranvier. J. Physiol. 573(Pt 1), 17-34. doi: 10.1113/ jphysiol.2006.106815

Schwindt, P. C., Spain, W. J., Foehring, R. C., Stafstrom, C. E., Chubb, M. C., and Crill, W. E. (1988). Multiple potassium conductances and their functions in neurons from cat sensorimotor cortex in vitro. J. Neurophysiol. 59, 424-449. doi: 10.1152/jn.1988.59.2.424

Shah, M. M., Anderson, A. E., Leung, V., Lin, X., and Johnston, D. (2004). Seizureinduced plasticity of $\mathrm{h}$ channels in entorhinal cortical layer III pyramidal neurons. Neuron 44, 495-508. doi: 10.1016/j.neuron.2004.10.011

Shakkottai, V. G., Chou, C., Oddo, S., Sailer, C. A., Knaus, H.-G., Gutman, G. A., et al. (2004). Enhanced neuronal excitability in the absence of neurodegeneration induces cerebellar ataxia. J. Clin. Investig. 113, 582-590. doi: $10.1172 /$ jci20216

Shang, Q., Xu, H., and Huang, L. (2012). Tanshinone IIA: a promising natural cardioprotective agent. Evid. Based Complement. Alternat. Med. 2012:716459. doi: 10.1155/2012/716459

Shin, M., Brager, D., Jaramillo, T. C., Johnston, D., and Chetkovich, D. M. (2008). Mislocalization of $\mathrm{h}$ channel subunits underlies $\mathrm{h}$ channelopathy in temporal lobe epilepsy. Neurobiol. Dis. 32, 26-36. doi: 10.1016/j.nbd.2008. 06.013

Shmukler, B. E., Bond, C. T., Wilhelm, S., Bruening-Wright, A., Maylie, J., Adelman, J. P., et al. (2001). Structure and complex transcription pattern of the mouse SK1 KCa channel gene, KCNN1. Biochim. Biophys. Acta Gene Struct. Expr. 1518, 36-46. doi: 10.1016/S0167-4781(01)00166-X

Smith, J. S., Iannotti, C. A., Dargis, P., Christian, E. P., and Aiyar, J. (2001). Differential expression of KCNQ2 splice variants: implications to M current function during neuronal development. J. Neurosci. 21, 1096-1103. doi: 10. 1523/jneurosci.21-04-01096.2001

Soldovieri, M. V., Ambrosino, P., Mosca, I., De Maria, M., Moretto, E., Miceli, F., et al. (2016). Early-onset epileptic encephalopathy caused by a reduced sensitivity of Kv7.2 potassium channels to phosphatidylinositol 4,5bisphosphate. Sci. Rep. 6:38167. doi: 10.1038/srep38167

Sørensen, U. S., Strøbaek, D., Christophersen, P., Hougaard, C., Jensen, M. L., Nielsen, E. $\varnothing$, et al. (2008). Synthesis and structure-activity relationship studies of 2-(N-substituted)-aminobenzimidazoles as potent negative gating modulators ofsmall conductance Ca2+-activated $\mathrm{K}+$ channels. J. Med. Chem. 51, 7625-7634. doi: 10.1021/jm800809f

Sourdet, V., Russier, M., Daoudal, G., Ankri, N., and Debanne, D. (2003). Longterm enhancement of neuronal excitability and temporal fidelity mediated by metabotropic glutamate receptor subtype 5. J. Neurosci. 23, 10238-10248. doi: 10.1523/jneurosci.23-32-10238.2003

Stieber, J., Stöckl, G., Herrmann, S., Hassfurth, B., and Hofmann, F. (2005). Functional expression of the human HCN3 channel. J. Biol. Chem. 280, 3463534643. doi: 10.1074/jbc.M502508200

Stocker, M., and Pedarzani, P. (2000). Differential distribution of three Ca2+activated K2+ channel subunits, SK1, SK2, and SK3, in the adult rat central nervous system. Mol. Cell. Neurosci. 15, 476-493. doi: 10.1006/mcne.2000.0842

Storm, J. F. (1990). Potassium currents in hippocampal pyramidal cells. Prog Brain Res. 83, 161-187. doi: 10.1016/s0079-6123(08)61248-0

Strassmaier, T., Bond, C. T., Sailer, C. A., Knaus, H. G., Maylie, J., and Adelman, J. P. (2005). A novel isoform of SK2 assembles with other SK subunits in mouse brain. J. Biol. Chem. 280, 21231-21236. doi: 10.1074/jbc.M413125200

Stutzmann, G. E. (2005). Calcium dysregulation, IP3 signaling, and Alzheimer's disease. Neuroscientist 11, 110-115. doi: 10.1177/107385840427 0899

Surges, R., Freiman, T. M., and Feuerstein, T. J. (2003). Gabapentin increases the hyperpolarization-activated cation current Ih in rat CA1 pyramidal cells. Epilepsia 44, 150-156. doi: 10.1046/j.1528-1157.2003.36802.x

Tacconi, S., Carletti, R., Bunnemann, B., Plumpton, C., Merlo Pich, E., and Terstappen, G. C. (2001). Distribution of the messenger RNA for the small conductance calcium-activated potassium channel SK3 in the adult rat brain and correlation with immunoreactivity. Neuroscience 102, 209-215. doi: 10. 1016/S0306-4522(00)00486-3 
Tae, H. S., Smith, K. M., Phillips, A. M., Boyle, K. A., Li, M., Forster, I. C., et al. (2017). Gabapentin modulates HCN4 channel voltage-dependence. Front. Pharmacol. 8:554. doi: 10.3389/fphar.2017.00554

Tanabe, M., Mori, M., Gähwiler, B. H., and Gerber, U. (1999). Apamin-sensitive conductance mediates the $\mathrm{K}+$ current response during chemical ischemia in CA3 pyramidal cells. J. Neurophysiol. 82, 2876-2882. doi: 10.1152/jn.1999.82.6. 2876

Tanguay, J., Callahan, K. M., and D'Avanzo, N. (2019). Characterization of drug binding within the HCN1 channel pore. Sci. Rep. 9:465. doi: 10.1038/s41598018-37116-2

Tatulian, L., and Brown, D. A. (2003). Effect of the KCNQ potassium channel opener retigabine on single KCNQ2/3 channels expressed in $\mathrm{CHO}$ cells. J. Physiol. 549, 57-63. doi: 10.1113/jphysiol.2003.039842

Tatulian, L., Delmas, P., Abogadie, F. C., and Brown, D. A. (2001). Activation of expressed KCNQ potassium currents and native neuronal M-type potassium currents by the anti-convulsant drug retigabine. J. Neurosci. 21, 5535-5545. doi: 10.1523/jneurosci.21-15-05535.2001

Teng, B. C., Song, Y., Zhang, F., Ma, T. Y., Qi, J. L., Zhang, H. L., et al. (2016). Activation of neuronal Kv7/KCNQ/M-channels by the opener QO58-lysine and its anti-nociceptive effects on inflammatory pain in rodents. Acta Pharmacol. Sin. 37, 1054-1062. doi: 10.1038/aps.2016.33

Terstappen, G. C., Pellacani, A., Aldegheri, L., Graziani, F., Carignani, C., Pula, G., et al. (2003). The antidepressant fluoxetine blocks the human small conductance calcium-activated potassium channels SK1, SK2 and SK3. Neurosci. Lett. 346, 85-88. doi: 10.1016/S0304-3940(03)00574-3

Terstappen, G. C., Pula, G., Carignani, C., Chen, M. X., and Roncarati, R. (2001). Pharmacological characterisation of the human small conductance calciumactivated potassium channel hSK3 reveals sensitivity to tricyclic antidepressants and antipsychotic phenothiazines. Neuropharmacology 40, 772-783. doi: 10 . 1016/S0028-3908(01)00007-7

Thompson, J. M., Yakhnitsa, V., Ji, G., and Neugebauer, V. (2018). Small conductance calcium activated potassium (SK) channel dependent and independent effects of riluzole on neuropathic pain-related amygdala activity and behaviors in rats. Neuropharmacology 138, 219-231. doi: 10.1016/j. neuropharm.2018.06.015

Tibbs, G. R., Rowley, T. J., Sanford, R. L., Herold, K. F., Proekt, A., Hemmings, H. C., et al. (2013). HCN1 channels as targets for anesthetic and nonanesthetic propofol analogs in the amelioration of mechanical and thermal hyperalgesia in a mouse model of neuropathic pains. J. Pharmacol. Exp. Ther. 345, 363-373. doi: 10.1124/jpet.113.203620

Tinel, N., Lauritzen, I., Chouabe, C., Lazdunski, M., Borsotto, M., and Antipolis, S. (1998). The KCnq2 potassium channel splice varinats functional and develpmental expression. FEBS Lett. 438, 171-176. doi: 10.1016/s0014-5793(98) 01296-4

Tobelaim, W. S., Dvir, M., Lebel, G., Cui, M., Buki, T., Peretz, A., et al. (2017). $\mathrm{Ca}^{2+}$-Calmodulin and PIP2 interactions at the proximal C-terminus of Kv7 channels. Channels 11, 686-695. doi: 10.1080/19336950.2017.1388478

Tober, C., Rostock, A., Rundfeldt, C., and Bartsch, R. (1996). D-23129: a potent anticonvulsant in the amygdala kindling model of complex partial seizures. Eur. J. Pharmacol. 303, 163-169. doi: 10.1016/0014-2999(96)00073-8

Tomita, H., Shakkottai, V. G., Gutman, G. A., Sun, G., Bunney, W. E., Cahalan, M. D., et al. (2003). Novel truncated isoform of SK3 potassium channel is a potent dominant-negative regulator of SK currents: implications in schizophrenia. Mol. Psychiatry 8, 524-535. doi: 10.1038/sj.mp.4001271

Valenti, O., Gill, K. M., and Grace, A. A. (2012). Different stressors produce excitation or inhibition of mesolimbic dopamine neuron activity: response alteration by stress pre-exposure. Eur. J. Neurosci. 35, 1312-1321. doi: 10.1111/ j.1460-9568.2012.08038.x

Van Der Staay, F. J., Fanelli, R. J., Blokland, A., and Schmidt, B. H. (1999). Behavioral effects of apamin, a selective inhibitor of the SK Ca-channel, in mice and rats. Neurosci. Biobehav. Rev. 23, 1087-1110. doi: 10.1016/s0149-7634(99) 00043-3

Vasilyev, D. V., Shan, Q., Lee, Y., Mayer, S. C., Bowlby, M. R., Strassle, B. W., et al. (2007). Direct inhibition of Ih by analgesic loperamide in rat DRG neurons. J. Neurophysiol. 97, 3713-3721. doi: 10.1152/jn.00841.2006

Vassar, R., Kuhn, P. H., Haass, C., Kennedy, M. E., Rajendran, L., Wong, P. C., et al. (2014). Function, therapeutic potential and cell biology of BACE proteases: current status and future prospects. J. Neurochem. 130, 4-28. doi: 10.1111/jnc. 12715
Vervaeke, K., Hu, H., Graham, L. J., and Storm, J. F. (2006). Contrasting effects of the persistent $\mathrm{Na}+$ current on neuronal excitability and spike timing. Neuron 49, 257-270. doi: 10.1016/j.neuron.2005.12.022

Villalobos, C., Shakkottai, V. G., Chandy, K. G., Michelhaugh, S. K., and Andrade, R. (2004). SKCa channels mediate the medium but not the slow calciumactivated afterhyperpolarization in cortical neurons. J. Neurosci. 24, 3537-3542. doi: 10.1523/JNEUROSCI.0380-04.2004

Villière, V., and McLachlan, E. M. (1996). Electrophysiological properties of neurons in intact rat dorsal root ganglia classified by conduction velocity and action potential duration. J. Neurophysiol. 76, 1924-1941. doi: 10.1152/jn.1996. 76.3.1924

Vossel, K. A., Beagle, A. J., Rabinovici, G. D., Shu, H., Lee, S. E., Naasan, G., et al. (2013). Seizures and epileptiform activity in the early stages of Alzheimer disease. JAMA Neurol. 70, 1158-1166. doi: 10.1001/jamaneurol.20 13.136

Wainger, B. J., Degennaro, M., Santoro, B., Siegelbaum, S. A., and Tibbs, G. R. (2001). Molecular mechanism of cAMP modulation of HCN pacemaker channels. Nature 411, 805-810. doi: 10.1038/35081088

Walter, J. T., Alviña, K., Womack, M. D., Chevez, C., and Khodakhah, K. (2006). Decreases in the precision of Purkinje cell pacemaking cause cerebellar dysfunction and ataxia. Nat. Neurosci. 9, 389-397. doi: 10.1038/nn1648

Wang, H. S., Pan, Z., Shi, W., Brown, B. S., Wymore, R. S., Cohen, I. S., et al. (1998). KCNQ2 and KCNQ3 potassium channel subunits: molecular correlates of the M-channel. Science 282, 1890-1893. doi: 10.1126/science.282.5395.1890

Wang, J., Chen, S., Nolan, M. F., and Siegelbaum, S. A. (2002). Activity-dependent regulation of HCN pacemaker channels by cyclic AMP: signaling through dynamic allosteric coupling. Neuron 36, 451-461. doi: 10.1016/S0896-6273(02) 00968-6

Wang, J., Li, Y., Hui, Z., Cao, M., Shi, R., Zhang, W., et al. (2015). Functional analysis of potassium channels in Kv7.2 G271V mutant causing early onset familial epilepsy. Brain Res. 1616, 112-122. doi: 10.1016/j.brainres.2015. 04.060

Wang, Y., Qu, L., Wang, X. L., Gao, L., Li, Z. Z., Gao, G. D., et al. (2014). Firing pattern modulation through SK channel current increase underlies neuronal survival in an organotypic slice model of Parkinson's disease. Mol. Neurobiol. 51, 424-436. doi: 10.1007/s12035-014-8728-3

Wang, Y., Yang, P. L., Tang, J. F., Lin, J. F., Cai, X. H., Wang, X. T., et al. (2008). Potassium channels: possible new therapeutic targets in Parkinson's disease. Med. Hypotheses 71, 546-550. doi: 10.1016/j.mehy.2008. 05.021

Wei, A. D., Gutman, G. A., Aldrich, R., Chandy, K. G., Grissmer, S., and Wulff, H. (2005). Nomenclature and molecular relationships of calciumactivated potassium channels. Pharmacol. Rev. 57, 463-472. doi: 10.1124/pr.57. 4.9.1

Weisenberg, J. L., and Wong, M. (2011). Profile of ezogabine (retigabine) and its potential as an adjunctive treatment for patients with partial-onset seizures. Neuropsychiatr. Dis. Treat. 7, 409-414. doi: 10.2147/NDT.S14208

Wickenden, A. D., Universitario, I., Antonio, D. B. I., Astrofisica, A., and Sánchez, F. (2009). Kv7 channels as targets for the treatment of pain. Curr. Pharm. Des. 15, 1773-1798. doi: 10.2174/138161209788186326

Wiener, R., Haitin, Y., Shamgar, L., Ferna, M. C., Martos, A., Chomsky-hecht, O., et al. (2008). The KCNQ1 (Kv7. 1) COOH terminus, a multitiered scaffold for subunit assembly and protein interaction. J. Biol. Chem. 283, 5815-5830. doi: 10.1074/jbc.M707541200

Williams, A. D., Jung, S., and Poolos, N. P. (2015). Protein kinase C bidirectionally modulates Ih and hyperpolarization-activated cyclic nucleotide-gated (HCN) channel surface expression in hippocampal pyramidal neurons. J. Physiol. 593, 2779-2792. doi: 10.1113/JP270453

Williams, S., Serafin, M., Mühlethaler, M., and Bernheim, L. (1997). Distinct contributions of high- and low-voltage-activated calcium currents to afterhyperpolarizations in cholinergic nucleus basalis neurons of the guinea pig. J. Neurosci. 17, 7307-7315. doi: 10.1523/jneurosci.17-19-07307. 1997

Wilson, G. W., and Garthwaite, J. (2010). Hyperpolarization-activated ion channels as targets for nitric oxide signalling in deep cerebellar nuclei. Eur. J. Neurosci. 31, 1935-1945. doi: 10.1111/j.1460-9568.2010.07226.x

Wittekindt, O., Jauch, A., Burgert, E., Schärer, L., Holtgreve-Grez, H., Yvert, G., et al. (1998). The human small conductance calcium-regulated potassium channel gene (hSKCa3) contains two CAG repeats in exon 1, is on chromosome 
1q21.3, and shows a possible association with schizophrenia. Neurogenetics 1, 259-265. doi: 10.1007/s100480050038

Wladyka, C. L., and Kunze, D. L. (2006). KCNQ / M-currents contribute to the resting membrane potential in rat visceral sensory neurons. J. Physiol. 1, 175-189. doi: 10.1113/jphysiol.2006.113308

Won, J., Lee, P. R., and Oh, S. B. (2019). Alpha 2 adrenoceptor agonist guanabenz directly inhibits hyperpolarization-activated, cyclic nucleotidemodulated $(\mathrm{HCN})$ channels in mesencephalic trigeminal nucleus neurons. Eur. J. Pharmacol. 854, 320-327. doi: 10.1016/j.ejphar.2019.04.036

Wrobel, E., Tapken, D., and Seebohm, G. (2012). The KCNE tango - how KCNE1 interacts with Kv7. 1. Front. Pharmacol. 3:142. doi: 10.3389/fphar.2012.00142

Wu, Z., Li, L., Xie, F., Du, J., Zuo, Y., Frost, J. A., et al. (2017). Activation of KCNQ channels suppresses spontaneous activity in dorsal root ganglion neurons and reduces chronic pain after spinal cord injury. J. Neurotrauma. 34, 1260-1270. doi: 10.1089/neu.2016.4789

Xia, X. M., Fakler, B., Rivard, A., Wayman, G., Johnson-Pais, T., Keen, J. E., et al. (1998). Mechanism of calcium gating in small-conductance calcium-activated potassium channels. Nature 395, 503-507. doi: 10.1038/26758

Xing, J. L., and Hu, S. J. (1999). Relationship between calcium-dependent potassium channel and ectopic spontaneous discharges of injured dorsal root ganglion neurons in the rat. Brain Res. 838, 218-221. doi: 10.1016/S00068993(99)01682-0

Xiong, Q., Sun, H., Zhang, Y., Nan, F., and Li, M. (2008). Combinatorial augmentation of voltage-gated KCNQ potassium channels by chemical openers. Proc. Natl. Acad. Sci. U.S.A. 105, 3128-3133. doi: 10.1073/pnas.0712256105

Xu, C., Datta, S., Wu, M., and Alreja, M. (2004). Hippocampal theta rhythm is reduced by suppression of the H-current in septohippocampal GABAergic neurons. Eur. J. Neurosci. 19, 2299-2309. doi: 10.1111/j.1460-9568.2004. 03316.x

Yagi, J., and Sumino, R. (1998). Inhibition of a hyperpolarization-activated current by clonidine in rat dorsal root ganglion neurons. J. Neurophysiol. 80, 1094-1104. doi: $10.1152 /$ jn.1998.80.3.1094

Ying, S. W., Kanda, V. A., Hu, Z., Purtell, K., King, E. C., Abbott, G. W., et al. (2012). Targeted deletion of Kcne2 impairs HCN channel function in mouse thalamocortical circuits. PLoS One 7:e42756. doi: 10.1371/journal.pone. 0042756

Ying, S., Tibbs, G. R., Picollo, A., Abbas, S. Y., Sanford, R. L., Accardi, A., et al. (2011). PIP 2 -mediated HCN3 channel gating is crucial for rhythmic burst firing in thalamic intergeniculate leaflet neurons. J. Neurosci. 31, 10412-10423. doi: 10.1523/JNEUROSCI.0021-11.2011

Yoo, A. S., Cheng, I., Chung, S., Grenfell, T. Z., Lee, H., Pack-Chung, E., et al. (2000). Presenilin-mediated modulation of capacitative calcium entry. Neuron 27, 561-572. doi: 10.1016/S0896-6273(00)00066-0

Young, G. T., Emery, E. C., Mooney, E. R., Tsantoulas, C., and Mcnaughton, P. A. (2014). Inflammatory and neuropathic pain are rapidly suppressed by peripheral block of hyperpolarisation-activated cyclic nucleotide-gated ion channels. Pain 155, 1708-1719. doi: 10.1016/j.pain.2014.05.021

Yu, H., Wu, J., Potapova, I., Wymore, R. T., Holmes, B., Zuckerman, J., et al. (2001). MinK-related peptide 1: a beta subunit for the HCN ion channel subunit family enhances expression and speeds activation. Circ. Res. 88, E84-E87. doi: 10.1161/hh1201.093511

Yu, T., Li, L., Liu, H., Li, H., Liu, Z., and Li, Z. (2018). KCNQ2/3/5 channels in dorsal root ganglion neurons can be therapeutic targets of neuropathic pain in diabetic rats. Mol. Pain. 14:1744806918793229. doi: 10.1177/1744806918793229

Zhang, D., Thimmapaya, R., Zhang, X., Anderson, D. J., Baranowski, J. L., Scanio, M., et al. (2011). KCNQ2 / 3 openers show differential selectivity and site of action across multiple KCNQ channels. J. Neurosci. Methods 200, 54-62. doi: 10.1016/j.jneumeth.2011.06.014

Zhang, F., Liu, Y., Tang, F., Liang, B., Chen, H., Zhang, H., et al. (2019). Electrophysiological and pharmacological characterization of a novel and potent neuronal Kv7 channel opener SCR2682 for antiepilepsy. FASEB J. 33, 9154-9166. doi: 10.1096/fj.201802848RR

Zhang, F., Mi, Y., Qi, J. L., Li, J. W., Si, M., Guan, B. C., et al. (2013). Modulation of $\mathrm{K}$ v 7 potassium channels by a novel opener pyrazolo [1,5-a] pyrimidin-7 $(4 \mathrm{H})$ -one compound QO-58. Br. J. Pharmacol. 168, 1030-1042. doi: 10.1111/j.14765381.2012.02232.x

Zhang, L., and McBain, C. J. (1995). Potassium conductances underlying repolarization and after-hyperpolarization in rat CA1 hippocampal interneurones. J. Physiol. 488, 661-672. doi: 10.1113/jphysiol.1995.sp020998

Zhang, M., Abrams, C., Wang, L., Gizzi, A., He, L., Lin, R., et al. (2012). Structural basis for calmodulin as a dynamic calcium sensor. Structure 20, 911-923. doi: 10.1016/j.str.2012.03.019

Zhang, M., Meng, X. Y., Cui, M., Pascal, J. M., Logothetis, D. E., and Zhang, J. F. (2014). Selective phosphorylation modulates the PIP 2 sensitivity of the CaMSK channel complex. Nat. Chem. Biol. 10, 753-759. doi: 10.1038/nchembio. 1592

Zhang, M., Pascal, J. M., and Zhang, J. F. (2013). Unstructured to structured transition of an intrinsically disordered protein peptide in coupling Ca2+sensing and SK channel activation. Proc. Natl. Acad. Sci. U.S.A. 110, 4828-4833. doi: $10.1073 /$ pnas. 1220253110

Zhang, S., You, Z., Wang, S., Yang, J., Yang, L., Sun, Y., et al. (2016). Neuropharmacology neuropeptide $S$ modulates the amygdaloidal HCN activities (I h) in rats: implication in chronic pain. Neuropharmacology 105, 420-433. doi: 10.1016/j.neuropharm.2016.02.004

Zhang, Y., Bonnan, A., Bony, G., Ferezou, I., Pietropaolo, S., Ginger, M., et al. (2014). Dendritic channelopathies contribute to neocortical and sensory hyperexcitability in Fmr1-/y mice. Nat. Neurosci. 17, 1701-1709. doi: 10.1038/ nn.3864

Zhao, W., Chuang, S.-C., Bianchi, R., and Wong, R. K. S. (2011). Dual regulation of fragile $\mathrm{X}$ mental retardation protein by group I metabotropic glutamate receptors controls translation-dependent epileptogenesis in the hippocampus. J. Neurosci. 31, 725-734. doi: 10.1523/JNEUROSCI.2915-10.2011

Zhao, W., Liang, P., Liu, J., Li, H., and Liao, D. (2019). Capsazepine prolongation of the duration of lidocaine block of sensory transmission in mice may be mediated by modulation of HCN channel currents. PeerJ 7:e7111. doi: 10.7717/ peerj.7111

Zobeiri, M., Chaudhary, R., Blaich, A., Rottmann, M., Herrmann, S., Meuth, P., et al. (2019). The hyperpolarization-activated HCN4 channel is important for proper maintenance of oscillatory activity in the thalamocortical system. Cereb. Cortex 29, 2291-2304. doi: 10.1093/cercor/bhz047

Zolles, G., Klöcker, N., Wenzel, D., Weisser-Thomas, J., Fleischmann, B. K., Roeper, J., et al. (2006). Pacemaking by HCN channels requires interaction with phosphoinositides. Neuron 52, 1027-1036. doi: 10.1016/j.neuron.2006. 12.005

Zong, X., Krause, S., Chen, C. C., Krüger, J., Gruner, C., Cao-Ehlker, X., et al. (2012). Regulation of hyperpolarization-activated cyclic nucleotide-gated (HCN) channel activity by cCMP. J Biol Chem 287, 26506-26512. doi: 10.1074/ jbc.M112.357129

Conflict of Interest: The authors declare that the research was conducted in the absence of any commercial or financial relationships that could be construed as a potential conflict of interest.

Copyright (c) 2021 Dwivedi and Bhalla. This is an open-access article distributed under the terms of the Creative Commons Attribution License (CC BY). The use, distribution or reproduction in other forums is permitted, provided the original author(s) and the copyright owner(s) are credited and that the original publication in this journal is cited, in accordance with accepted academic practice. No use, distribution or reproduction is permitted which does not comply with these terms. 